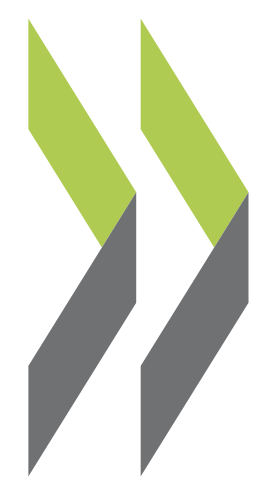

OECD Local Economic and Employment Development (LEED) Papers 2010/03

Leveraging Training: Skills Development in SMEs - An Analysis of Canterbury Paul Dalziel Region, New Zealand 


\section{Leveraging Training}

\section{Skills Development in SMEs}

AN ANALYSIS OF CANTERBURY REGION, NEW ZEALAND 


\title{
About the OECD
}

The Organisation for Economic Co-operation and Development (OECD) is a unique forum where the governments of 30 market democracies work together to address the economic, social and governance challenges of globalisation as well as to exploit its opportunities. The OECD's way of working consists of a highly effective process that begins with data collection and analysis and moves on to collective discussion of policy, then decision-making and implementation. Mutual examination by governments, multilateral surveillance and peer pressure to conform or reform are at the heart of OECD effectiveness.

Much of the material collected and analysed at the OECD is published on paper or online; from press releases and regular compilations of data and projections to one-time publications or monographs on particular issues; from economic surveys of each member country to regular reviews of education systems, science and technology policies or environmental performance. For more information on the OECD, please visit www.oecd.org/about.

\begin{abstract}
About LEED
The OECD Programme on Local Economic and Employment Development (LEED) has advised government and communities since 1982 on how to respond to economic change and tackle complex problems in a fast-changing world. It draws on a comparative analysis of experience from some 50 countries in the Americas, Asia, Australasia and Europe in fostering economic growth, employment and inclusion. For more information on the LEED Programme, please visit www.oecd.org/cfe/leed.
\end{abstract}

\section{Note on the author}

This country report was prepared by Paul Dalziel, who is Professor of Economics and Director of the Regional Development research programme at the AERU Research Centre, Lincoln University, New Zealand. Professor Dalziel's research focuses on New Zealand economic and social policy. He is currently the President of the Australia and New Zealand Regional Science Association International (ANZRSAI).

The views contained in this report are those of the author and do not necessarily represent those of the OECD or its member governments. For further information, please contact the author: paul.dalziel@lincoln.ac.nz

ISSN 2079-4797 (PDF)

OECD Local Economic and Employment Development (LEED) Working Paper Series

This report is part of a series of working papers from the OECD Local Economic and Employment Development (LEED) Programme. The LEED Programme identifies, analyses and disseminates innovative ideas for local development, governance and the social economy. Governments from OECD member and non-member economies look to LEED and work through it to generate innovative guidance on policies to support employment creation and economic development through locally based initiatives. 


\section{PREFACE}

Access to training and the effective utilisation of skills in Small and Medium-Sized Enterprises (SMEs) has long been an area of interest to public policy makers and economic development practitioners. SMEs often lack capabilities and infrastructure to make the most of their human capabilities - and as a consequence tend to have lower levels of training and skills development. It is against this back drop that the Department of Labour initiated this study with the OECD in conjunction with the Ministry of Economic Development, Tertiary Education Commission, Industry Training Federation and Business New Zealand. These organisations have a strong desire to see the results of the study feed into responses to help lift the performance of SMEs.

New Zealand is the first of five countries to participate in the OECD project on Leveraging Training and Skills Development in SMEs. Canterbury has been chosen as a case study region on account of its relatively well-connected firms and education and training providers. The Canterbury Employers' Chamber of Commerce and several development agencies and training providers have given valuable input to the study. The study highlights the diversity of education and training provision and the fact that SMEs upgrade skills through a number of different means. There is a strong link between training and innovative firms - highlighting the potential for SMEs to improve New Zealand's economic performance.

Informal skills acquisition is an important contributor to firm performance - yet this area is not well understood. The results of this aspect of the study raise some important questions. For example, can skills formation in SMEs be increased through ways other than formal tertiary education and training? How could business planning activities, for example, be used to reinforce a more systematic approach to skills development in SMEs? What are the appropriate roles of Government and industry associations in designing and delivering more flexible SME-centred business support, information, and training packages?

The New Zealand country report provides an important body of knowledge to help untap the economic potential of SMEs. Other recent studies, such as "Management Matters" and the analysis of NZ firm dynamics also provide important evidence on which to base public policy responses and firm strategies. The insights from this study, combined with the international comparisons from the other participating OECD countries, will provide a valuable source of knowledge to help fulfil the potential of SMEs.

Paul Barker, Department of Labour Convenor, NZ Country Study Steering Group June 2010 


\section{ACKNOWLEDGEMENTS}

The author is grateful to the many people who have helped with the research for this report. Sylvain Giguère and Cristina Martinez-Fernandez at the OECD designed the methods used in the research as part of a wider international project, while their colleague Damian Garnys implemented the web-based survey. Sheelagh Delf, Helen Easton and Damian Garnys prepared the document for publication. The international project is conducted under the direction of Cristina Martinez-Fernandez.

The national steering committee in New Zealand was made up of representatives from several agencies, including Anne Alkema, Jeremy Baker, Paul Barker, Ron Clink, Lis Cowey, Daniel Haines, Nyk Huntington, Carrie Murdoch, Paul Swallow, Barbara Tebbs, Jason Timmins, Tony Waldegrave and Felicity Wong. In Canterbury, Phil Agnew, Tafflyn Bradford-James, Rob Brawley, Mike Gorinski, Andrea Miller, Gay Sharlotte, Wendy Smith, Janine Sundberg, Peter Townsend, Tamara Weyman and Simon Worthington made important contributions to the survey and to the successful hosting of a regional skills ecosystem workshop in Christchurch. Che Tibby provided insightful comments on an early draft of this report.

The whole research team is very grateful to the people who participated in the web-based survey, to all the participants in the skills ecosystem workshop, and to the managers who made themselves available to be interviewed for the five case studies: Tim Armitage, Howard Nicholls, David O'Neill, Matt Southorn and Grahame Wright. We also thank Budd Lister at the Department of Labour for preparing the collage on the cover, which includes a photo kindly supplied by Windflow Technology Ltd, one of the five firms that participated as a case study for this project. Finally, I am very grateful to my colleagues in the AERU, Teresa Cunningham, Meike Guenther, Bill Kaye-Blake and Caroline Saunders for their help at different stages of the project. 


\section{Table of Contents}

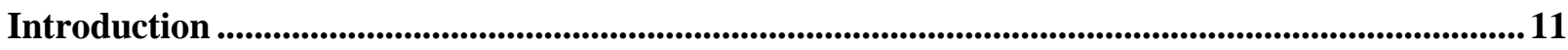

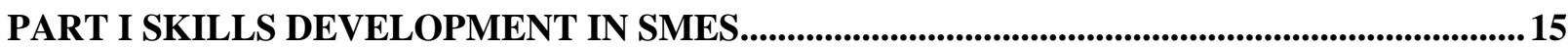

Chapter 1 - The OECD Survey of Canterbury SMEs ..................................................................................... 17

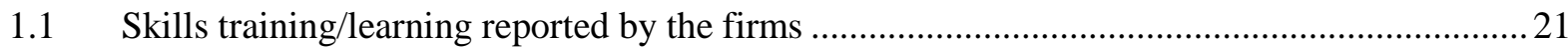

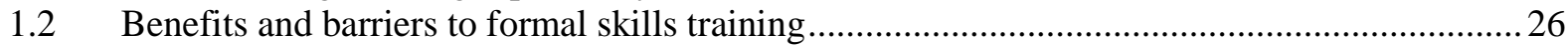

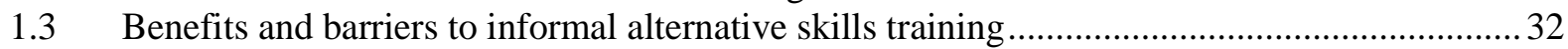

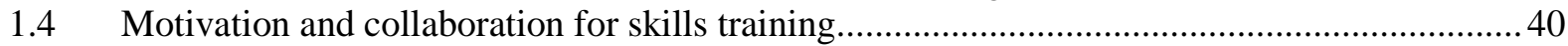

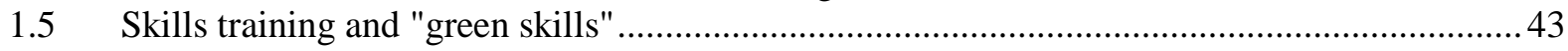

PART II THE REGIONAL SKILLS AND TRAINING ECOSYSTEM IN CANTERBURY ........ 45

Chapter 2 - The OECD Workshop in Christchurch....................................................................47

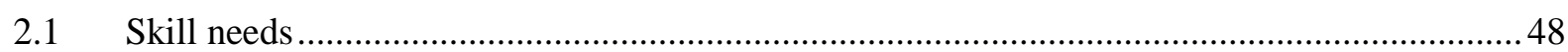

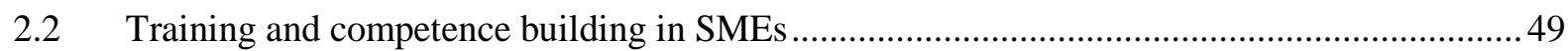

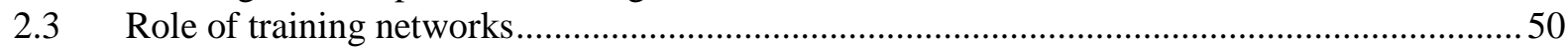

2.4 Outcomes of training and competence building activities ....................................................... 52

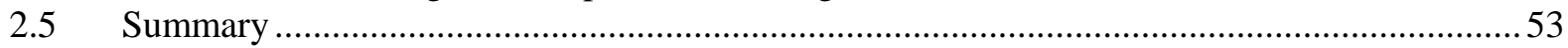

Chapter 3 - The Canterbury SME Case Studies........................................................................................... 55

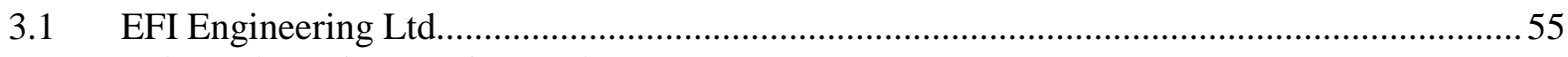

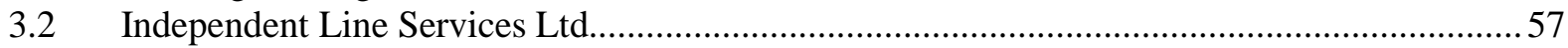

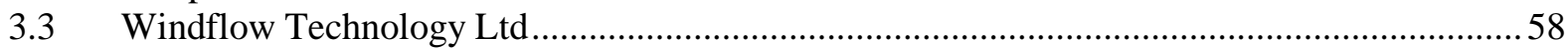

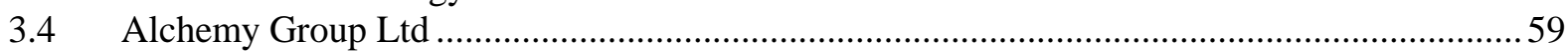

3.5 Lakewood Court Rest Home and Straven House.................................................................... 61

PART III ANALYSIS OF MAJOR THEMES AND CONCLUSIONS ............................................63

Chapter 4 - Major Themes.......................................................................................................................................65

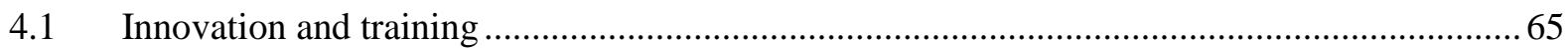

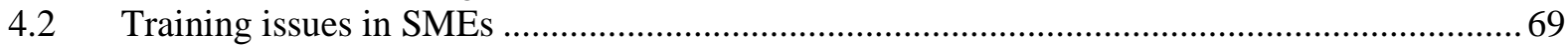

4.3 The importance of informal alternative ways of training.......................................................... 70

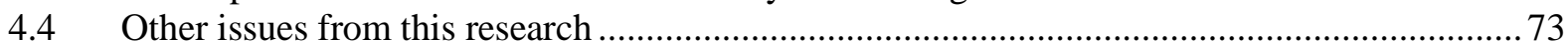

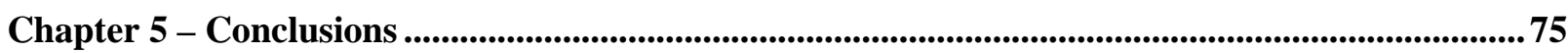

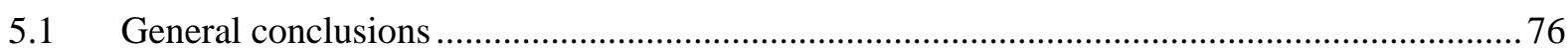

P.2 Possible implications for policy development and further research......................................... 76

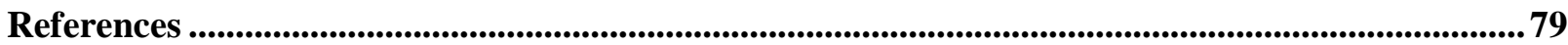

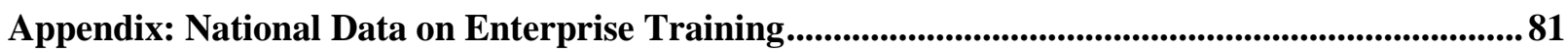




\section{List of Tables}

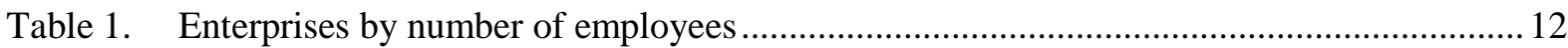

Table 2. Motivations for participation in formal and informal training.......................................... 41

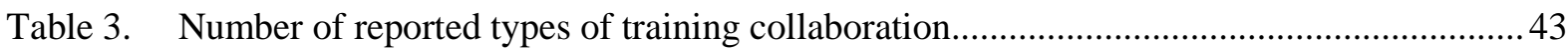

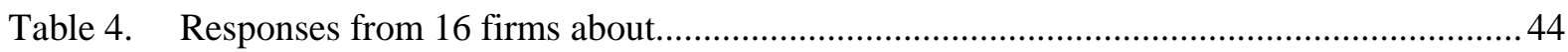

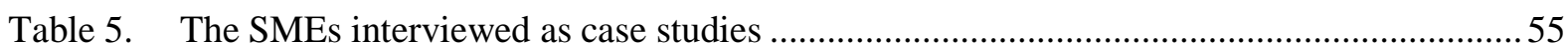

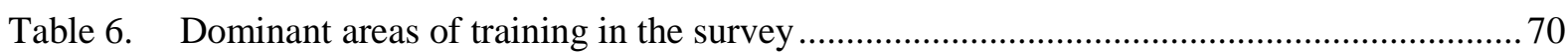

Table A1. Involvement of firms in training staff in the previous financial year .................................. 83

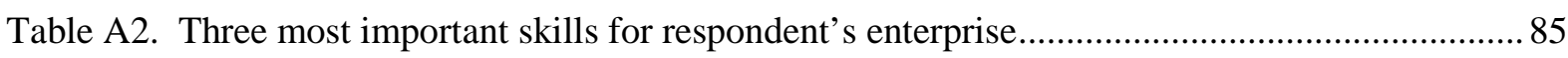

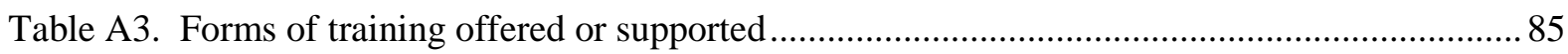

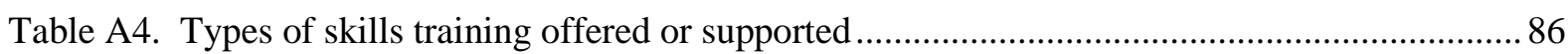

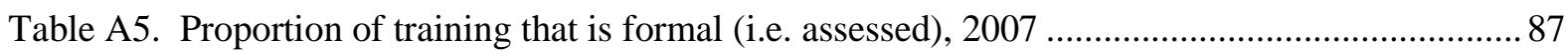

Table A6. Three most important reasons for supporting less or no training ......................................... 88

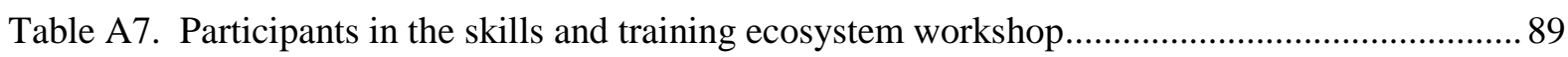

\section{List of Figures}

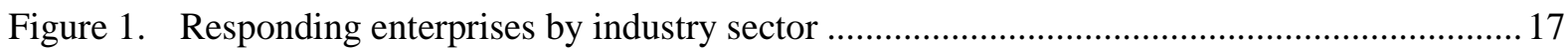

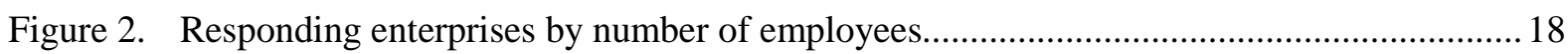

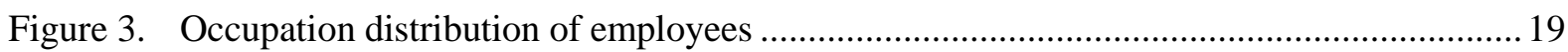

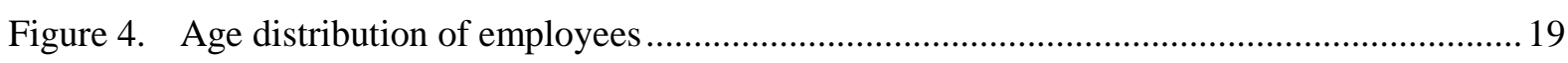

Figure 5. Responding enterprises by number of apprentices or trainees............................................ 20

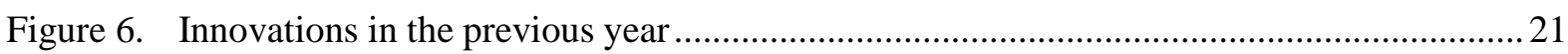

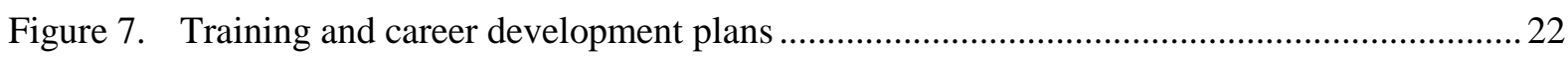

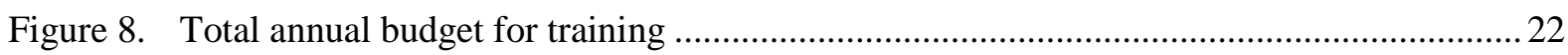

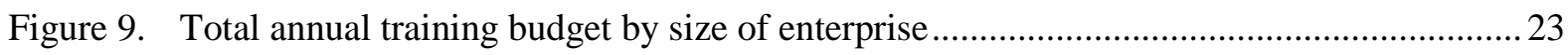

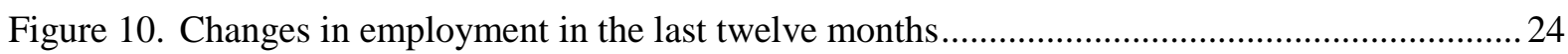

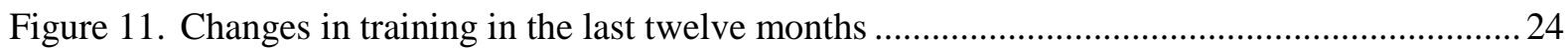

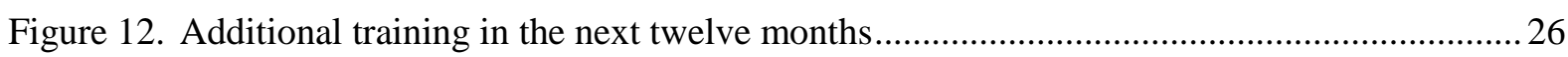

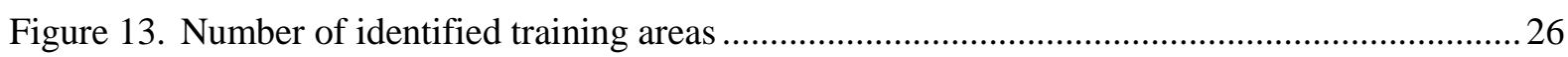

Figure 14. Participation in formal training in the last twelve months .................................................28

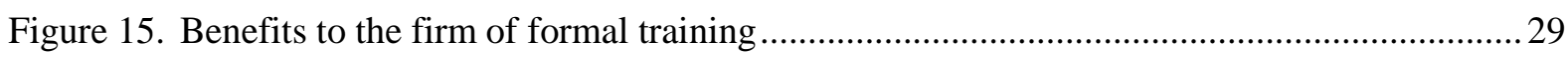

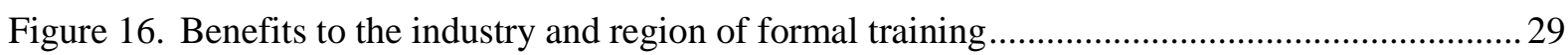

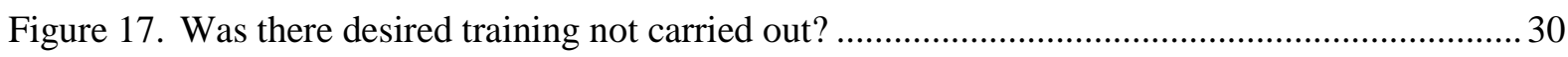


Figure 18. Barriers for medium to high skilled employee training ..................................................... 31

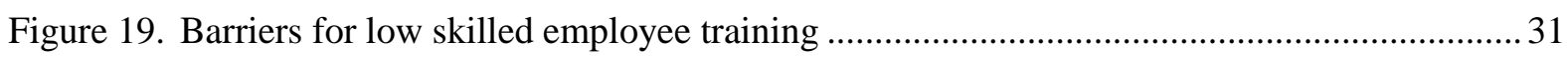

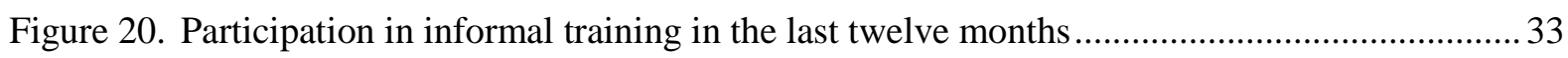

Figure 21. Highly important sources of informal training in the last twelve months............................ 34

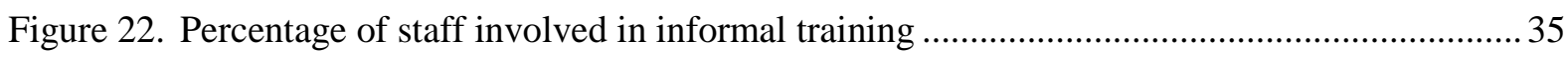

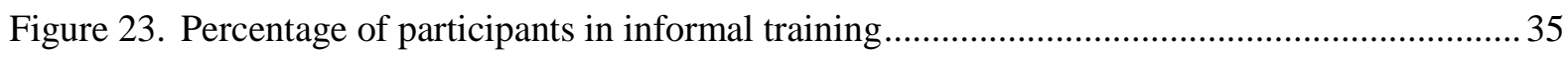

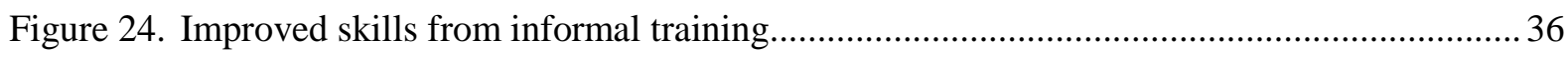

Figure 25. Other employee benefits from informal training ........................................................... 37

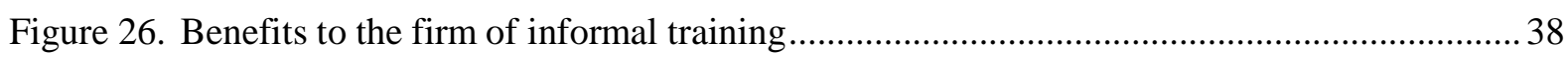

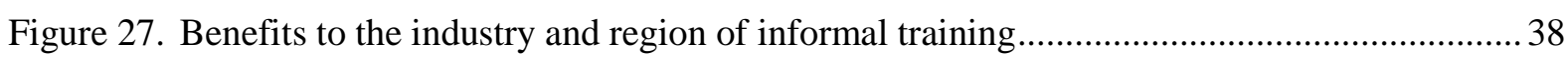

Figure 28. Better sources than formal education (medium to high skilled employees) ....................... 39

Figure 29. Better sources than formal education (low skilled employees) ............................................ 40

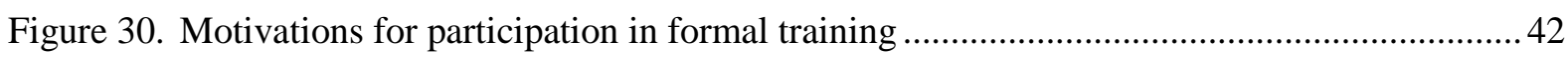

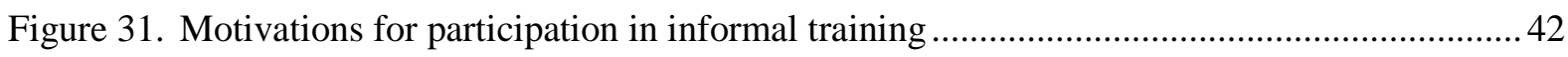

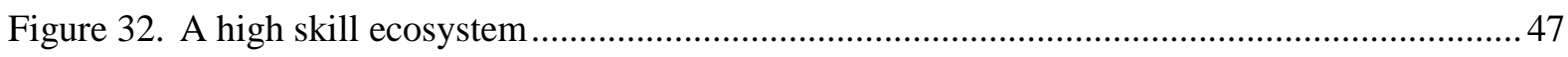

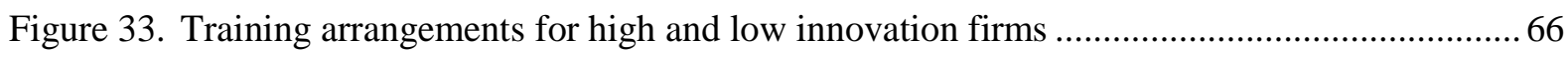

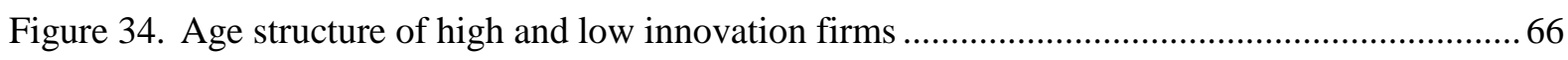

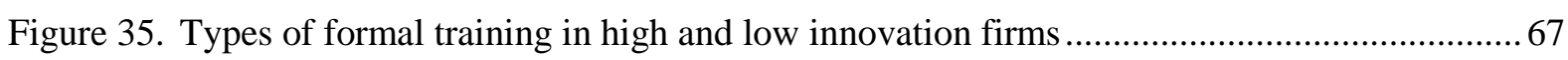

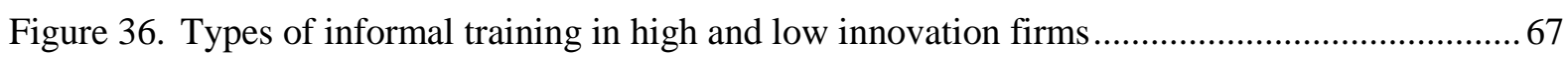

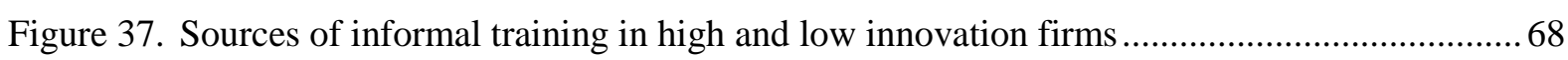

Figure 38. Participation in formal and informal training in the last twelve months............................. 72

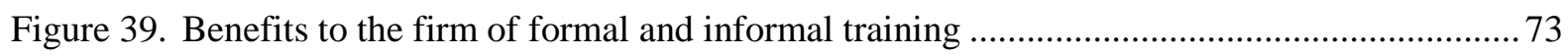

Figure A1. Factors resulting in staff not having all the skills to do their job, ..................................... 82

Figure A2. Skills that existing staff most need to improve .............................................................. 82

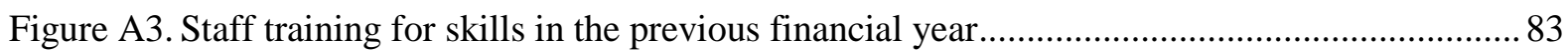

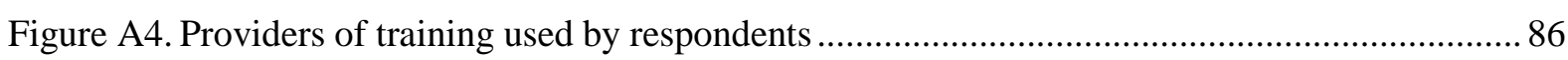





\section{Introduction}

New Zealand's post-war economic development in the twentieth century was largely based on exporting agricultural commodities (especially sheep meat, wool and dairy products) to the United Kingdom, while an extensive system of import licensing was used to maintain foreign exchange reserves and protect domestic light manufacturing. This was no longer sustainable after the United Kingdom entered the European Economic Community in 1973, despite initial efforts to protect producers through greater government controls. The need for change was recognised after a new government was elected in July 1984. Reforms introduced over the following decade reduced the role of the public sector in the economy and opened up domestic markets to greater local and international competition. Since then, government policy has aimed to promote economic development through market-oriented innovation and a more productive labour force. In the Speech from the Throne at the State Opening of Parliament on 9 December 2008, for example, the Governor General described the driving goal of the new government in the following terms ${ }^{1}$ :
My Government intends to embrace New Zealand's clear opportunities for improved economic performance and to use them to deliver better wages and living conditions for all New Zealanders. It commits to, amongst other steps, an ongoing programme of personal tax reductions; a step-up in infrastructure investment; a reduction in government bureaucracy in favour of frontline services; an across-the-board commitment to lifting productivity growth and a renewed effort to lift education standards.

The goals of raising productivity growth and education standards are established priorities in public policy (Barker, 2007). The New Zealand Treasury, for example, has a substantial work programme on productivity growth, beginning with its influential report, Putting Productivity First, published in April 2008. That report identified five key drivers of productivity growth (p. 8): enterprise, innovation, skills, investment and natural resources. This framework has been accepted by other lead organisations; Business New Zealand, for example, has used it to create a 50-point productivity action plan in their publication Setting New Zealand Apart - Getting More Productive and Competitive - A Plan for Action. The government's draft Tertiary Education Strategy 2010-2015, released in October 2009, targeted four of its six priorities to increasing the number of people achieving higher-level qualifications as well as assisting adult learners to gain literacy, language and numeracy skills which lead to higher-level study or skilled employment.

A key element in recent policy initiatives aims to increase skills levels in the existing labour force, on the basis that $80 \%$ of those currently employed will still be in the workforce in 2020 (New Zealand Government, 2008, p. 6). Effective policies to support training and skills development in the workforce must take into account that New Zealand businesses are predominantly small and medium-sized enterprises, or SMEs (Long et al, 2000; Coetzer, 2002; Vaughan, 2002; Fraser, 2005; TEC, 2005; Coetzer, 2007; Coetzer et al, 2007; Massey and Ingley, 2007). Two-thirds of New Zealand enterprises have zero employees, and almost two-thirds of businesses which do employ staff have no more than five employees (MED, 2009). The New Zealand Centre for SME Research describes these firms as "micro

1 www.beehive.govt.nz/speech/speech+throne+0 
enterprises"; see, for example, Cameron and Massey, 1999). Table 1 presents data on the distribution of employing enterprises as at February 2008 - more than 90\% employ between 1 and 19 employees, and only $1.4 \%$ employ 100 staff or more.

Table 1. Number of employing enterprises by number of employees, February 2008

\begin{tabular}{|c|c|c|c|}
\hline $\begin{array}{l}\text { Employee } \\
\text { Size Group }\end{array}$ & $\begin{array}{l}\text { Number of } \\
\text { Enterprises }\end{array}$ & $\begin{array}{l}\text { Percentage of All Enterprises with } \\
\text { Employees }\end{array}$ & $\begin{array}{l}\text { Cumulative } \\
\text { Percentage }\end{array}$ \\
\hline $1-5$ & 100,459 & 66.2 & 66.2 \\
\hline $6-9$ & 20,526 & 13.5 & 79.8 \\
\hline $10-19$ & 16,771 & 11.1 & 90.8 \\
\hline $20-49$ & 9,104 & 6.0 & 96.8 \\
\hline 50-99 & 2,579 & 1.7 & 98.5 \\
\hline 100-499 & 1,859 & 1.2 & 99.8 \\
\hline $500+$ & 340 & 0.2 & 100.0 \\
\hline TOTAL & 151,638 & 100.0 & \\
\hline
\end{tabular}

Source: MED (2009, p. 9).

This feature of the New Zealand economy, which is shared by other economies, is significant because there is considerable evidence that small and medium-sized enterprises generally face significant barriers to engagement with formal training programmes (see Coetzer, 2002, p. 4). These barriers have been summarised as follows in the extensive literature review of Vaughan (2002, pp. 7-8):

- A preoccupation with short-term survival issues takes priority over training which is long-term in planning requirements and benefit realisation.

- Skill deficiencies tend to be solved with the labour market by employing previously trained staff.

- Training is oriented to large enterprises and their needs, yet small to medium-sized enterprises are not scaled-down versions of large ones, in terms of characteristics, organisation, and daily operation.

- Informal and on-the-job, unstructured training is seen as more relevant than training through formal courses.

- Financial costs are disproportionately higher for SMEs than large enterprises.

- SME employers tend to be independent and suspicious of formal training and education.

- Opportunity costs preclude the release of staff for training, or the provision of "cover" for employees in training.

- There is conflicting evidence about demonstrable benefits in terms of profit and growth from training to the SME itself; benefits tend to be most clearly seen in terms of the individual employee or the economy generally.

- Formal training is often not flexible enough in timing, access, or convenience for SMEs.

- Customisation of training packages, which would make training more convenient and relevant for SMEs, is expensive. 
Data across OECD countries show that small to medium sized enterprises (SMEs) participate 50\% less in training activities than large firms, with some systematic access gaps meaning that younger, better educated workers in high-skilled occupations (such as managers, professionals and technicians) have greater access to training opportunities than the less-educated ones (see OECD, 2008a, p. 5). Further, Coetzer (2002, p. 5), Vaughan (2002, p. 5) and OECD (2008a, pp. 21-26) all draw attention to the important role that informal training plays in SMEs. Coetzer cites the Australian study of Field (1998) which reported a rich and complex picture of learning in SMEs despite limited use of structured training, while Vaughan (2002, p. 5) suggests that "attention to informal training carried out in or by SMEs can provide valuable insight into the priorities and training needs of SMEs".

Against this background of strong evidence, the LEED programme of the OECD initiated a project to identify ways of overcoming barriers to workforce development in SMEs. New Zealand is a participant in this project. The research for the project has involved gathering and analysing new data on SMEs labour force participation in formal and informal training, analysing the impact of training and skills development activities in firms, and examining local approaches to learn how incentives can be provided to employers and employees for training activities that generate results for all employees (OECD, 2008, p. 3). This report presents the results of this research, undertaken by the author in close collaboration with the OECD research team, Dr Sylvain Giguère and Dr Cristina Martinez-Fernandez.

As well as focusing on formal and informal training in SMEs, the research has been informed by another important theme in the international literature. Coetzer (2002, p. 2) cites several studies that argue "we have entered a knowledge-based era where the emphasis is increasingly on human capital, rather than financial and physical assets" so that "individuals at every level have to think for themselves, exercise initiative, innovate, and solve problems at the source as quickly as possible". The OECD has formalised this feature of modern enterprise in a concept termed Knowledge-Intensive Service Activities abbreviated as KISA (see especially OECD, 2006; a New Zealand application to the software industry has been reported by Williams, 2006). The concept has been well summarised by Martinez-Fernandez (2006, p. 109):

\begin{abstract}
Knowledge Intensive Service Activities (KISA) are defined as the activities originated by the production and integration of knowledge-intensive services crucial for the innovation process of the firm. They may be undertaken by firms in manufacturing or service sectors, and in combination with manufactured outputs or as stand-alone services (OECD, 2003, p. 2). Typical examples of KISA include $R \& D$ services, management consulting, IT services, human resource management services, legal services (such as those on IP-related issues), accounting, financing, and marketing services. Activities oriented toward the use and integration of knowledge are instrumental for building and maintaining a firm's innovation capability. In practice, KISA in a firm are achieved by the use of inhouse, or the combination of in-house and external, expertise. The capacity of the firm to perform these KISA more effectively may indeed be what differentiates a firm from its competitors.
\end{abstract}

Three aspects of the KISA concept are particularly relevant for the present study. First, it includes what is often considered the core activity for an innovating firm (research and development, or R\&D), but it also recognises a much wider range of activities ranging from accounting to marketing. This is consistent with previous research on the ICT sector in New Zealand which reported industry criticism that government support for innovation tended to focus on R\&D, whereas "the funds used for research grants could be made more effective if they were leveraged with access to capital, if they encouraged early adoption of good company governance structures, and if a portion of the grants could be accessed for international marketing" (Saunders and Dalziel, 2006). 
Second, the OECD research has identified that small firms can experience difficulty accessing knowledge-intensive service activities. In a Norwegian aquaculture study, for example, researchers found that "small low technology family firms were struggling to survive, and regarded KISA, if they thought of them at all, as a luxury they could not afford" (OECD, 2006, p. 39). More generally, the research found that (OECD, 2006, p. 40):

In many of the studies, however, small firms provided their own services because they could not afford to purchase them on the market. They recognised the need for, say, business planning or accounting, or personnel management services, and so they developed sufficient expertise to perform the needed services themselves. Sometimes they begrudged the time and effort away from what they saw as their core business, and hoped that in the future they would be able to buy the service in the market place.

Third, the link between KISA and innovation capability depends on the absorptive capacity of staff to recognise and make use of new knowledge, which in turn raises fundamental issues about staff training (OECD, 2006, pp. 44-45). This includes processes of learning by doing, participation in training from external providers (including suppliers of inputs to the firm) and creating systems to record and share new knowledge that is co-produced through customer relationships and industry networks.

The New Zealand study adopted the research method designed for the international project by the OECD (2008b). This required two different areas of analysis, reported here in Part I and Part II respectively. Part I focuses on individual enterprises. It presents results from a web-based survey of SMEs in a region of New Zealand (Canterbury) that invited participants to provide information on themes related to training and skills development in their enterprise.

Part II focuses on the regional "skills and training ecosystem" in Canterbury, exploring skills and training related interactions between firms and other organisations in the region. The analysis for Part II is based on a workshop held in Christchurch on 1 July 2009, attended by the OECD research team with invited participants with expertise in skill development in SMEs. This is supported by five case studies of small firms in Canterbury that examine in greater depth barriers and opportunities for formal and informal training of employees.

The research reported in Parts I and II included new areas of enquiry in New Zealand, particularly in those parts of the research that sought to better understand informal training issues faced by SMEs. It should be noted that the study is of a relatively small number of participants (both in the survey and in the case studies) drawn from just one region in the country. The report therefore seeks to distinguish between research findings that are generally supported in the existing literature and other findings that might be regarded as breaking new ground. The former are a solid basis for policy development, while the latter findings provide suggestive hypotheses for further research and industry consultation in the future.

Part III of the report draws on the research findings to distil major themes for future research and policy development to support skills development and labour productivity growth in small and mediumsized enterprises. It finishes with a summary of specific conclusions arising from the New Zealand country study. These will be considered alongside conclusions from the other country studies in this OECD research programme before recommendations are formulated for future policy development. 
Part I

Skills Development in SMEs 



\section{Chapter 1 - The OECD Survey of Canterbury SMEs}

The OECD research team prepared a web-based survey in collaboration with the New Zealand team to collect new data on skills and training in small to medium-sized enterprises from a selected region in each of the project's participating countries. The project's national stakeholders chose Canterbury as the New Zealand region. Invitations to complete the survey were sent to SMEs listed in the databases of the Canterbury Employers' Chamber of Commerce, the Ashburton Business Association, Enterprise Ashburton, the South Canterbury Chamber of Commerce (with the Aoraki Development Trust), the Canterbury Development Corporation and the Apparel and Textile Industry Training Organisation. ${ }^{2}$

The survey was administered in two waves. In the first wave, the survey was open to respondents from the first four organisations from 4 - 24 June. This produced 55 valid replies. In the second wave, the survey was open to respondents from the last two organisations from 6 August to 31 August. This produced a further 17 replies, so that the results presented in this first part of the report are from 72 SMEs. There was a good cross section of industry sector representation in the sample, as presented in Figure 1.

Figure 1. Responding enterprises by industry sector

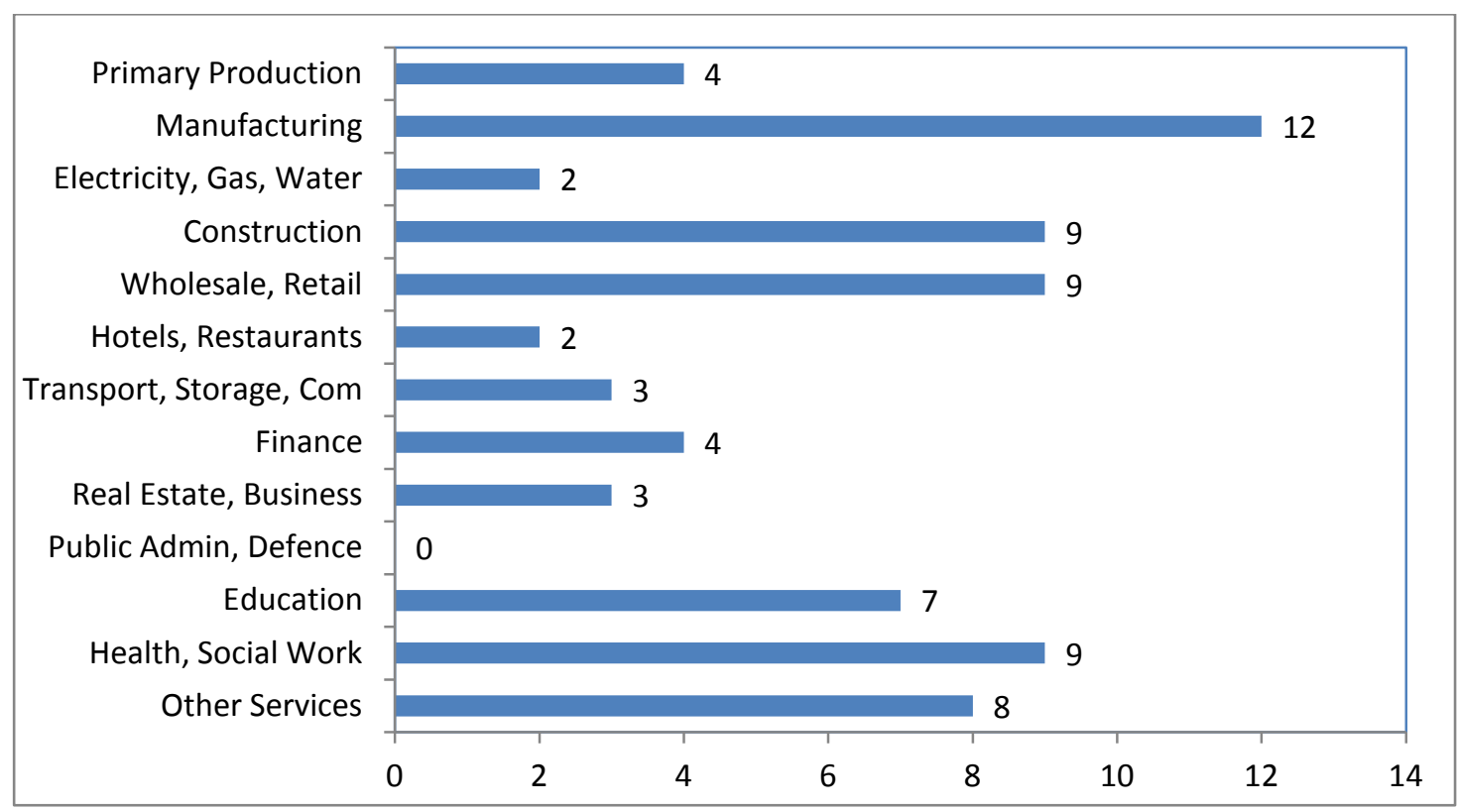

2 The research team is grateful to Peter Townsend and Tafflyn Bradford-James, Janine Sundberg, Rob Brawley, Wendy Smith and Andrea Miller, Simon Worthington and Mike Gorinski respectively for allowing and assisting the project to use these databases. 
The responding enterprises were well established; all but eight reported being in operation for five years or more, with 48 of these having been in operation for at least ten years. The enterprises were also asked about the primary place where they sell their products or services. Local markets were the primary place for 38 of the respondents, with another 22 reporting national markets. Only 12 respondents indicated that their primary markets are international.

The project used the standard OECD definition of a SME as any enterprise with 250 or fewer employees. It should be noted that the top half of that range would generally be considered a large enterprise in New Zealand; the New Zealand Centre for SME Research adopts a cut-off figure of less than 100 employees (Massey and Ingley, 2007, p. 4), for example, while for many purposes the Ministry of Economic Development in New Zealand defines an SME as an enterprise with fewer than 20 employees (see MED, 2009, p. 7). Figure 2 presents data on the size of the enterprises who responded to the OECD survey. Fifty-seven out of the 72 firms met the MED definition of 19 or fewer employees, while all but one firm met the definition of the New Zealand Centre for SME Research.

Figure 2. Responding enterprises by number of employees

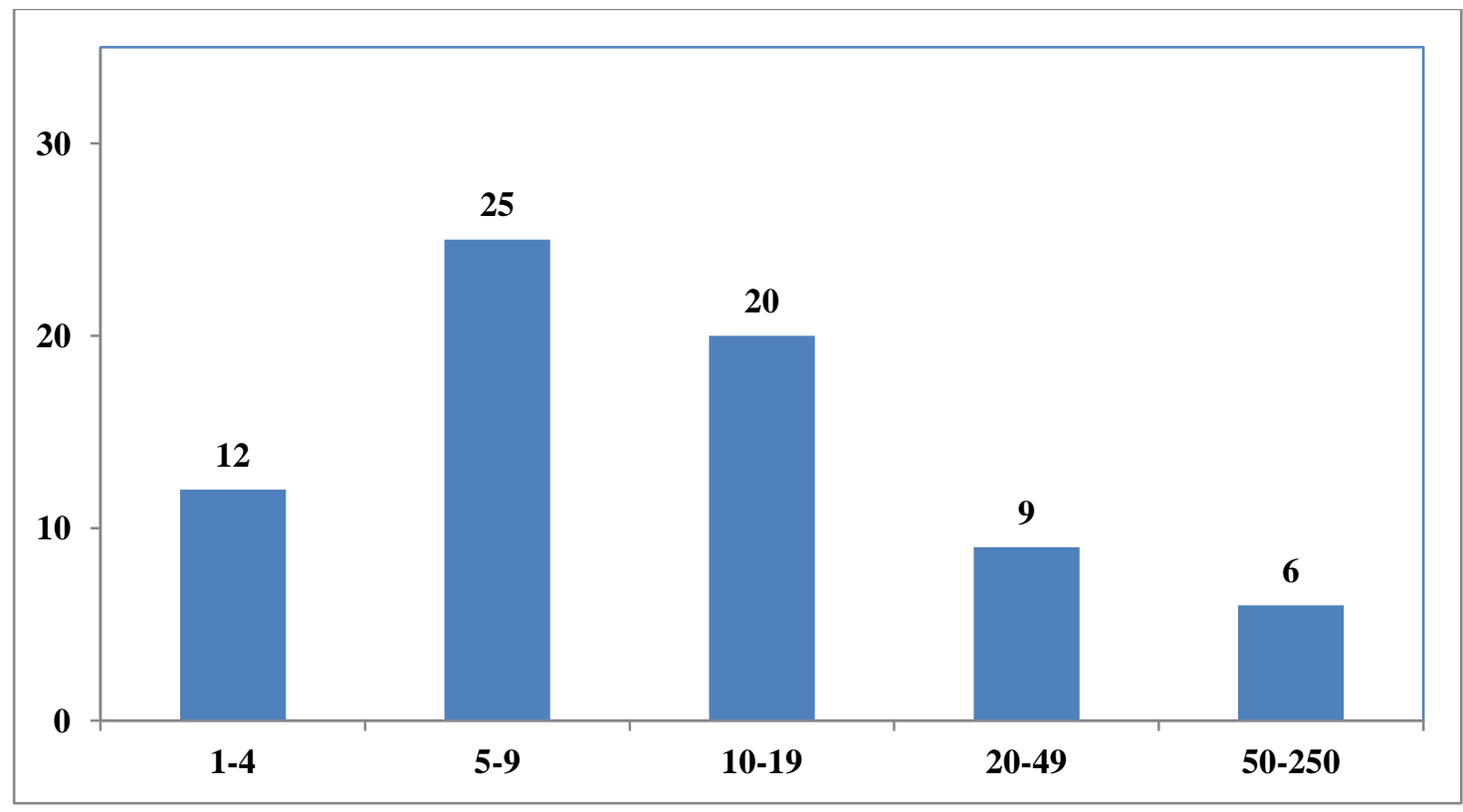

Nearly two-thirds of the work-force was identified as full-time (64\%) and one-quarter as part-time (26\%). The remaining $10 \%$ were reported as casual workers.

The survey asked questions about the occupation and age structure of the firm's workforce. The answers are summarised in Figures 3 and 4. The survey defined high-skilled occupations as manager, professional and technical; $40 \%$ of the employees were identified in this category. The skilled trades, personal service and sales occupations were classified as medium-skilled occupations, accounting for another $43 \%$. 9\% of the employees were recorded as "Don't Know", so that only $8 \%$ were identified as low skilled workers (plant workers and elementary workers). These last workers were employed in just 18 of the 72 firms, so that three-quarters of the sample reported that they do not have staff in the low skilled occupations of plant and elementary workers. 
Figure 3. Occupation distribution of employees

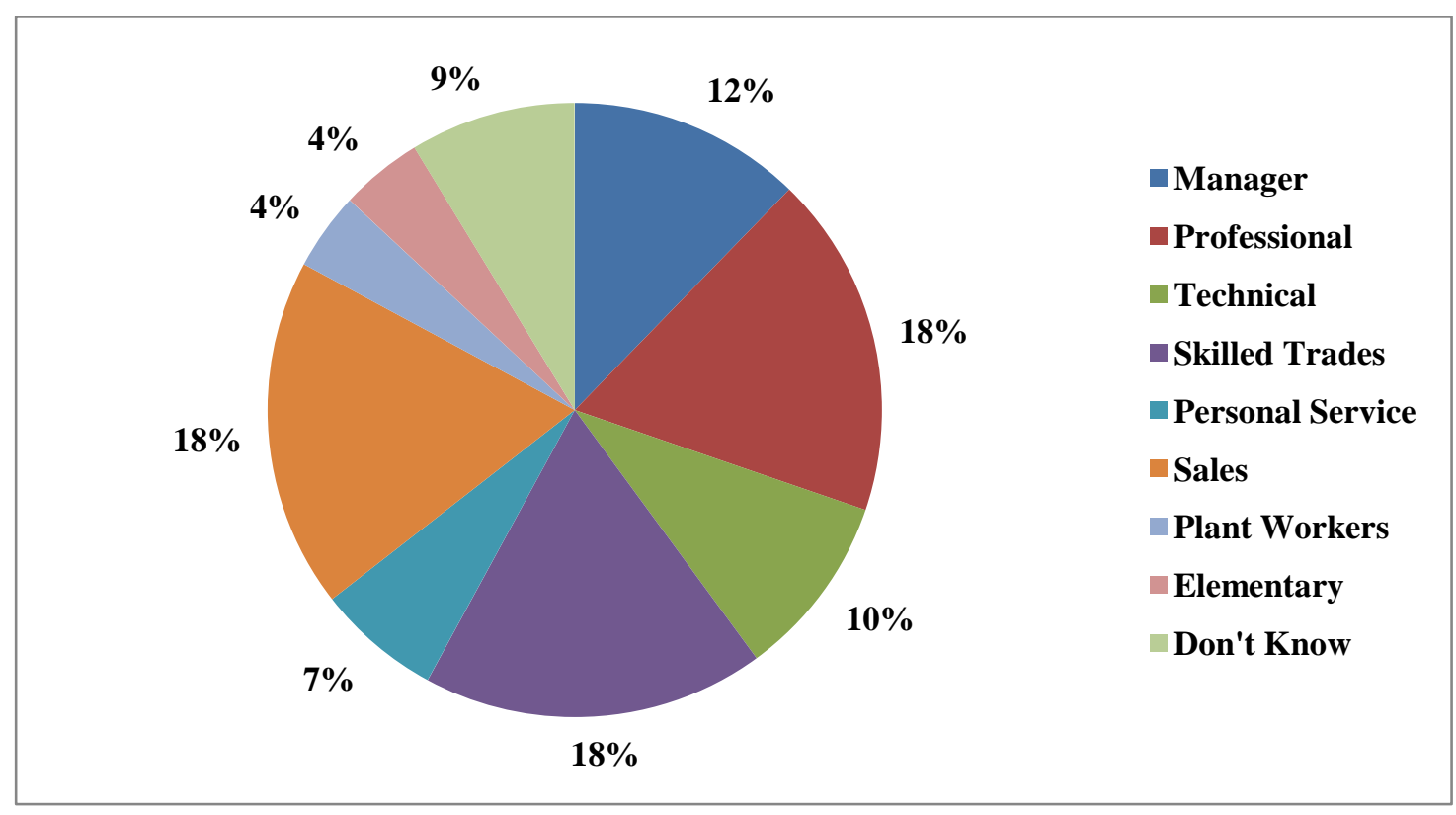

There was a reasonably high level of "Don't Know" replies to the question about the age distribution of the firm's workforce (15\%). In contrast, the percentage of the workforce identified as less than 24 years of age was just 11\%, employed in 32\% of the firms (44\%).

Figure 4. Age distribution of employees

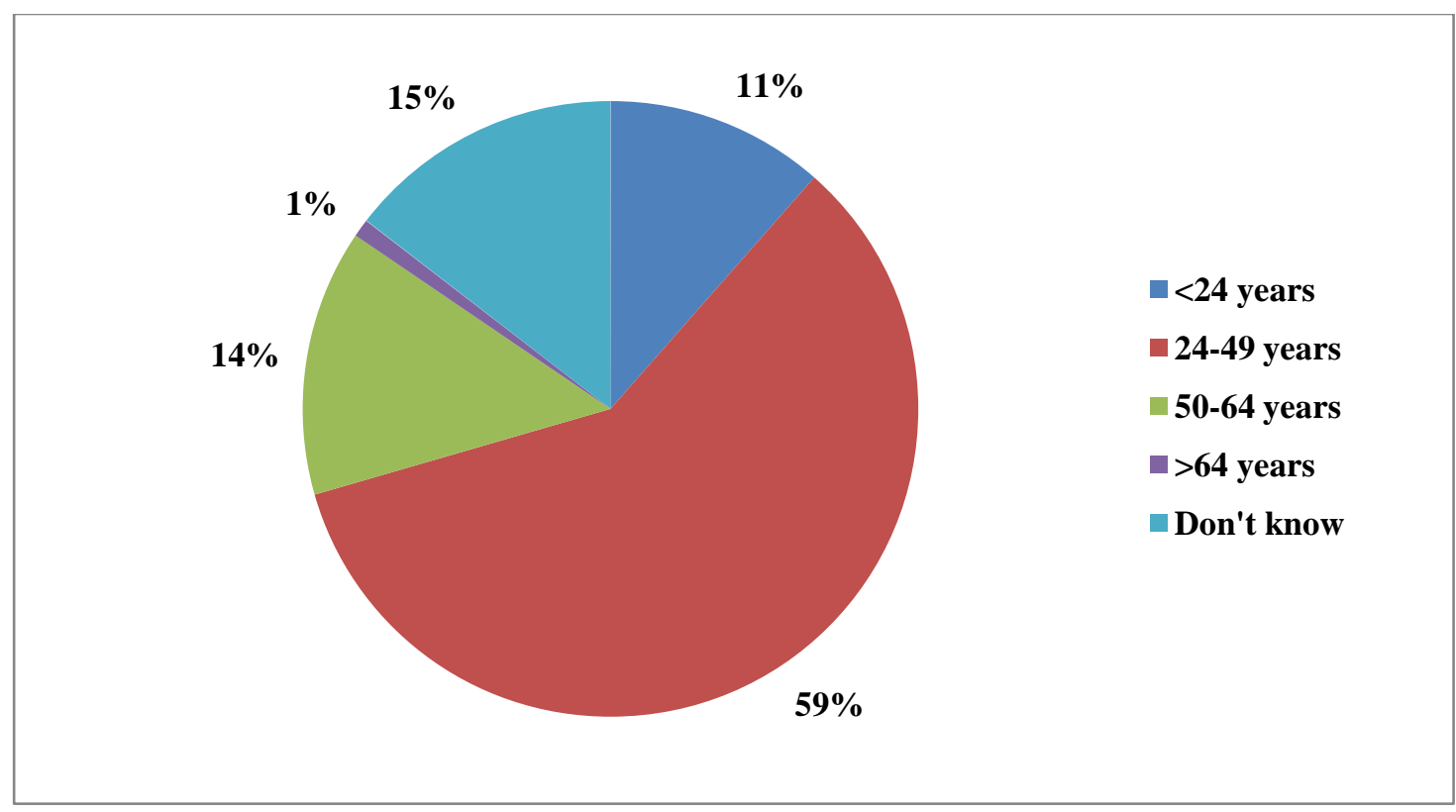

The survey asked how many of the firm's employees are apprentices or trainees. Figure 5 records that the majority of respondents (49, or $68.1 \%)$ reported they have no apprentices or trainees. There were 17 replies reporting one or two apprentices or trainees, while only 6 replies indicated more than two. 
Figure 5. Responding enterprises by number of apprentices or trainees

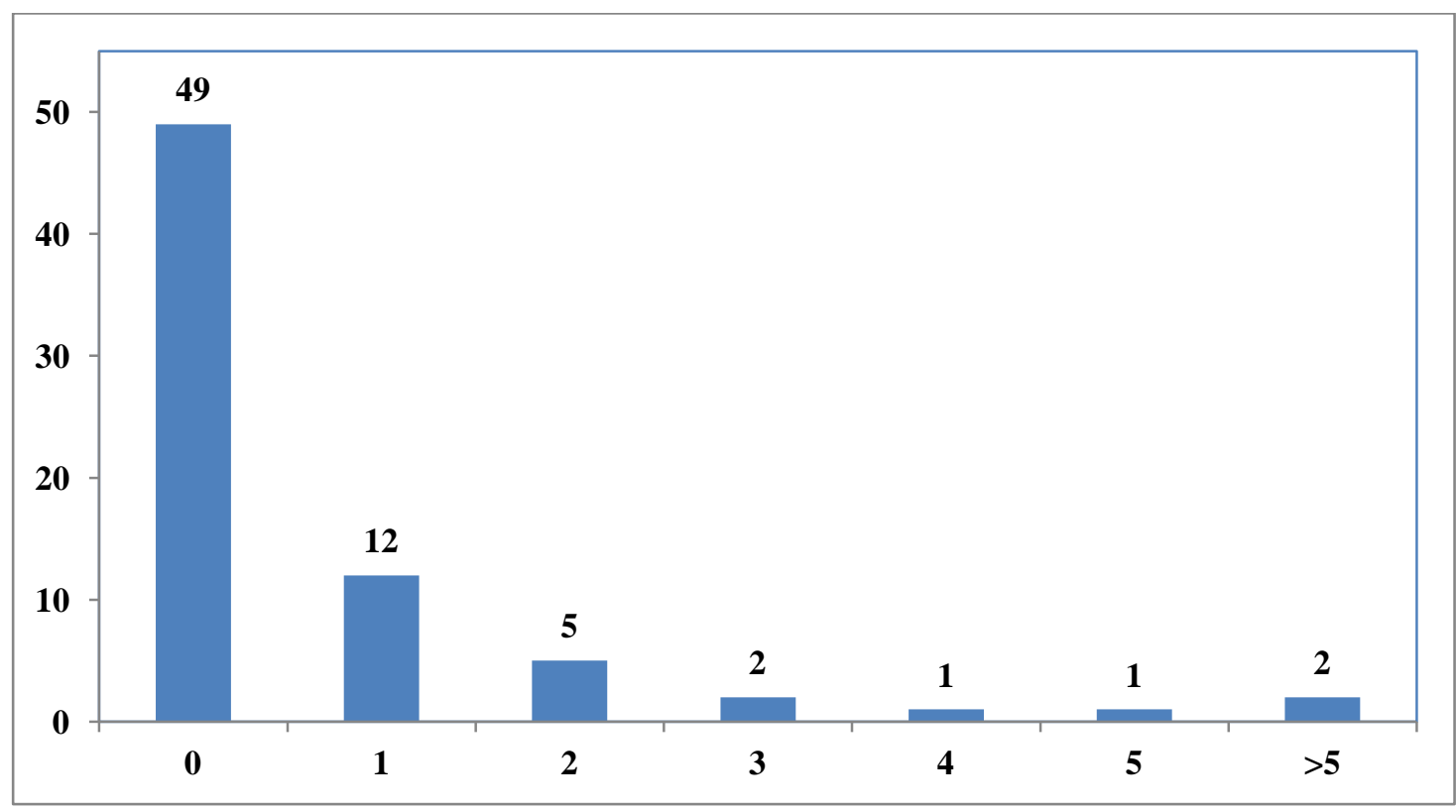

The survey reported a high level of innovation among the enterprises. This result is likely to be affected by "non-response bias" in the sample, since managers were more likely to have participated in this voluntary survey if they have an interest in its focus on training and innovation. The survey offered four areas of potential innovation, and asked participants if there had been any changes in the previous twelve months introducing:

- A new product/service (or a substantially changed product/service).

- A new way of producing an existing product/service (e.g. a new operational process).

- Changes to the way the firm does things such as a new or substantially changed accounting system or human resource management system (e.g. a new management process).

- A new technology or equipment. ${ }^{3}$

Where there had been a change, the survey also asked for an indication of whether the innovation had been incremental or radical. The results are presented in Figure 6. Of the respondents, 63.9\% reported that they had introduced a product innovation in the previous twelve months. This was the highest area of innovation. More than half $(52.8 \%)$ of the respondents reported an innovation in management, while the remaining two categories were reported by just under one-half ( $48.6 \%$ in both cases).

3 The second wave of the survey also asked for any changes in a fifth category: introducing a new product or service or operation due to climate change adaptation/regulation. 
Figure 6. Innovations in the previous year

(\% of Respondents)

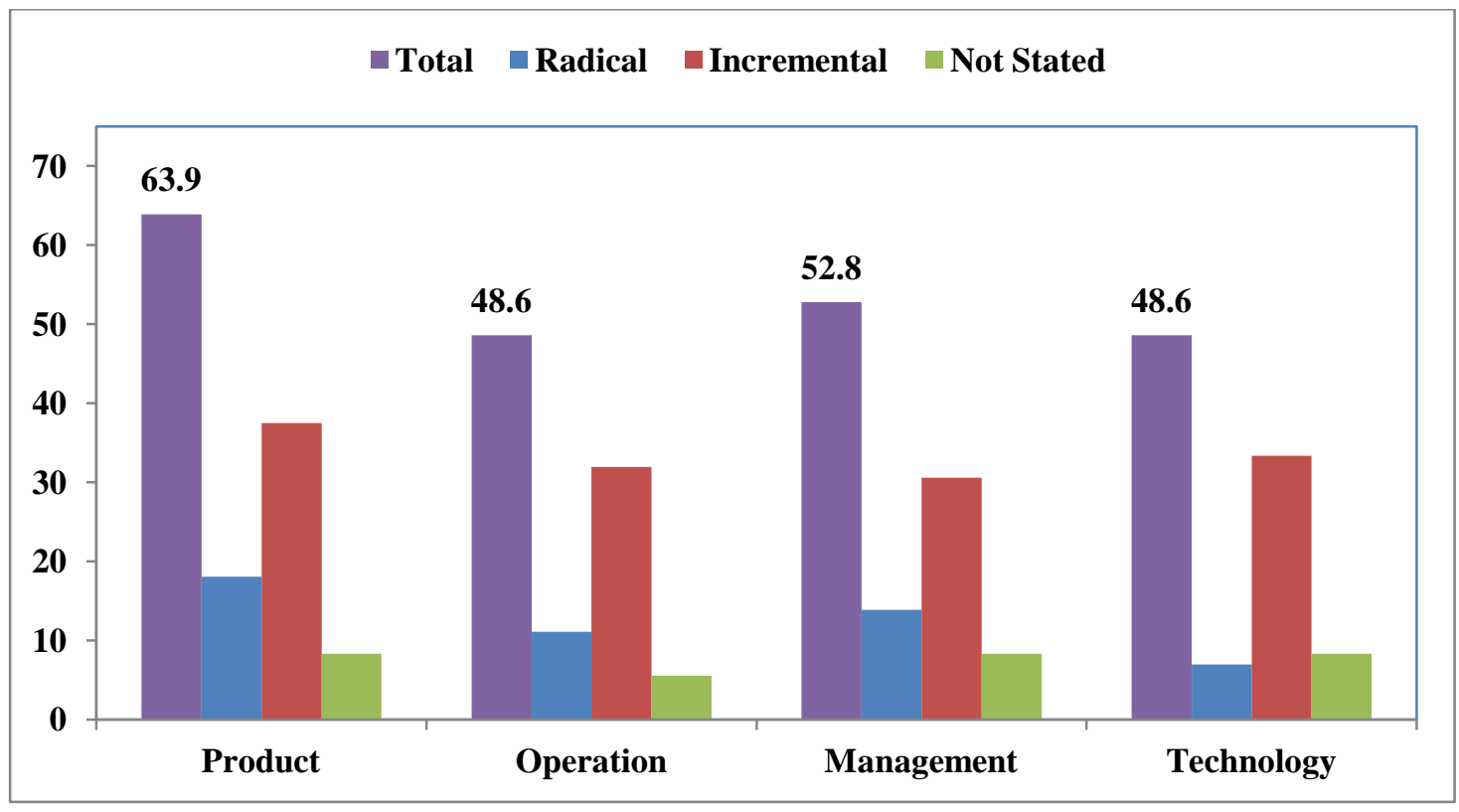

Following standard OECD definitions, the more highly innovative firms in the sample are those that made at least one radical innovation or made serial innovations in three or four of the four dimensions (product, process, management or technology) in the survey's innovation question. Using these definitions, the sample included 22 radical innovators and 32 serial innovators. There were 17 firms satisfying both criteria, so overall there were 37 highly innovative enterprises, one more than half the sample. The highly innovative enterprises in the sample tended to be older and in a mid-range size band:

- $76 \%$ of the highly innovative firms were 10 years or older, compared to $57 \%$ of the less innovative firms.

- $35 \%$ of the highly innovative firms had $10-19$ employees, compared to $20 \%$ of the less innovative firms.

\subsection{Skills training/learning reported by the firms}

The survey asked about skills training and learning in the enterprise, making a distinction between formal training/learning and informal alternative training/learning. The survey included the following definitions of these two types of activity.

Formal Training refers to learning that occurs in an organised and structured environment (e.g. in an education or training institution or on the job) and is explicitly designated as learning (in terms of objectives, time or resources). Formal learning is intentional from the learner's point of view. It typically leads to validation and certification.

Informal Alternative Training refers to learning resulting from daily activities related to work, family or leisure. It is not organised or structured in terms of objectives, time or learning support. Informal learning is in most cases unintentional from the learner's perspective. 
Respondents were asked whether their business has formal training and career development plans for employees (e.g. plans for career advancement and promotion), and does it have an annual budget for training expenditure (e.g. formal/informal training; on/off the job; covering direct costs). 34 firms reported that they have a formal plan (47\%), and 45 firms that they have an annual training budget (63\%); see Figure 7. The last group were asked to indicate the size of the budget, with the results shown in Figure 8.

Figure 7. Training and career development plans

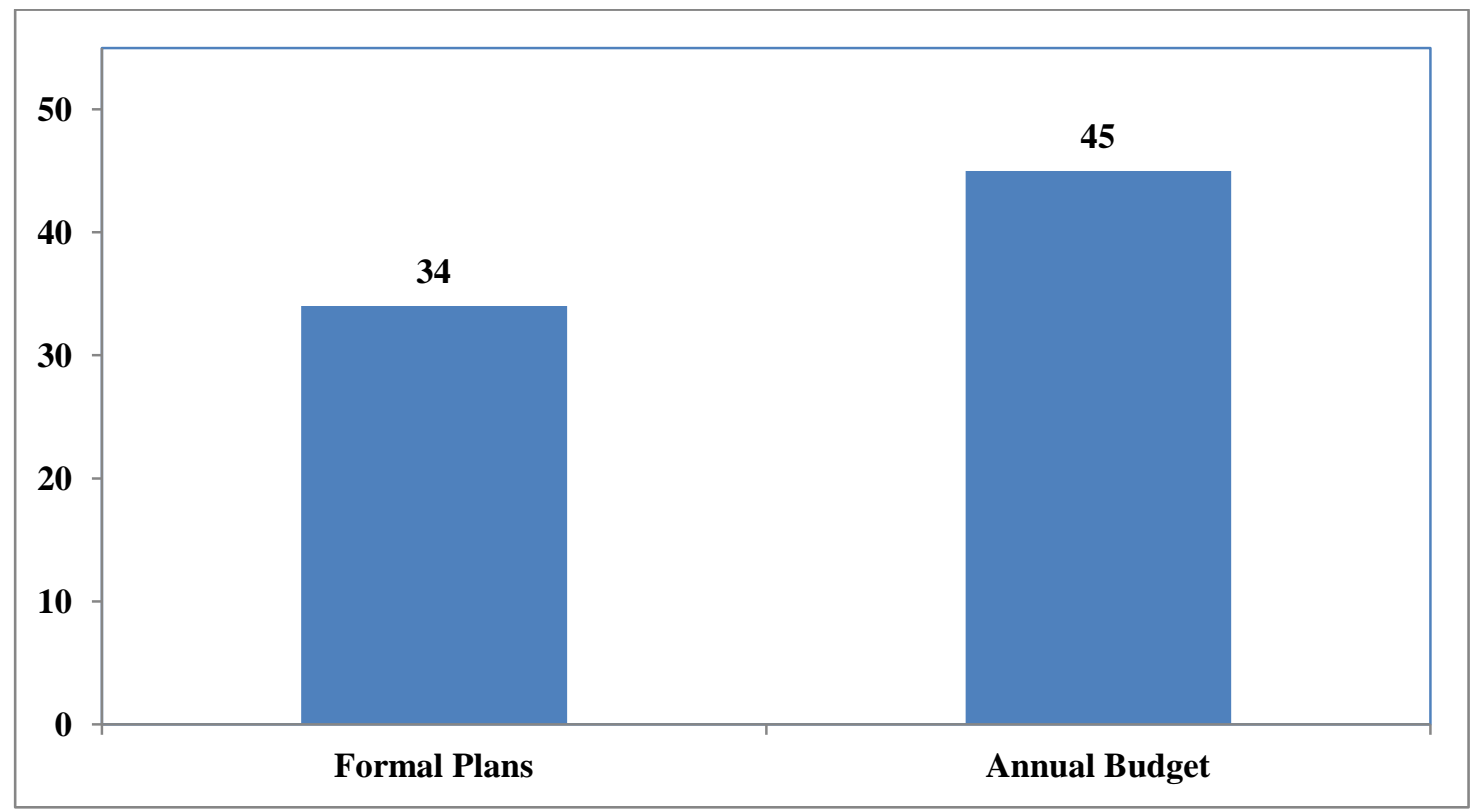

Figure 8. Total annual budget for training (NZD)

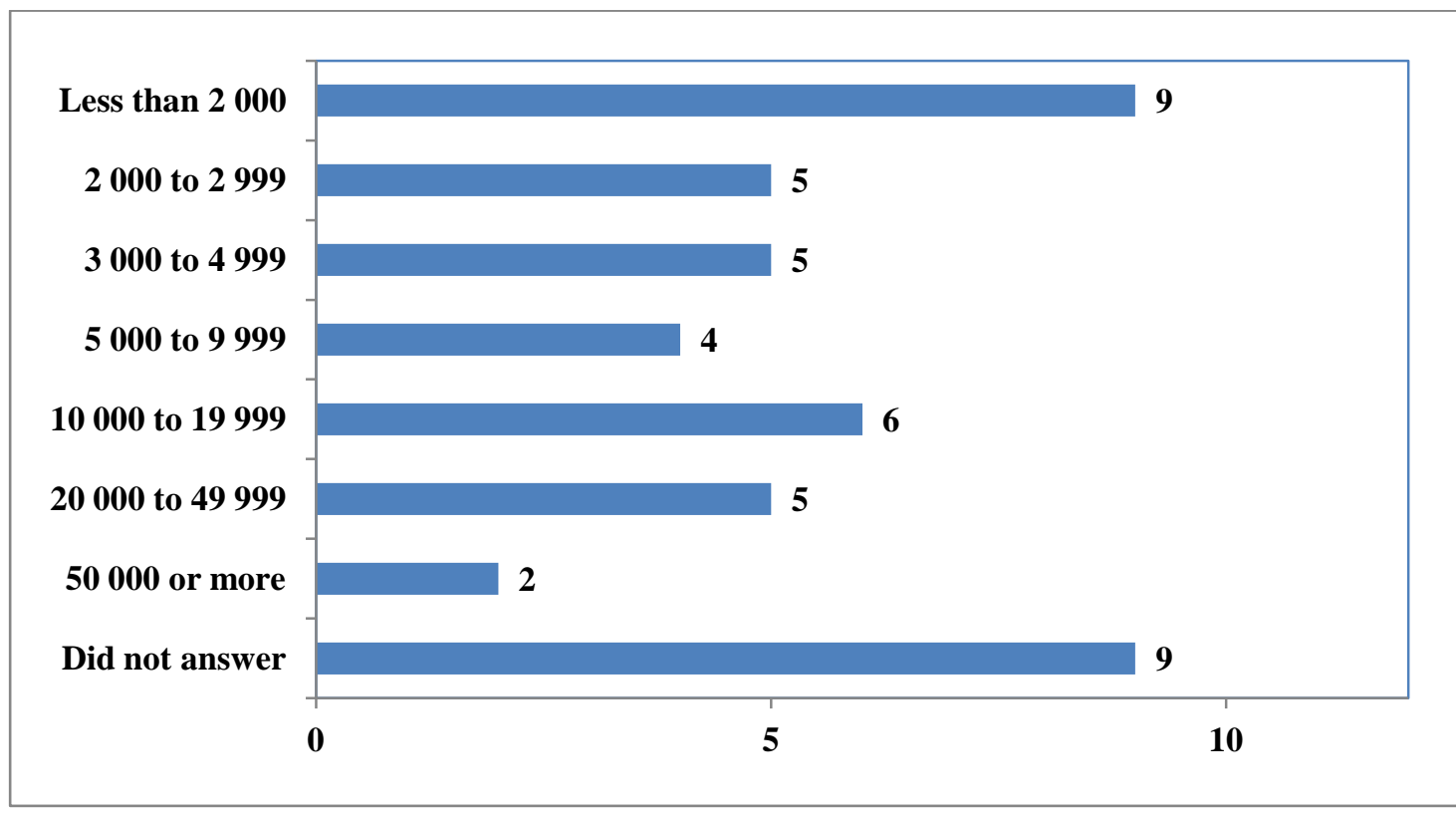

Figure 9 presents data on the total annual training budget (including those who reported they had no budget, but excluding four firms that either did not answer or appeared to give an answer measured in percentage rather than dollar units) analysed by the size of the enterprise. Firms with less than 
20 employees (the MED definition of an SME in New Zealand) tended to have low budgets; 32 out of 55 firms in this category reported no annual budget, and only five firms reported an annual budget greater than NZD 5000.

Figure 9. Total annual training budget by size of enterprise (NZD)

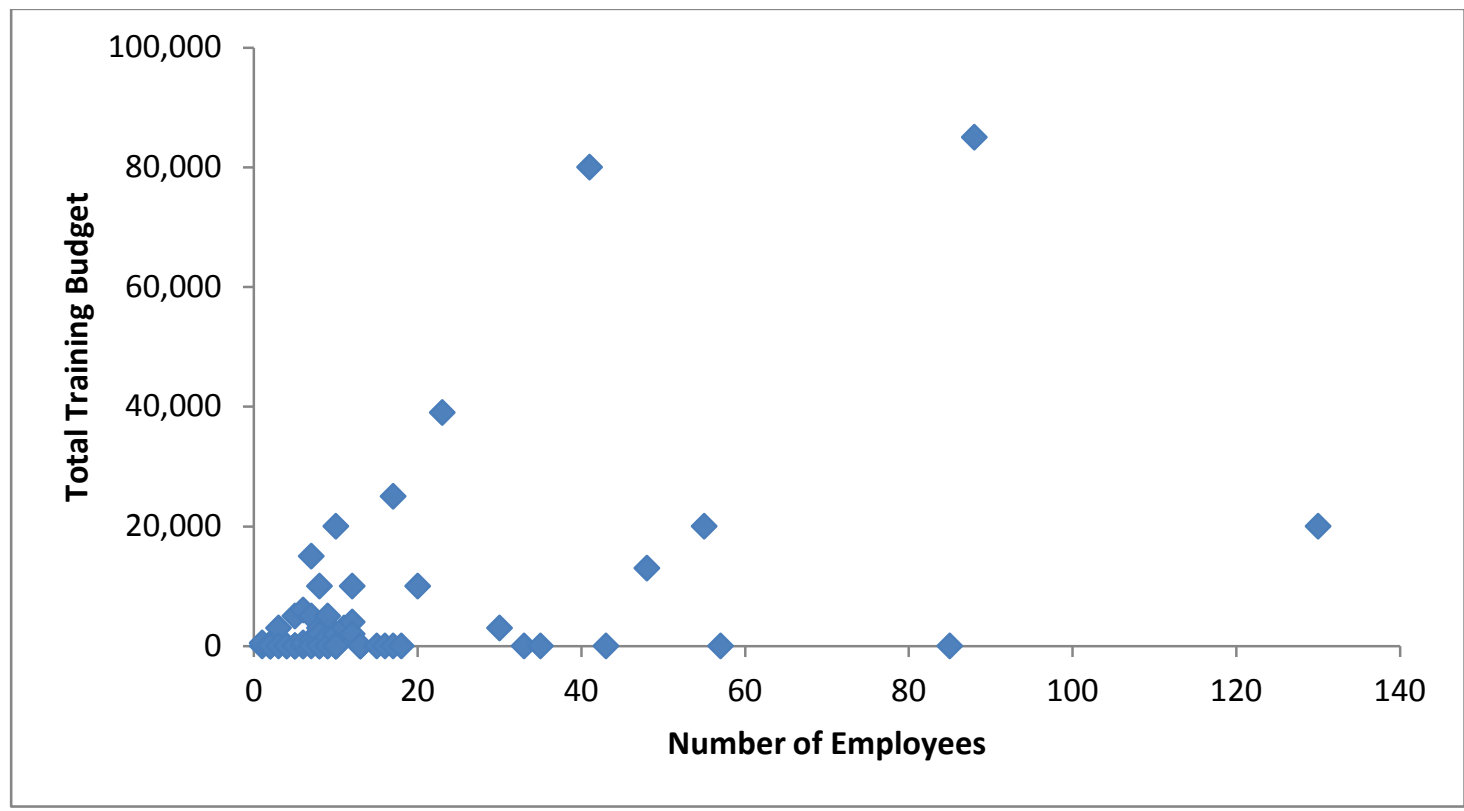

The survey took place at a time when the global economic recession was having a strong impact on New Zealand businesses. The country's official unemployment rate (seasonally adjusted) in June 2009 was 5.7\%, compared to 4.0\% in June 2008 and 3.3\% in June 2007. Against this background, firms were asked whether the recession had changed any of the following eight items in their business:

- The number of staff employed at the establishment in total.

- The number of young people aged under 24 recruited to their first job.

- The number of apprentices and new trainees recruited by the establishment.

- The proportion of employees provided with training.

- $\quad$ Expenditure on training per employee.

- The emphasis placed on informal learning instead of formal learning.

- The proportion of your total training delivered by external providers.

- The amount of formal training, leading to recognised qualifications that the business supports.

The responses to these questions are summarised in Figures 10 and 11. The number of firms reporting an increase in total employment exactly matched the number who reported a reduction, with the largest number reporting no change. Most of the respondents could not say if there had been any changes in the number of trainees or young people recruited to their first job, but 13 respondents reported an increase in the number of apprentices and new trainees compared to only two who reported a decrease. 
Figure 10. Changes in employment in the last twelve months

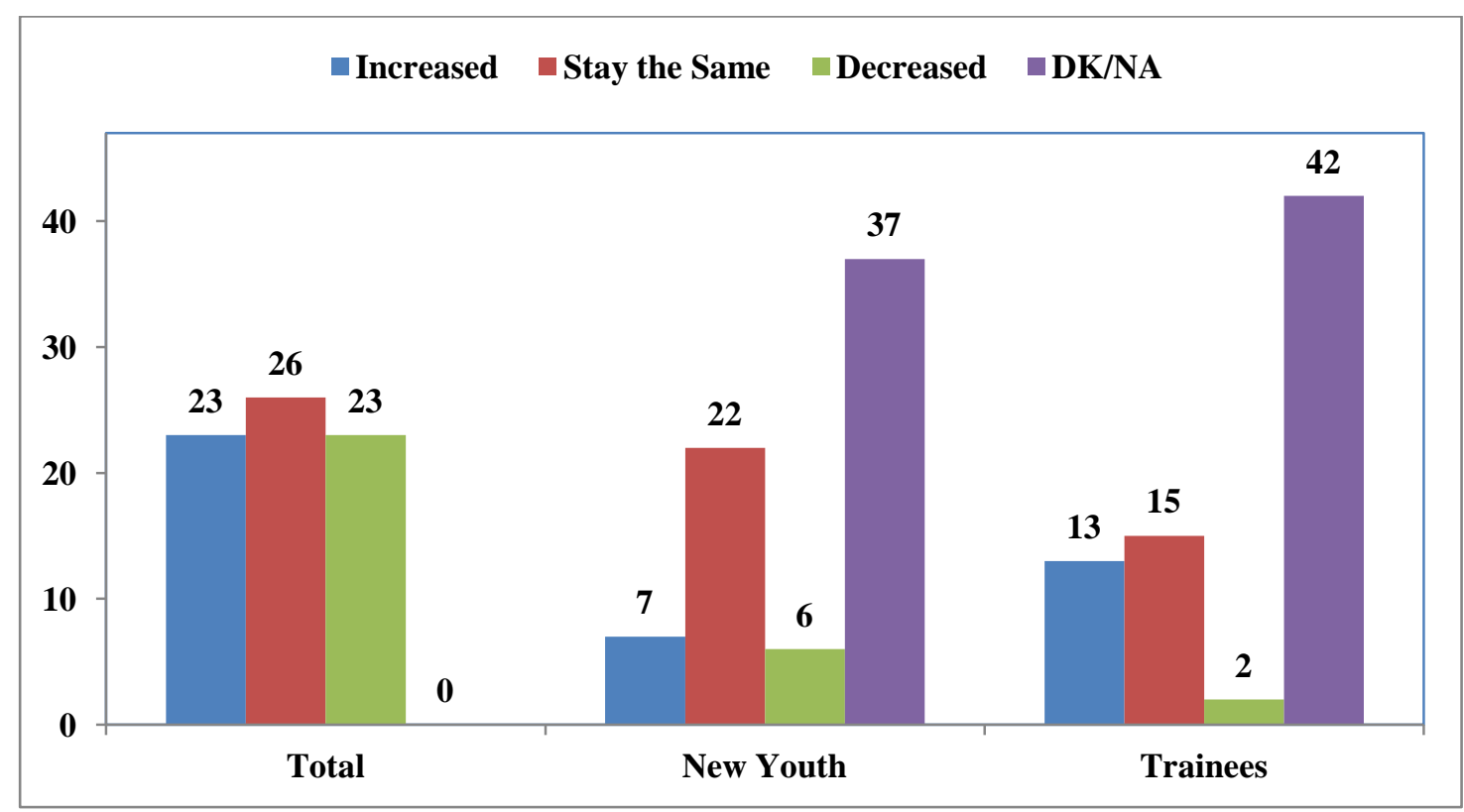

Note: DK/NA is “Don’t Know/Not Answered”.

Figure 11. Changes in training in the last twelve months

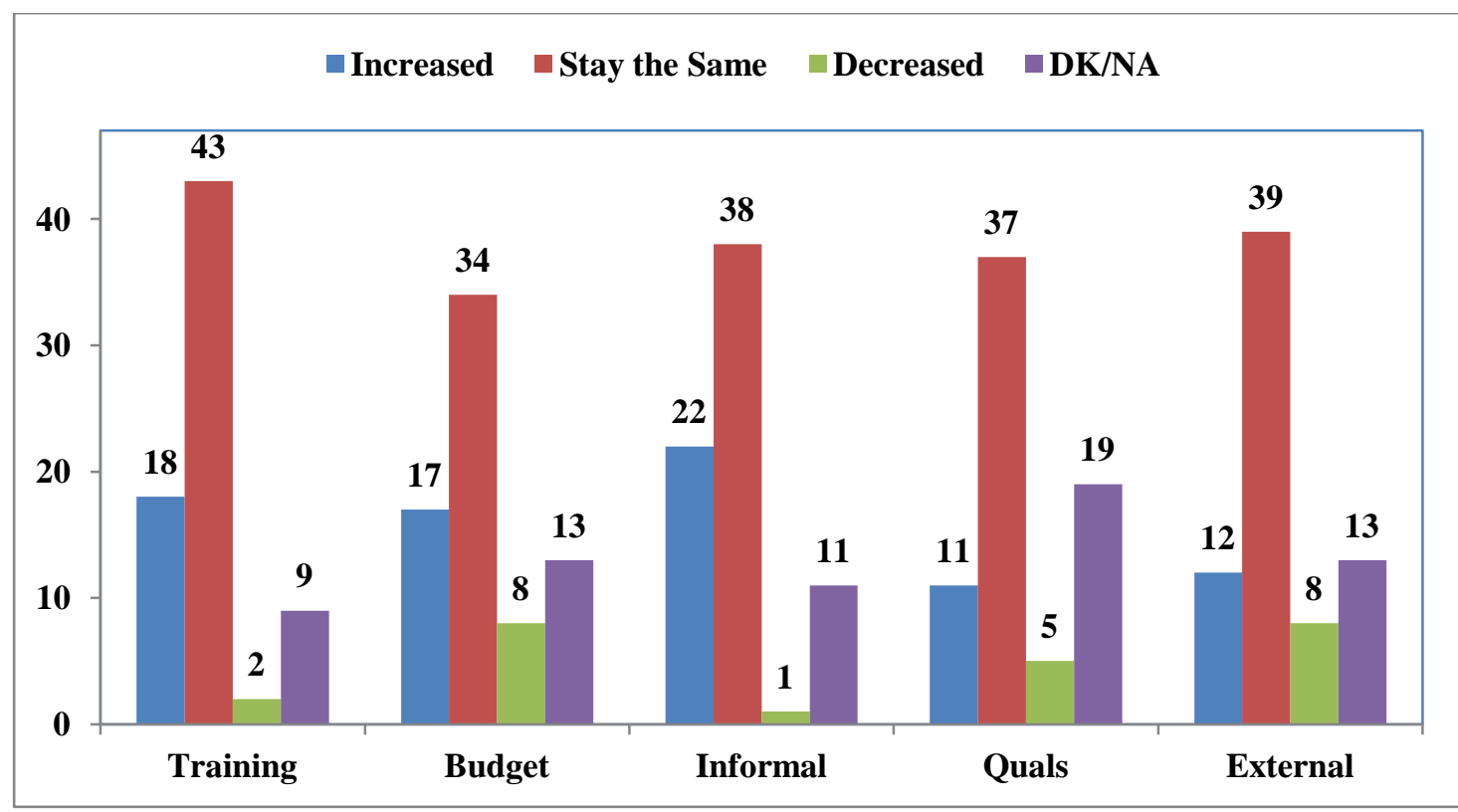

Note: DK/NA is “Don’t Know/Not Answered”.

The responses to the questions about training (Figure 11) were dominated by those reporting no change in each of the five categories. In each case, more firms reported an increase in the last twelve months than reported a decrease. This was particularly noticeable in the number who reported a change in the emphasis placed on informal learning instead of formal learning (22 reporting a positive change, with only one reporting a decrease).

This suggests that SMEs have been able, at least to some degree, to respond positively to the challenges of the recession. During a time when publicly funded education supply remained capped, 
there is evidence of SMEs shifting their training emphasis towards seeking out opportunities for nongovernment funded informal learning.

Respondents were asked where they thought additional training was needed in their business (ongoing need or newly needed) over the next 12 months, covering seven or eight categories.

- Generic - general IT user skills, oral communication, written communication, numeracy and literacy, office admin skills.

- $\quad$ Routine - repetitive, more basic, low knowledge intensive skills.

- Technical/Advanced - skills required for problem solving; design, operation, rethinking and maintenance of machinery or technological structures; IT professional skills.

- Management - skills for business planning, regulations and quality control, human resources planning (recruitment, training and skills development) and allocation of resources.

- Social - motivation and appreciation of people's characteristics for individual and team working purposes, customer handling; appreciation of networks and value-chain partners.

- Language and cultural - ability to communicate in more than one language, appreciation of cultural characteristics of different ethnic groups.

- Entrepreneurial - specific skills for start-ups such as risk, strategic thinking, selfconfidence, the ability to make the best of personal networks and the ability of dealing with challenges and requirements of different nature.

- Green - specific skills required to adjust products, services or operations due to climate change adjustments, requirements or regulations (note: this category was available only in the second wave of the survey, and so is not reported here). It is reported in Section 1.5.

The results from this question are presented in Figures 12 and 13. For each category, firms were asked whether there was "some need" or a "high need" for training. Figure 12 records that no more than 14 firms (19\%) reported a high need in any specific category, with entrepreneurial skills being the most cited in this category.

Virtually all of the firms, however, recognised that there was at least some need for training in their enterprise. Figure 13 depicts the number of areas identified by the firms as needing training in the following 12 months. Only one firm in the sample did not recognise the need for any training, while half of the sample (36 out of 72 firms) identified five or more areas where there is some need or a high need for training. Figure 13 records that the most popular area was business skills (59 positive responses) followed by social skills (52) and generic skills (50). 
Figure 12. Additional training in the next twelve months

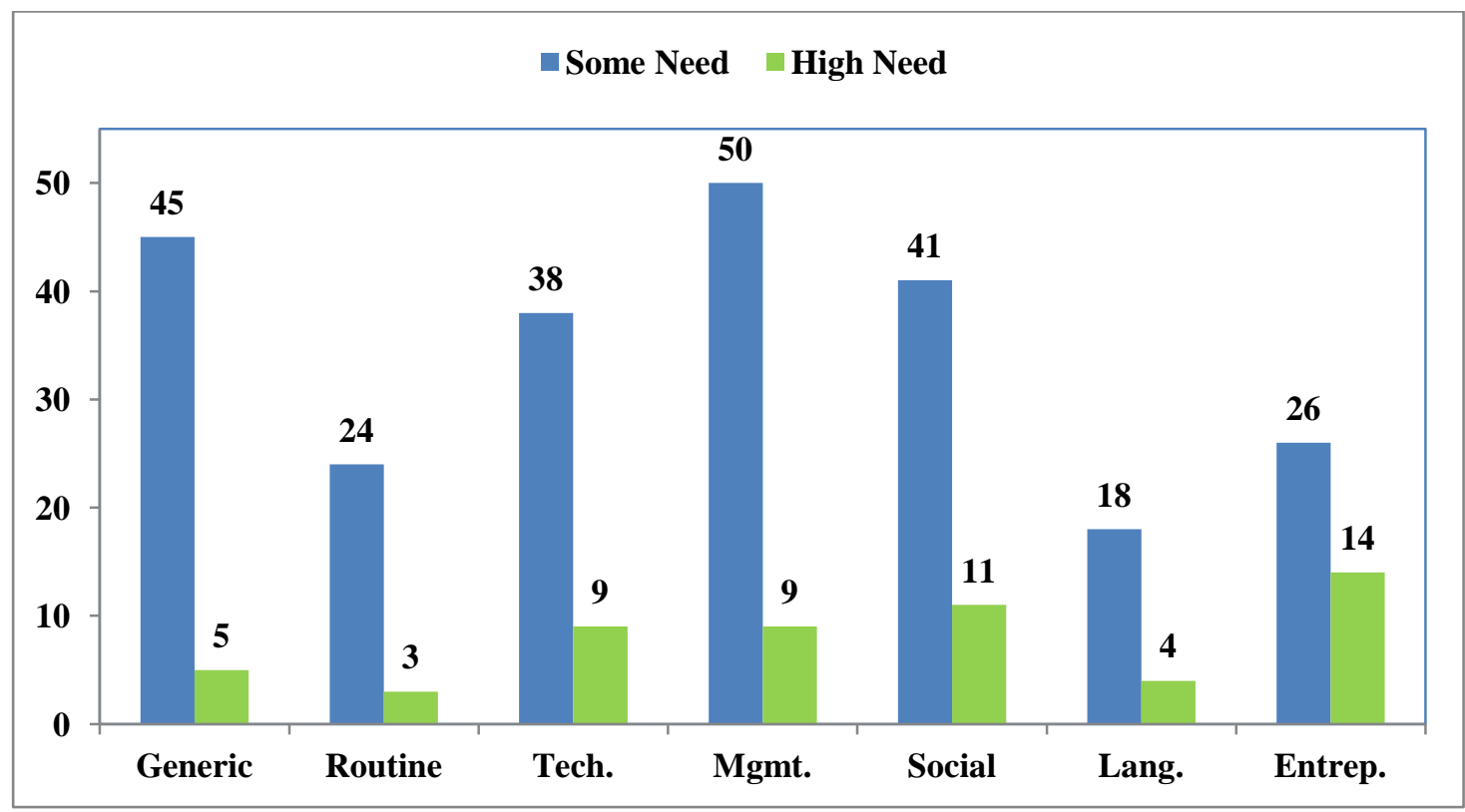

Figure 13. Number of identified training areas

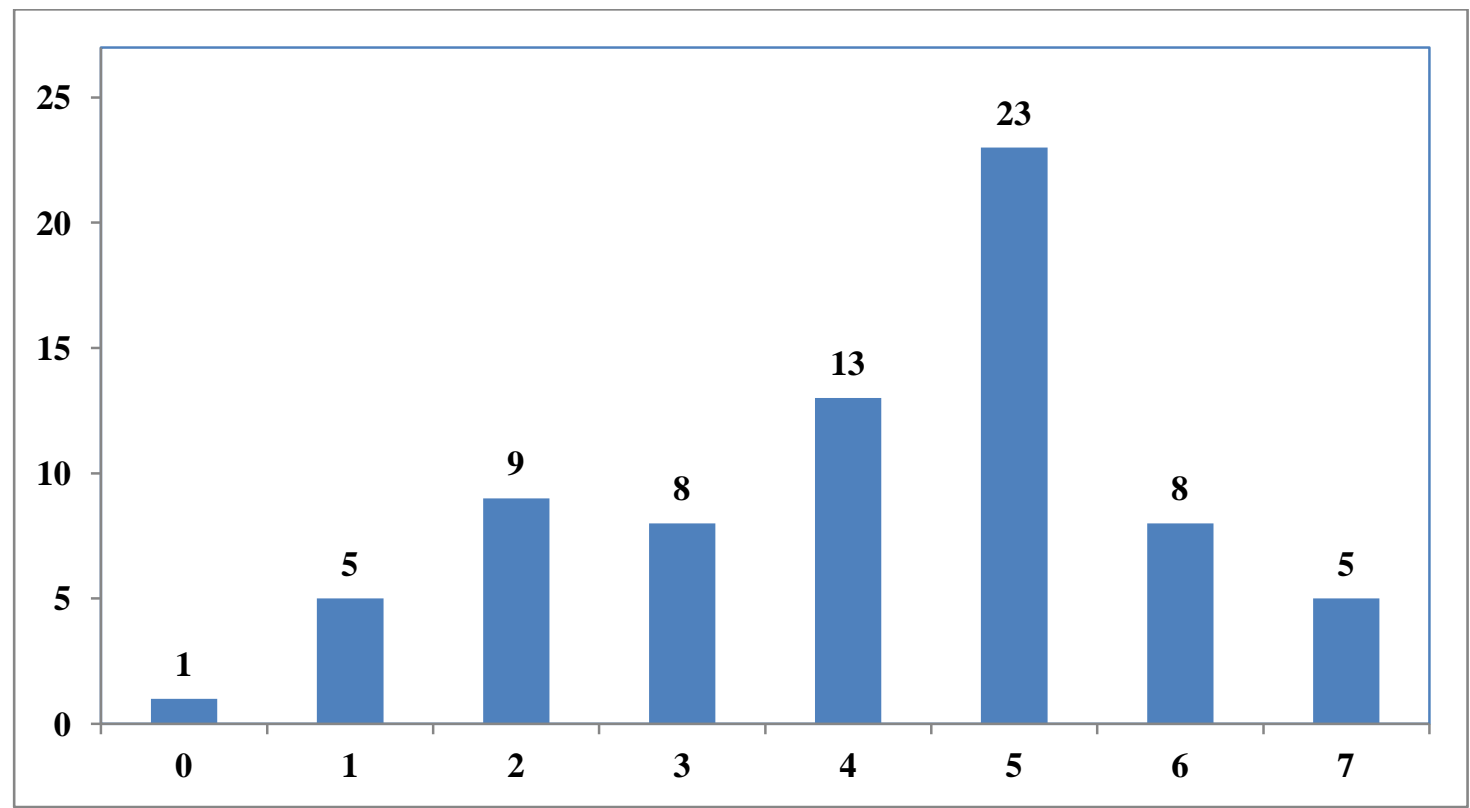

\subsection{Benefits and barriers to formal skills training}

Section 2 of the survey asked about formal education and training in the firms under the general heading of "industry training and vocational education and training (VET) activities". Respondents were asked if any of their employees participated in formal training in any of the following areas during the past 12 months:

- Business planning (including management and leadership training)

- Marketing and promotion 
- $\quad$ Research (including market research) and product development

- Accounting and finance

- Information and Technology

- Human Resources

- $\quad$ Legal courses (IP, patents etc.)

- $\quad$ E-Commerce

- Organisational Health and Safety

- Job-specific technical training

- Language courses

- Social skills development

- Entrepreneurship related training

- Green skills development

(note: this category was available only in the second wave of the survey, and so is not reported in the Figure 14)

- $\quad$ Other

Respondents were also asked in each category to indicate whether their employees were involved on a one-off basis to meet a specific need or were involved regularly in the particular training (defined as weekly or monthly). The responses are summarised in Figure 14. Two areas stand out: job-specific technical training (52 firms, or $72 \%$ ) and business planning (48 firms or 67\%). The job-specific technical training was the item most likely to involve regular training, while most of the business planning was one-off training.

Two other clusters of training areas are apparent in Figure 14. There was strong participation in core business skills (marketing and promotion, information technology, and accounting and finance) and in workforce skills (health and safety, and human resources), again with a bias towards one-off rather than regular training.

These observations support one of the themes noted in the introduction to this report about the importance of knowledge intensive service activities (KISA). In this survey, only 18 firms out of 72 participants (25\%) reported that their staff had been involved in training for research (including market research) and product development. This made it only eighth in the ranking implicit in Figure 14, with other KISA categories being considerably more popular in the sample.

An interesting point concerns training in entrepreneurial skills. Recall from Figure 12 that this was an area identified with a high need for training, but in Figure 14 it is one of the least popular items in terms of participation in formal training activities. ${ }^{4}$

\footnotetext{
4 A new report by the OECD (2010) focusing on SMEs, Entrepreneurship and Innovation, indicates the lack of entrepreneurial programmes and formal training for SMEs.
} 
Figure 14. Participation in formal training in the last twelve months

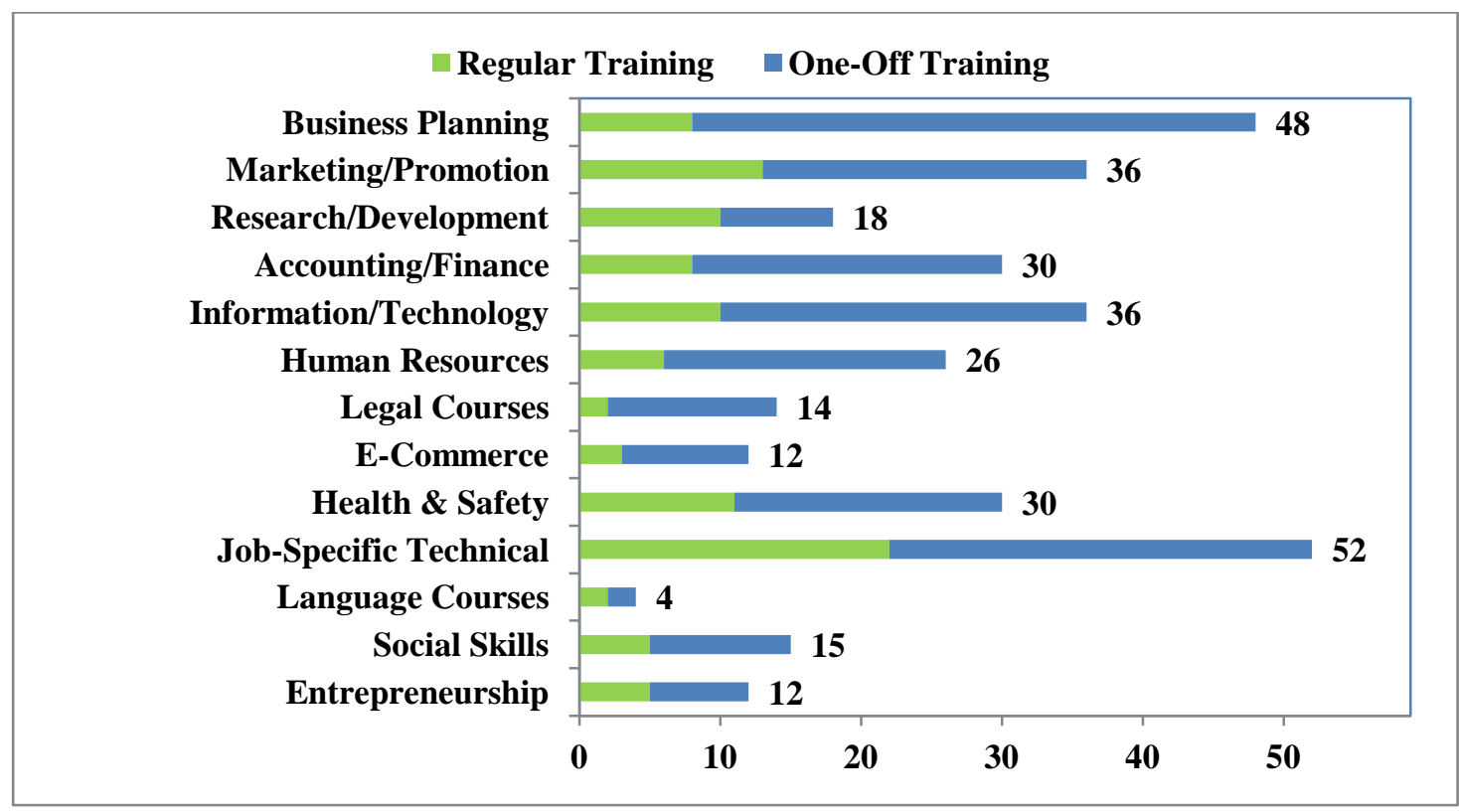

Firms were asked to identify benefits to themselves, their industry and the Canterbury region from the participation of their employees in training using the following pre-defined categories.

- Increased productivity

- Increased innovation (new/improved products or services or new/improved management processes)

- $\quad$ Market positioning (local, national, international)

- Increased competitiveness

- $\quad$ Upgraded skill levels

- Increased levels of education attainment

- Increased levels of trainers' expertise in designated areas

- Mitigation of climate change/contributing to the greening of the economy (note: this category was available only in the second wave of the survey, and so is not reported in the Figure 15)

- $\quad$ Other

The results are shown in Figures 15 and 16, drawn to the same scale on the horizontal axis. Respondents were far more confident in identifying benefits to the firm (Figure 15) than they were at identifying benefits to the industry and region (Figure 16). In particular, more than two-thirds of the sample (52 and 50 respondents respectively) recognised that the formal training contributed to high skill levels and higher productivity in the firm. More than half of the sample also recognised contributions to market position, competitiveness and innovation at the enterprise level. 
Figure 15. Benefits to the firm of formal training

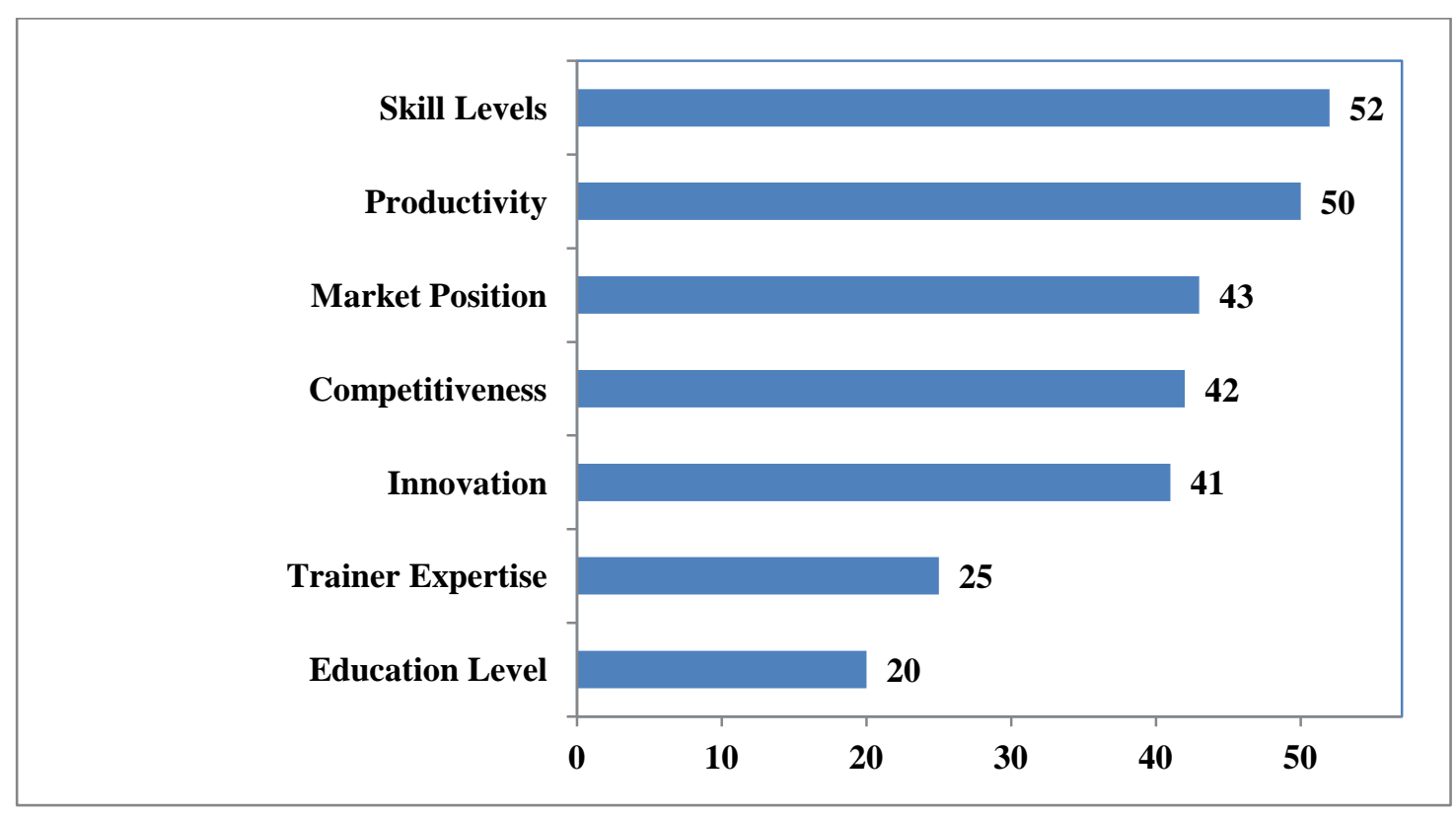

In contrast, Figure 16 records that in each of the categories, no more than 10 respondents recognised a benefit of their employee training to the industry, and no more than 9 recognised a benefit to the region. This result may suggest that the training decisions of firms are motivated by firm-specific skill needs (as might be expected from the VET literature on this point), with little attention to the value of those skills to the industry or region more generally.

Figure 16. Benefits to the industry and region of formal training

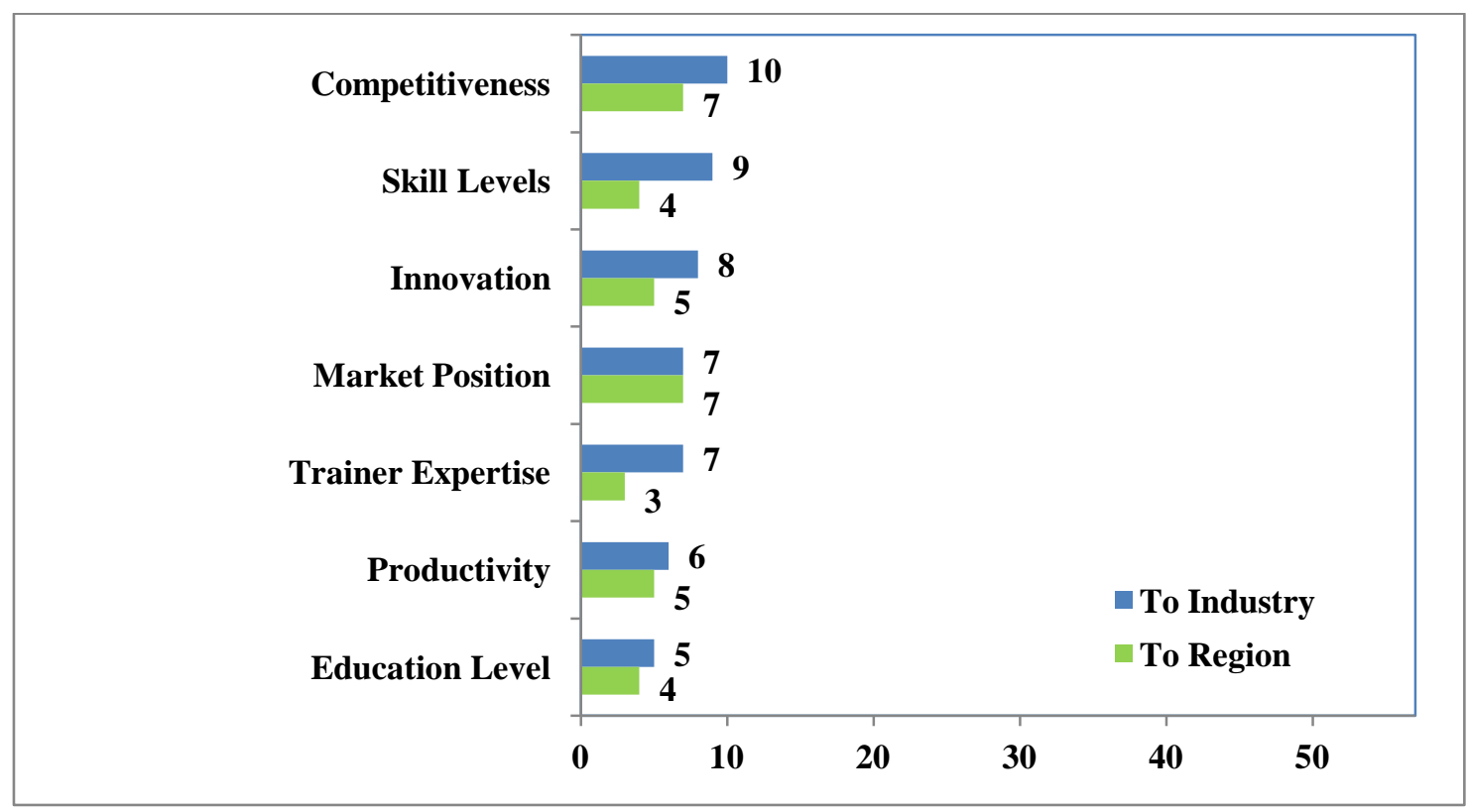

Firms were asked whether there any training activities that they would have liked to have carried out but did not in the previous twelve months. Half of the respondents answered that there was (Figure 17). 
Figure 17. Was there desired training not carried out?

(\% of Respondents)

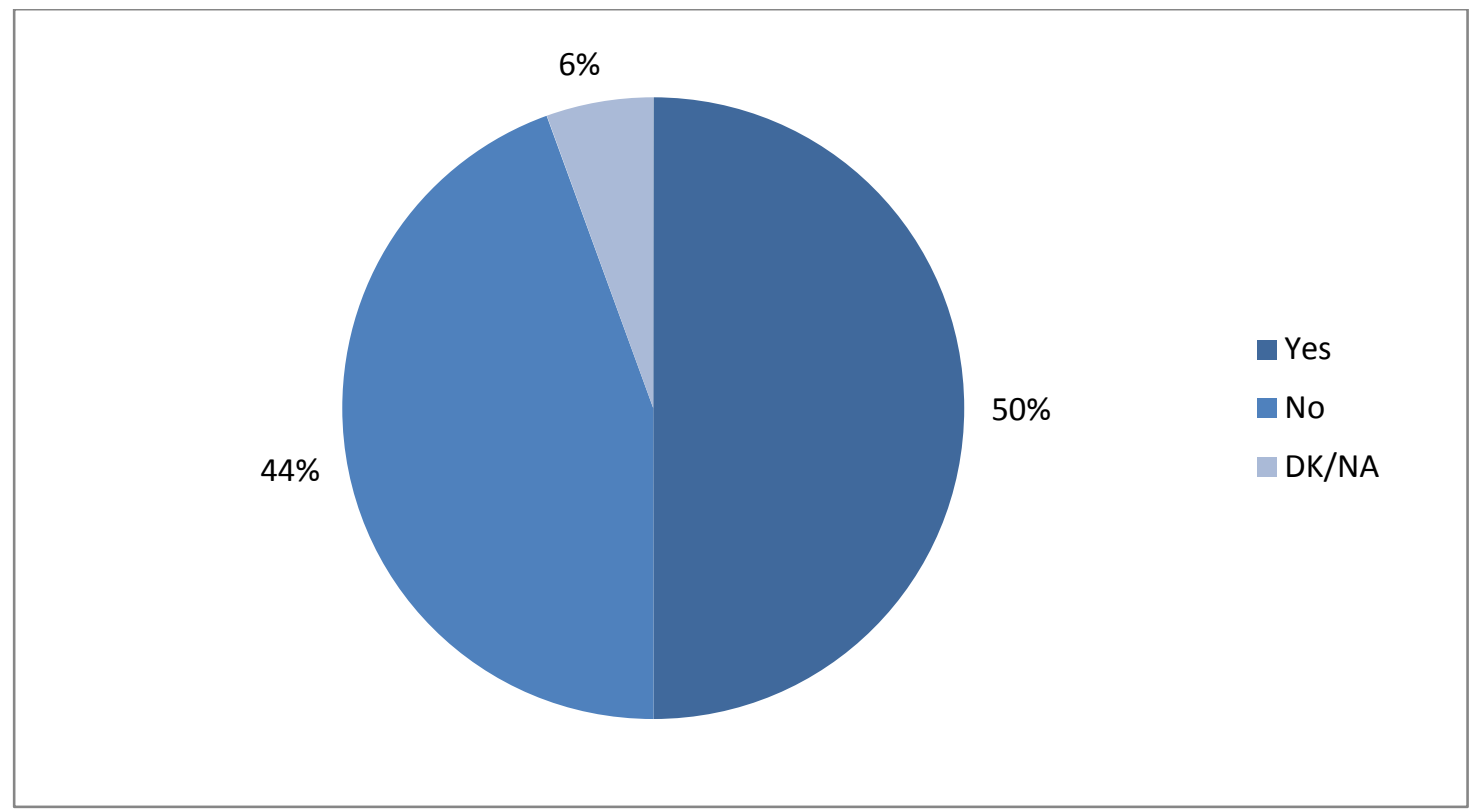

Note: DK/NA is “Don't Know/Not Answered”.

The survey explored the barriers leading to desired training not being carried out. Again respondents were provided with a list of predetermined options, which they were asked to consider for medium to high skilled employee training and for low skilled employee training:

- High costs/too expensive

- People recruited with skills needed (initial training sufficient)

- $\quad$ Lack of public financing

- Impossible to interrupt production/no time

- Difficult to assess enterprise needs

- $\quad$ Staff not willing to participate in training

- Training is too difficult to implement

- $\quad$ Risk of poaching after training

- Too difficult to identify suitable training providers

- Too difficult to access training (location; availability at a suitable time)

- $\quad$ Other barriers

The responses are summarised in Figures 18 and 19. The lower response rate for low skilled employee training is not surprising; recall that only $25 \%$ of the sample reported that they employ workers in the occupation categories identified as low skilled (see the discussion earlier in the chapter about the data in Figure 3). 
Figure 18. Barriers for medium to high skilled employee training

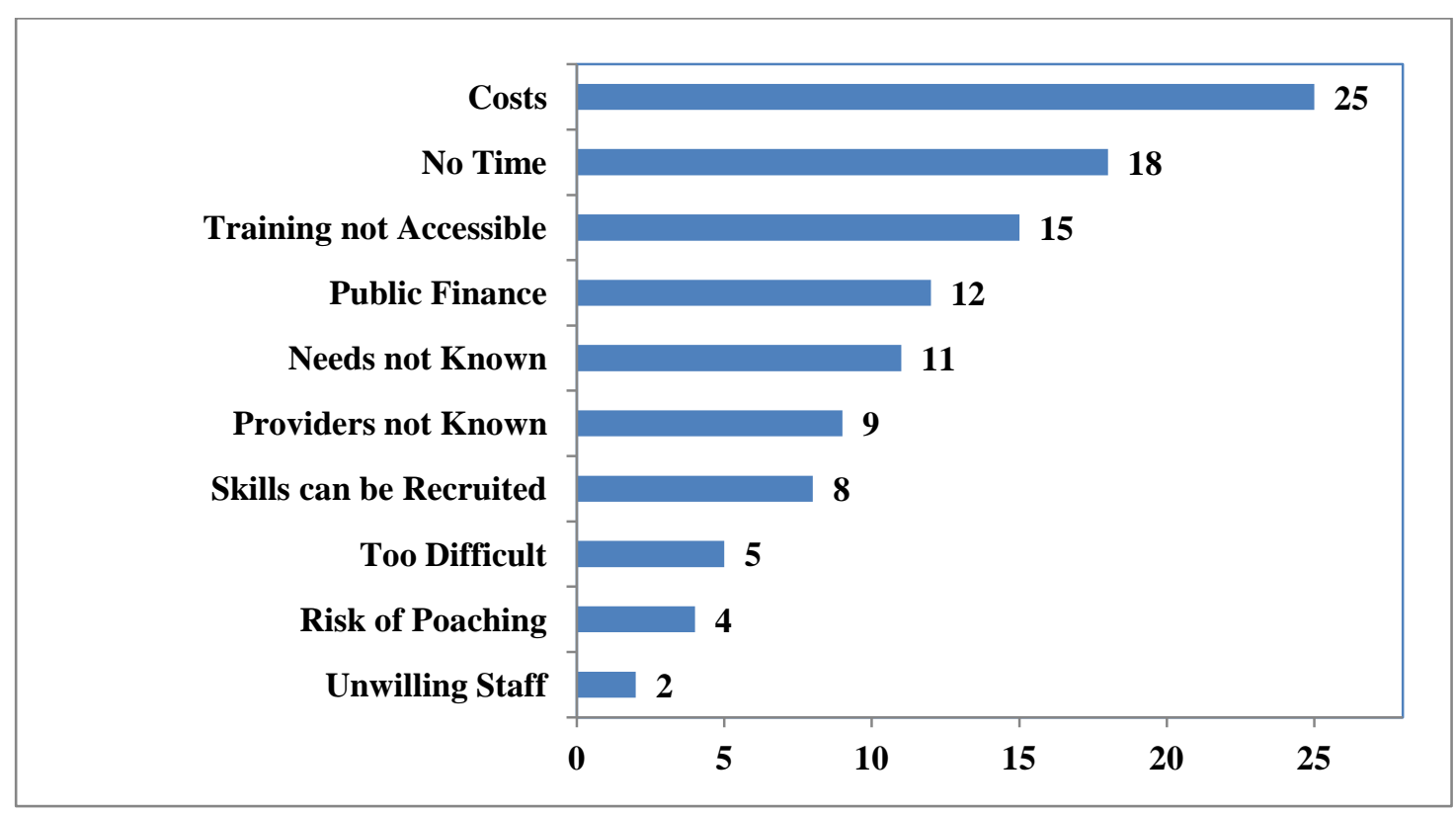

Figure 19. Barriers for low skilled employee training

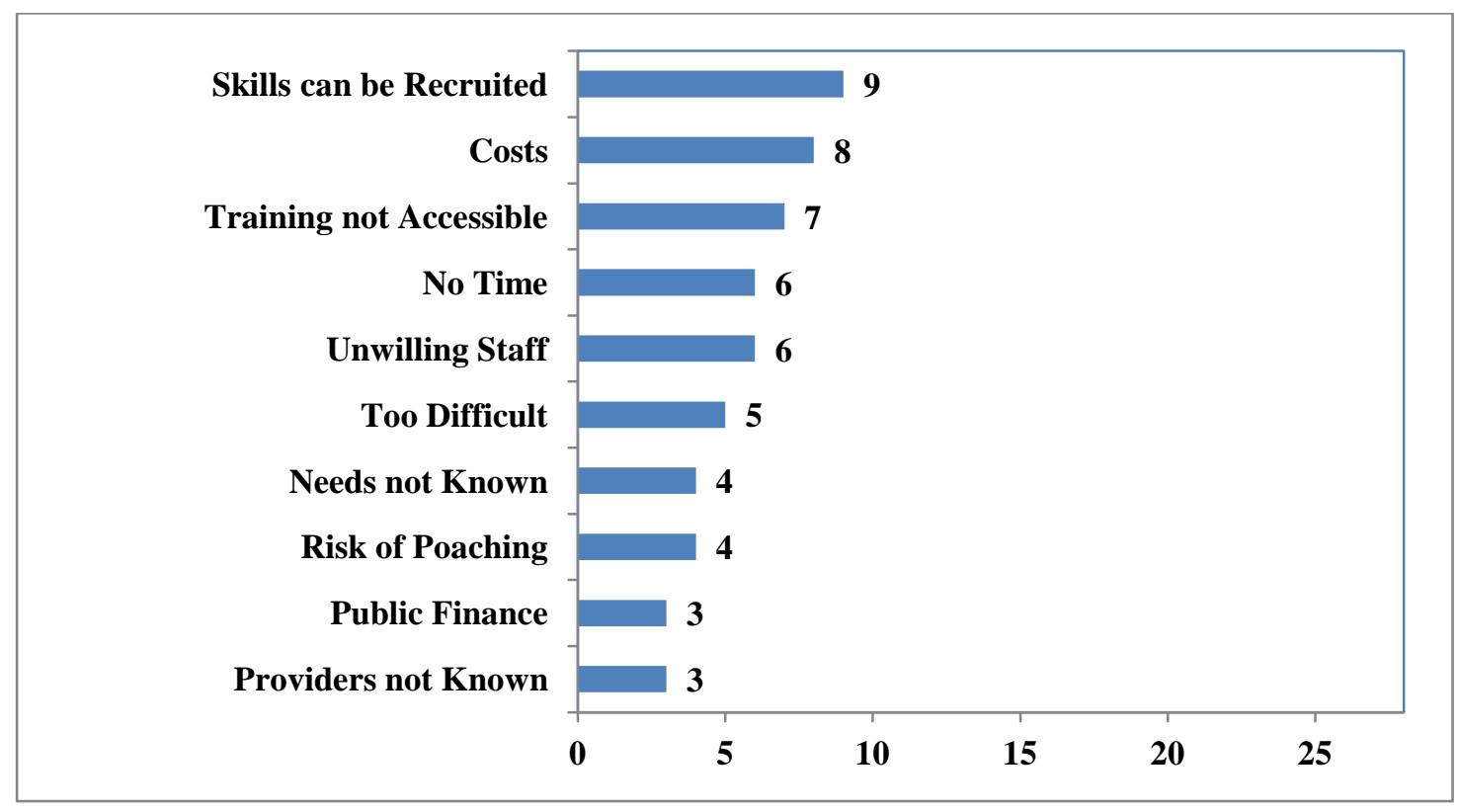

There are some interesting similarities and differences in the two lists. With one exception, the top three barriers for both sets of employees are costs, no time and training not accessible. The exception is that firms reported that skills can be recruited for low skilled occupations, whereas this response is well down the list for the medium to high skilled occupations. This may reflect that the industry training system is largely geared towards lower skill levels. Another point of difference is that unwilling staff was given as the fifth reason for low skilled employees, but was the last reason for medium to high skilled employees. Another similarity is that risk of poaching is not important in either list, supporting the suggestion made earlier that perhaps firms tend to focus on training their employees in firm-specific skills. 


\subsection{Benefits and barriers to informal alternative skills training}

Section 3 of the survey explored informal alternative training activities that may increase the skills, knowledge or competencies of employees in significant ways. Employees may learn, for example, through interactions with co-workers, suppliers, clients or consultants. Alternatively, projects internal to a firm to improve work processes (such as quality control and product development) might result in staff learning and development. In these situations, the skills, competencies or knowledge gained are not part of recognised or formal education and training programmes. Consequently, Section 3 began by asking whether in addition to any training activities that had been mentioned previously, the business carried out, in the previous twelve months, any of the following activities which significantly increased the skills, competencies or knowledge of the firm's employees:

- Business planning (including management and leadership services, consultancy and advice)

- Marketing and promotion services

- $\quad$ Research (including market research) and product development

- Accounting and finance services

- Information and Technology services

- Human Resource services

- Legal advice and services (IP, patents etc.)

- $\quad$ E-Commerce (e.g. on-line work with clients and suppliers; access to web-based information)

- Organisational Health and Safety advice

- Job-specific technical activities (e.g. advice on utilisation of new plant or equipment)

- Language or communication coaching

- Social skills development

- Entrepreneurship related activities (e.g. brainstorming about opening new markets or new range of products and services)

- Green skills development (e.g. co-operation with other organisations to find ways to adjust production to minimise climate change) (note: this category was available only in the second wave of the survey, and so is not reported in the Figure 20)

- $\quad$ Other

This list is similar to the formal training list at the beginning of Section 2 of the survey, and has a similar focus on knowledge intensive service activities. There are some strong similarities with the reported participation of staff in informal training (shown in Figure 20) compared to their participation in their formal training (Figure 14 in Section 1.2), with one exception. The exception is participation in entrepreneurship related activities, which is fourth on the list for informal training, reported by 39 firms (of whom 21 reported this was a regular event). Otherwise the top activities were comprised of the same five items: business planning, job-specific technical skills, marketing and promotion, information and technology, and health and safety. 
Figure 20. Participation in informal training in the last twelve months

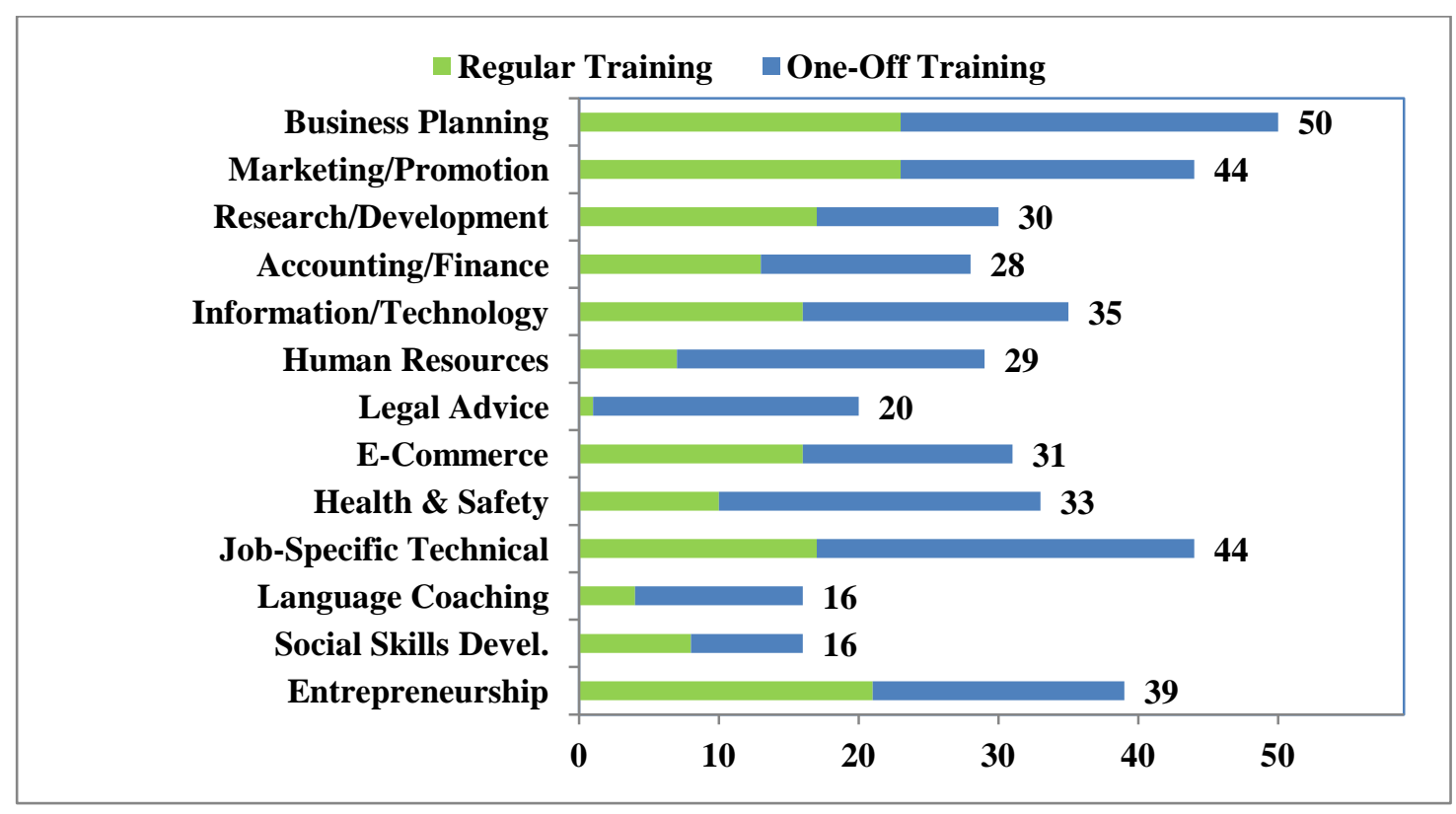

A feature of informal training through knowledge intensive service activities is that the learning takes place through interaction with others in the course of doing business. Consequently the survey sought to identify the most important sources of learning from the sample, and asked respondents to indicate the importance of the following groups in the alternative training activities their business did during the previous 12 months:

- Co-workers

- $\quad$ Suppliers

- $\quad$ Clients

- Business consultants

- $\quad$ Competitors

- Firms from the same industry clusters

- Firms from value-chain

- Industry associations

- Government departments

- Informal networks

- $\quad$ Other

Figure 21 shows the number of respondents who stated that each category was highly important in the previous twelve months. Clients and co-workers clearly stand out as the most important sources of informal training, with another important group comprised of informal networks, suppliers and industry associations. The very low value for academics ( 7 out of 72 firms, and bottom of the list) is consistent with policy concern in New Zealand that there needs to be stronger incentives for university and polytechnic staff to be more engaged with their local business communities. 
Figure 21. Highly important sources of informal training in the last twelve months

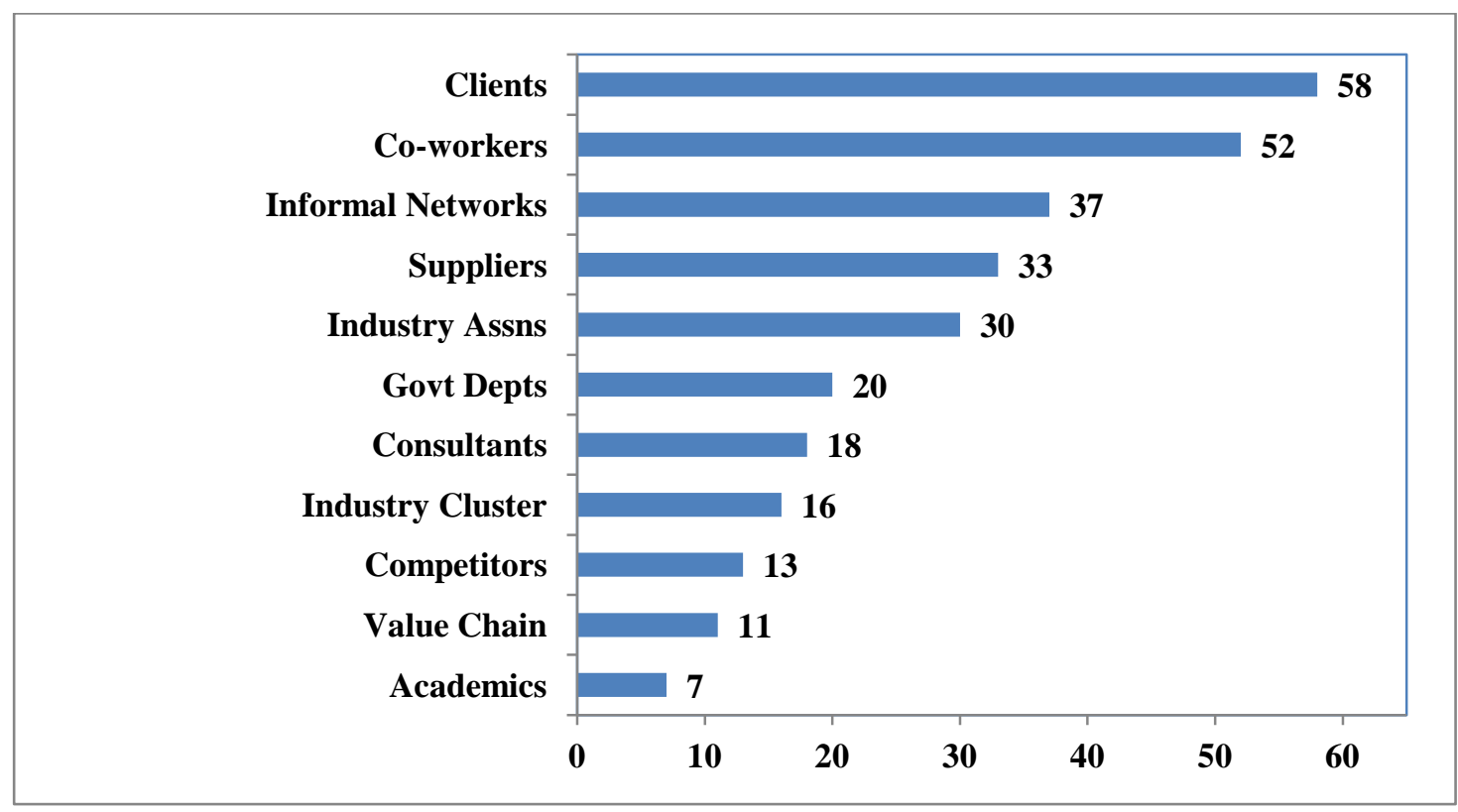

Firms were asked what percentage of their employees participated in these type of activities during the past 12 months. The results are presented in the pie chart of Figure 22. The most common response was that all staff were involved (39\% of the sample), with a further $13 \%$ reporting that between $80 \%$ and $99 \%$ of their staff participated in informal training activities. Only $7 \%$ reported that less than one-fifth of their staff were involved in informal training.

The respondents were also asked to indicate what proportion of the participating employees were low skilled, and what proportion were young. The former question needs to be interpreted carefully, since only $25 \%$ of the sample reported employing workers in unskilled occupations, and these workers made up only $8 \%$ of the workforce in the sample. Thus it is not surprising that the firms reported very low proportions of participation by low skilled workers.

More interesting is the results for young workers aged under 24, reported in Figure 23. Fifty-eight per cent of the sample did not have any employees in this age group, or did not know if they were involved in training or not. Of the remaining $42 \%$, the firms were reasonably evenly split between those who provided training (22\%) and those who did not (20\%). 
Figure 22. Percentage of staff involved in informal training

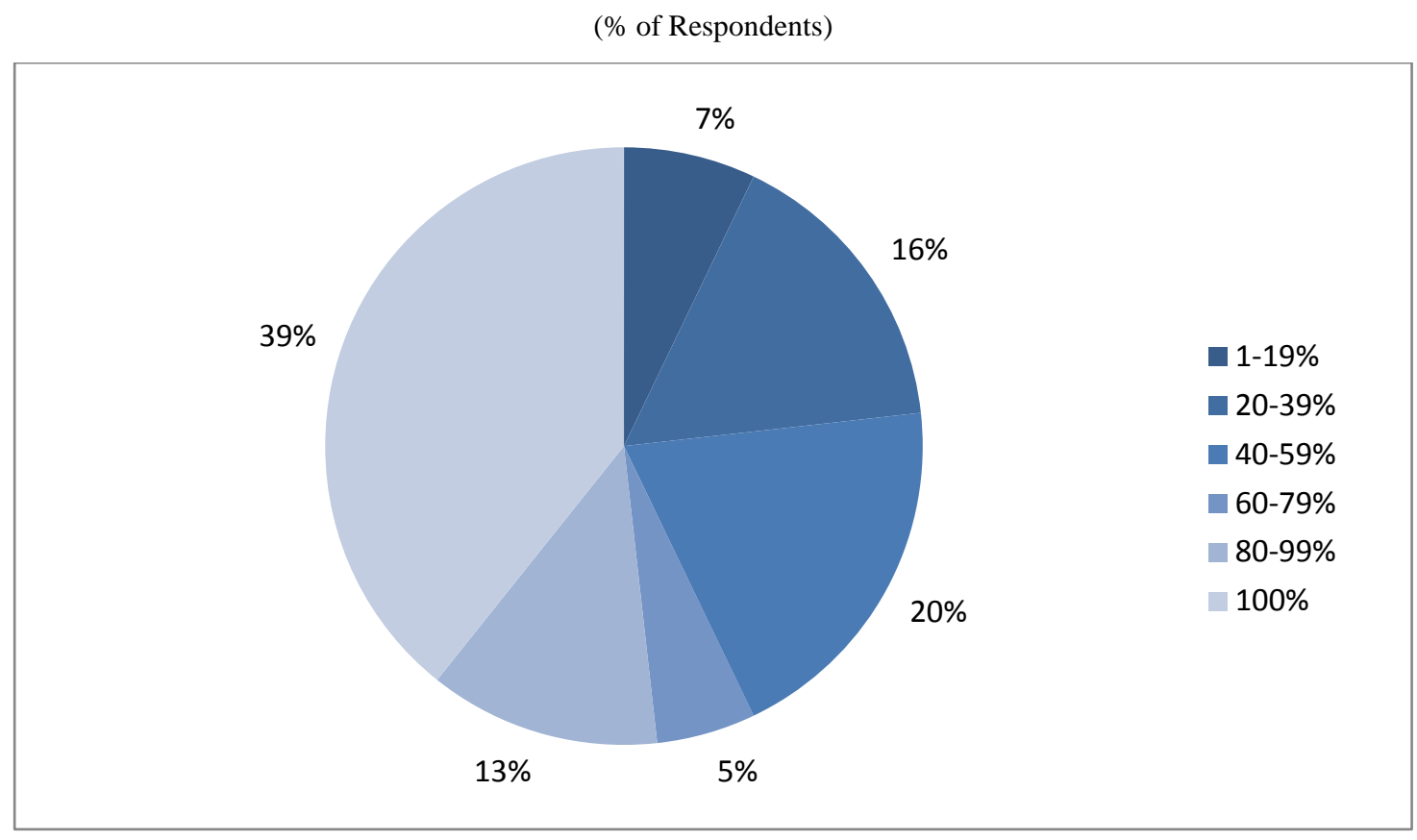

Figure 23. Percentage of participants in informal training

(\% of Respondents)

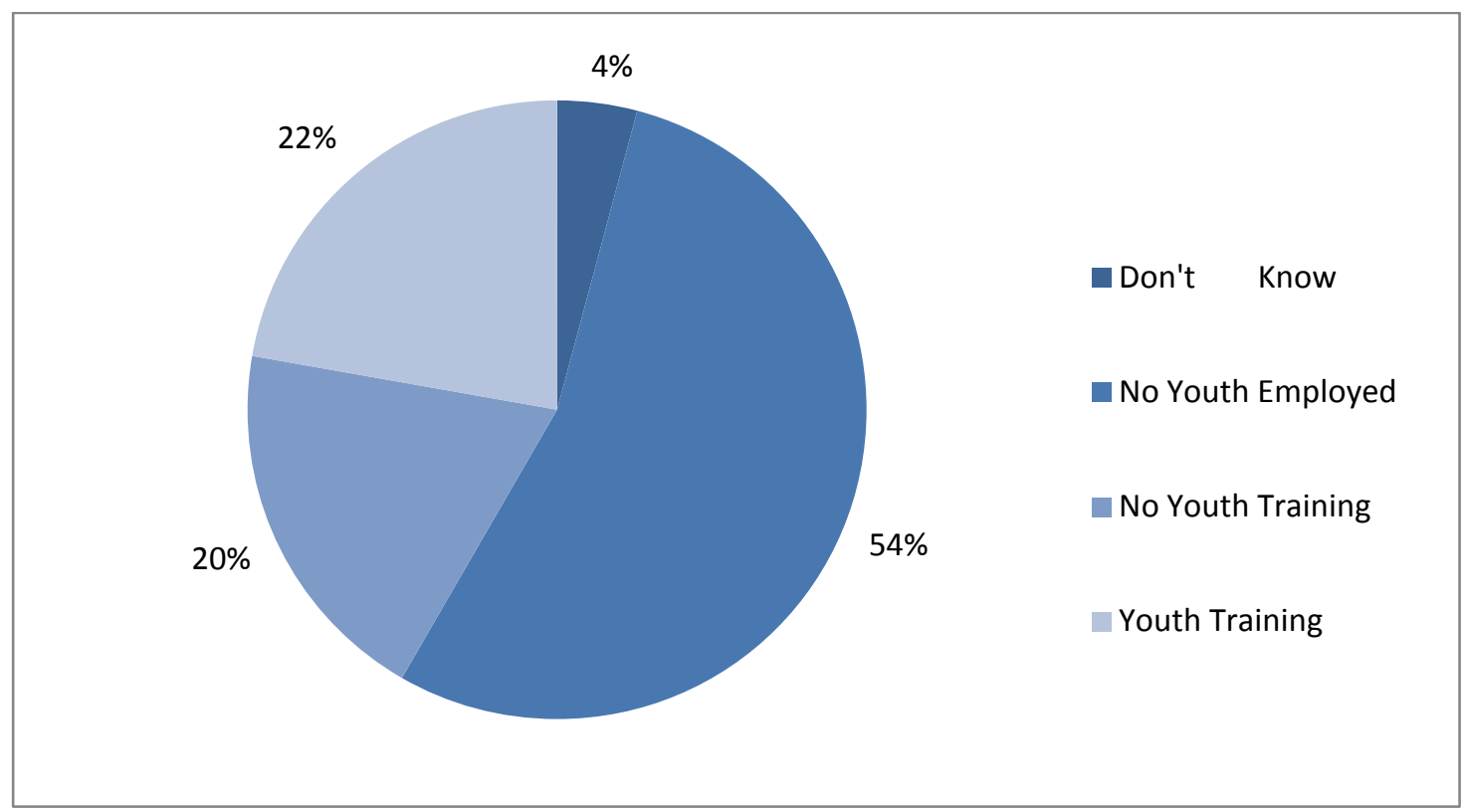

The respondents were asked to indicate the benefits to employees from their participation, both in terms of the skills gained (using the same list of categories reported in section 1.1) and in term of employment progression or career advancement, higher wages, or higher job mobility within the firm or industry sector. The results are presented in Figures 24 and 25, analysed by the responses for medium to high skilled staff and low skilled staff. 
Figure 24. Improved skills from informal training (\%)

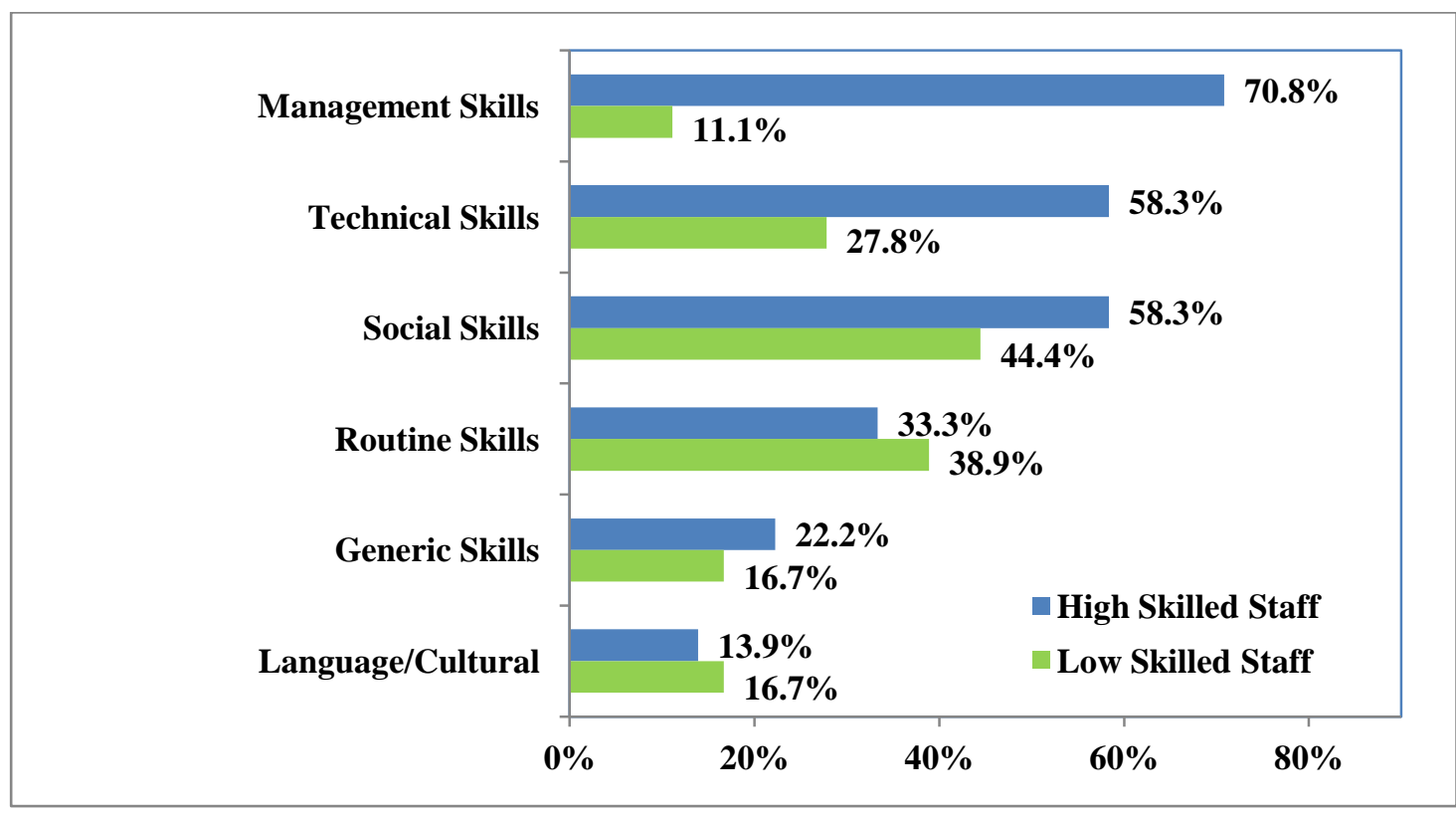

The data in Figures 24 and 25 are expressed as percentages. The data for medium to high skilled staff are expressed as a percentage of all respondents (72 firms). The data for low skilled staff are a percentage of the respondents who reported employing staff in the low skilled occupations (18 firms). The item that stands out in Figure 24 is the learning of management skills by medium to high skilled staff, reported by 51 of the 72 firms (71\%). Technical skills and social skills were also key improvements from participation in informal training by this skilled group (reported by 42 firms each, or 58\%). In contrast, social skills and routine skills were the two most common categories for low skilled staff. 
Figure 25. Other employee benefits from informal training (\%)

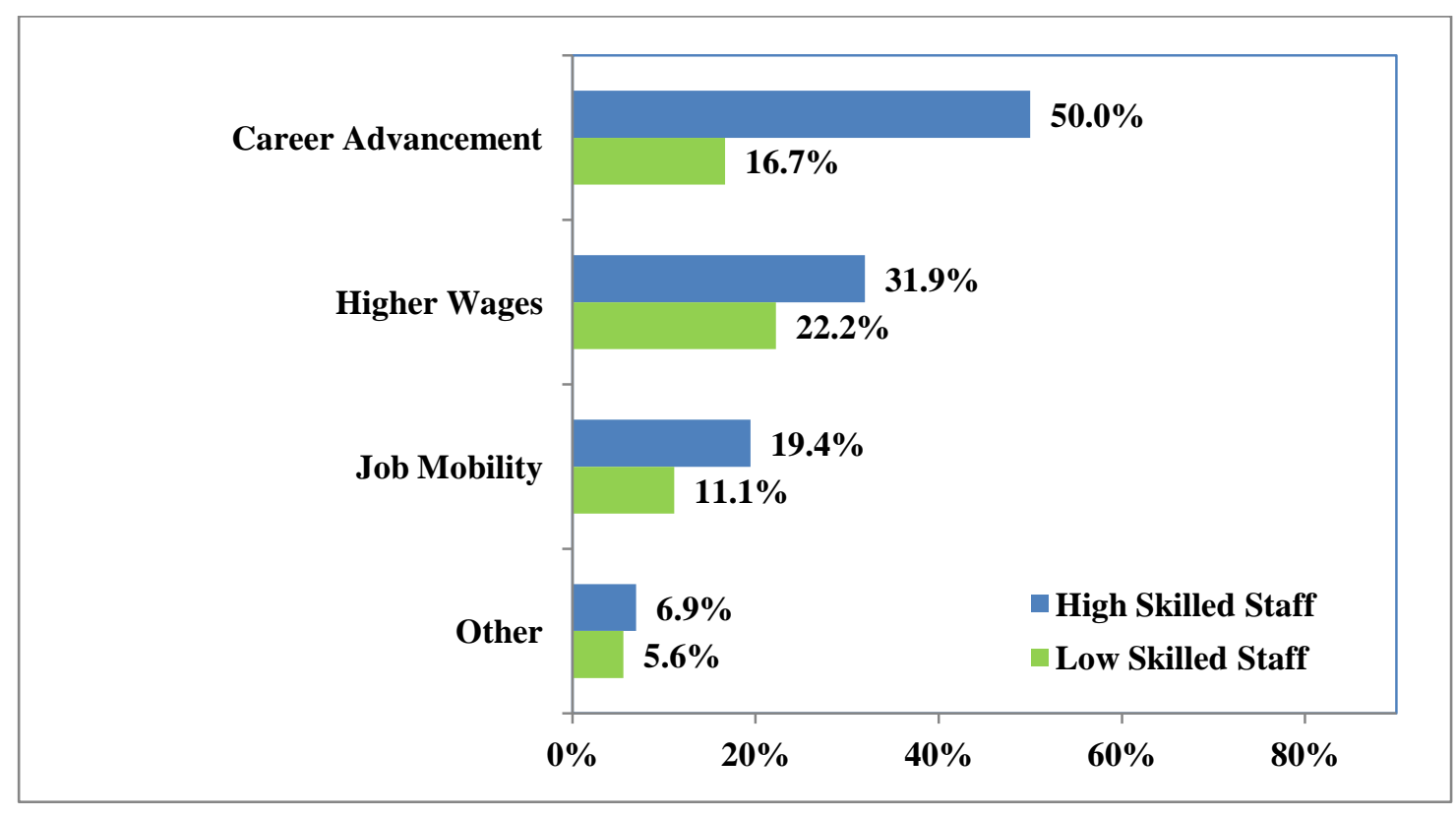

From Figure 25, employees who participated in informal training were thought by their managers to have benefited through career advancement and higher wages, with a smaller number increasing job mobility. The other benefits listed by respondents were: achievement of personal goals and personal satisfaction of the role they are in; improved client service levels, promotion, improved efficiency, and two unspecified other benefits. The benefits were weighted towards medium to high skilled staff, particularly career advancement.

Firms were asked to identify benefits to themselves, their industry and the Canterbury region from the participation of their employees in informal training using the same pre-defined categories as listed in section 1.2 for the formal training.

The results are shown in Figures 26 and 27, drawn to the same scale on the horizontal axis. Again the respondents were far more confident in identifying benefits to the firm (Figure 26) than they were at identifying benefits to the industry and region (Figure 27). The most commonly reported firm-level benefits were productivity and skill levels (49 firms, or 68\%), closely followed by market position and competitiveness (46 firms, 64\%). Perhaps surprisingly, innovation was cited by just 37 of the firms (51\%) and came in fifth on the list. 
Figure 26. Benefits to the firm of informal training

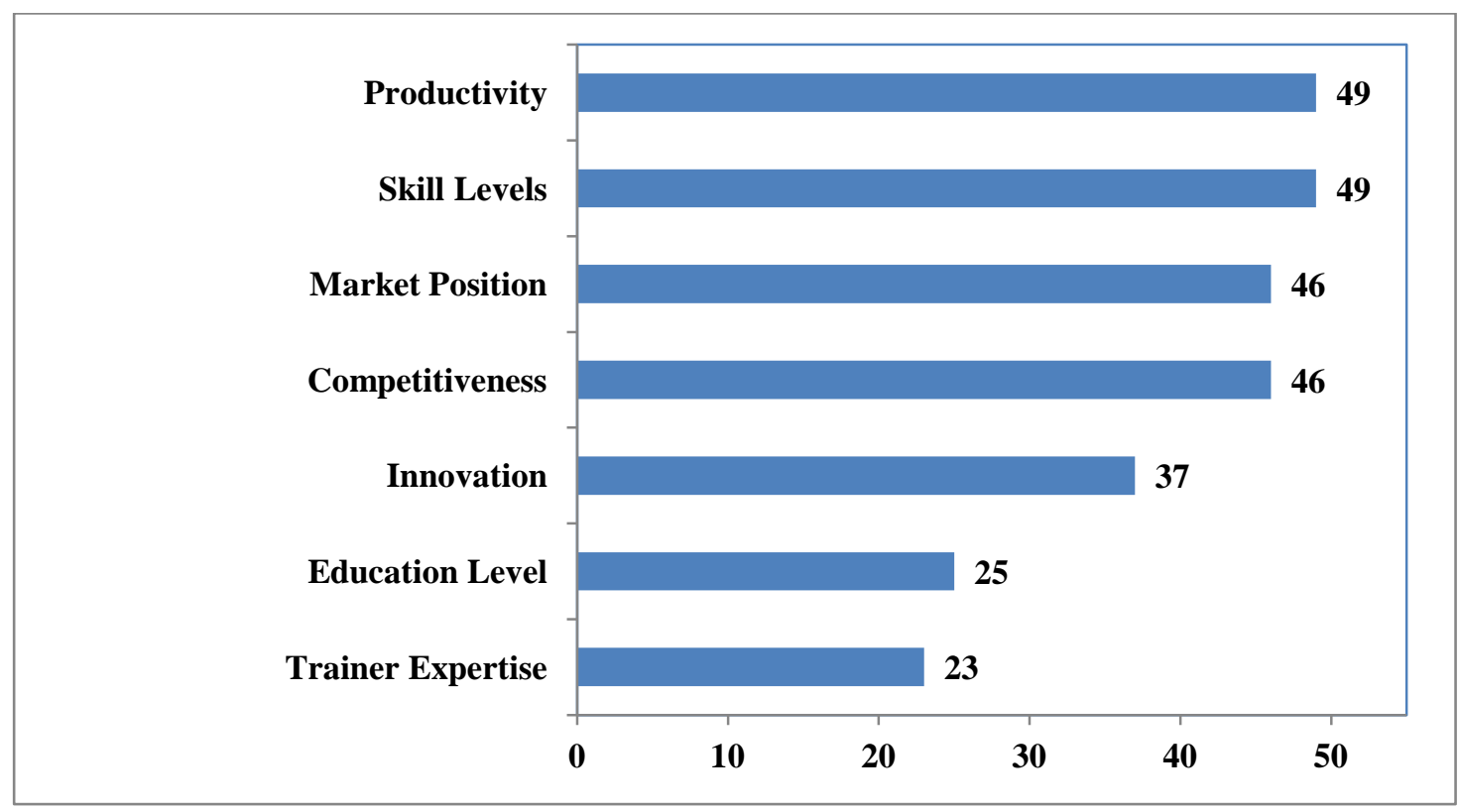

In contrast, Figure 27 records that in each of the categories, no more than 12 respondents recognised a benefit of their employee training to the industry, and no more than 6 recognised a benefit to the region. Again this result may suggest that the enterprises are focusing on training their employees in skills that are specifically needed within the firm. The highest ranked benefit to the industry was innovation (in contrast to its position as fifth in the firm-level ranking). This perhaps provides some evidence that the participants recognised that a higher skilled workforce is helpful for enhancing the sector's innovation.

Figure 27. Benefits to the industry and region of informal training

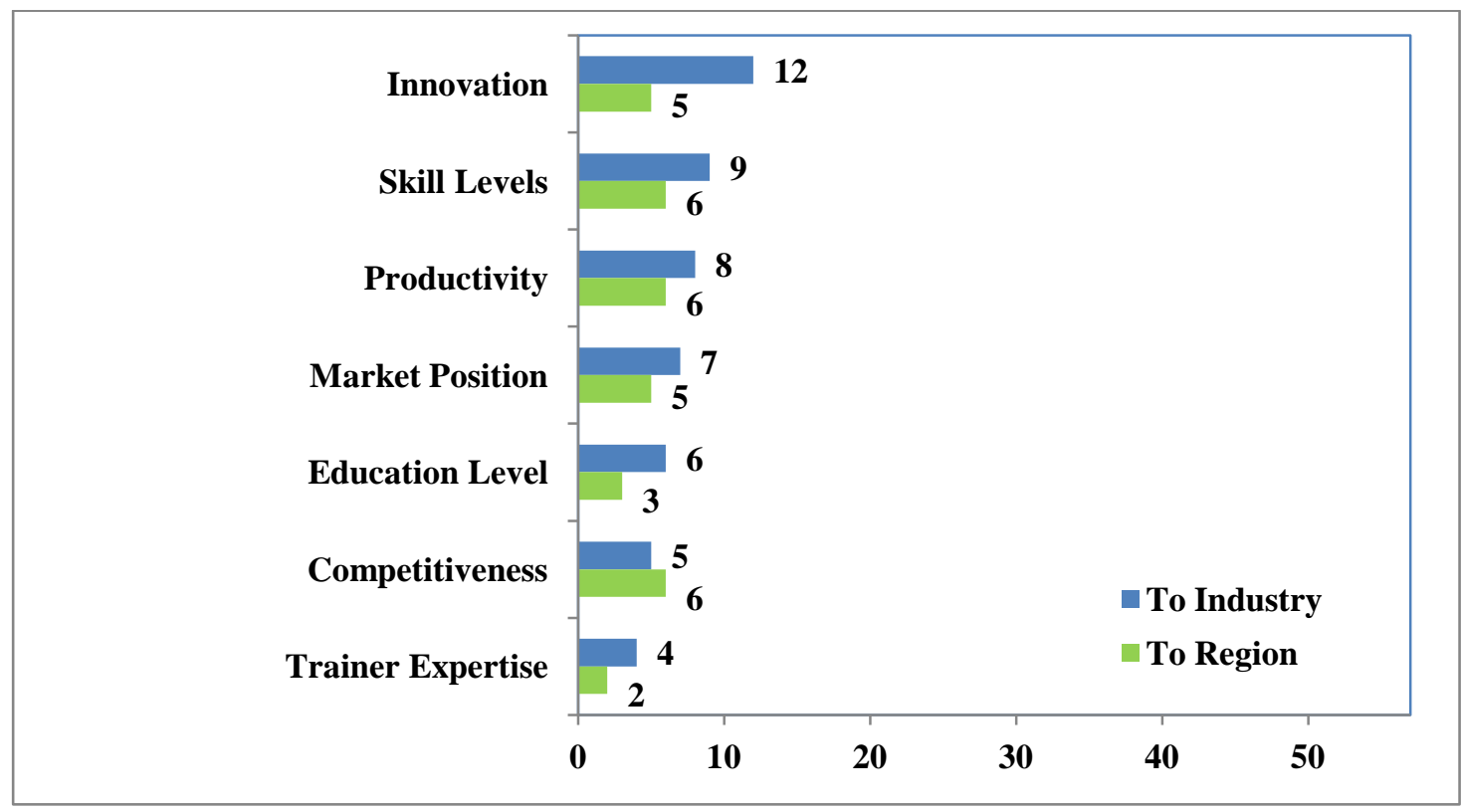

Finally, Section 3 of the survey asked participants if they considered any of the informal training activities in the list in section 1.3 to be better sources of learning for staff than formal education and 
training courses. They were asked to differentiate between high-medium and low skilled employees, with the different responses presented in Figures 28 and 29. Although the second part of the question was answered by more firms than just those who reported employees in the two low-skilled categories, comparisons between the two sets of data in the two figures need to be treated cautiously because so few firms in the sample employ staff in the low skill categories.

Figure 28. Better sources than formal education (medium to high skilled employees)

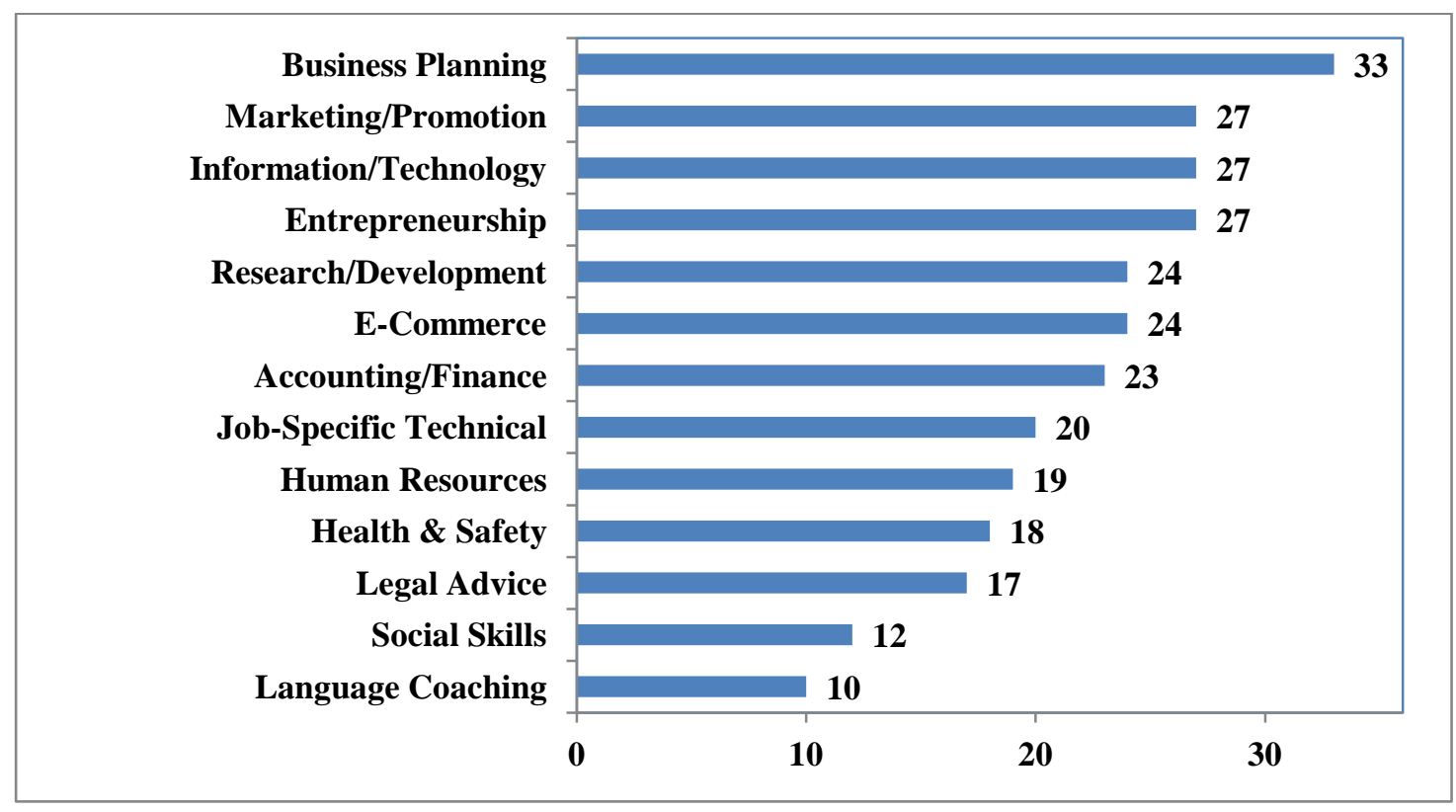

None of the categories in either figure were supported by half or more of the respondents. Nevertheless, in Figure 28 there is a strong emphasis on business oriented sources form the medium to high skilled staff: business planning is top of the ranking (33 firms) followed closely by marketing and promotion, information and technology, and entrepreneurship (all nominated by 27 firms) and another cluster around research and development, e-commerce, and accounting and finance (24 or 23 firms). In contrast, Figure 29 reveals that for the low skilled staff the emphasis is on social skills (17 firms), health and safety (14 firms), job-specific technical activities (14 firms) and language coaching (11 firms). 
Figure 29. Better sources than formal education (low skilled employees)

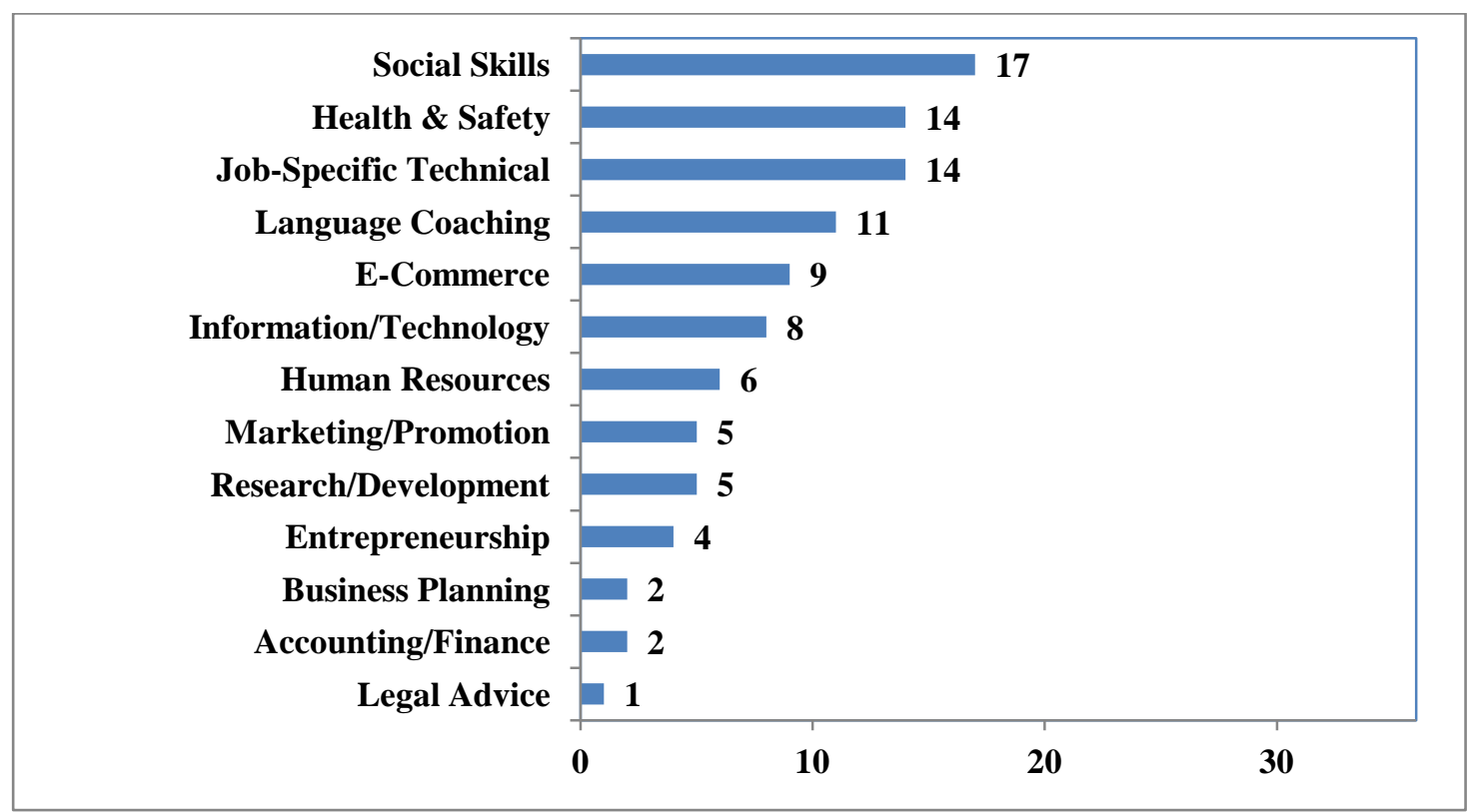

\subsection{Motivation and collaboration for skills training}

The final section of the survey involved two questions asking respondents about their reasons for training and skills development activities in their business (formal and informal) and about the organisations with whom their business associates for this purpose. For the first question, respondents were offered a comprehensive list of possible motivating factors listed in Table 2 . They were asked to indicate the relevant motivating factors for formal activities (Industry training and VET courses) and informal activities (other activities that develop skills and competencies). Figures 30 and 31 present the top eleven factors for the two classes of training activity.

The first point to note from the two figures is that there were many more responses for informal training, and that the top four items for informal training (each of which was indicated by more than half the sample) were motivated by in-house incentives: service requirements; need to increase employee skill levels; new product or service development; and production needs. Further, there is no mention of policy incentives or government programmes in the top eleven motivations for informal training. In short, the motivation for informal training comes primarily from the business needs of the enterprise, followed by local industry and business networks. 


\section{Table 2. Motivations for participation in formal and informal training}

Public incentives/government programmes

- International (e.g. EU policies, Trans-Tasman policies/programmes)

- $\quad$ National (country specific government programmes)

- $\quad$ Regional (metropolitan / regional programmes)

- $\quad$ Local (council / local government programmes)

- $\quad$ Country regulations (e.g. training levies, training requirements)

Private incentives (including facilitation/promotion/information of training)

- $\quad$ Collective agreements (trade unions)

- Industry sector association services/activities

- $\quad$ Chambers of Commerce services/activities

- $\quad$ Industry clusters services/activities

- Value-chain firms’ activities

- $\quad$ Business networks activities

- $\quad$ Local networks activities

- $\quad$ Foundations activities

In-house incentives

- $\quad$ Production needs

- $\quad$ Service requirements

- $\quad$ New product / service development

- $\quad$ Adjustments to financial constraints

- $\quad$ Adjustments to climate change impacts

- Job/position adjustments

- $\quad$ Need to increase employee skills level

Other

- $\quad$ Requested to specify 
Figure 30. Motivations for participation in formal training

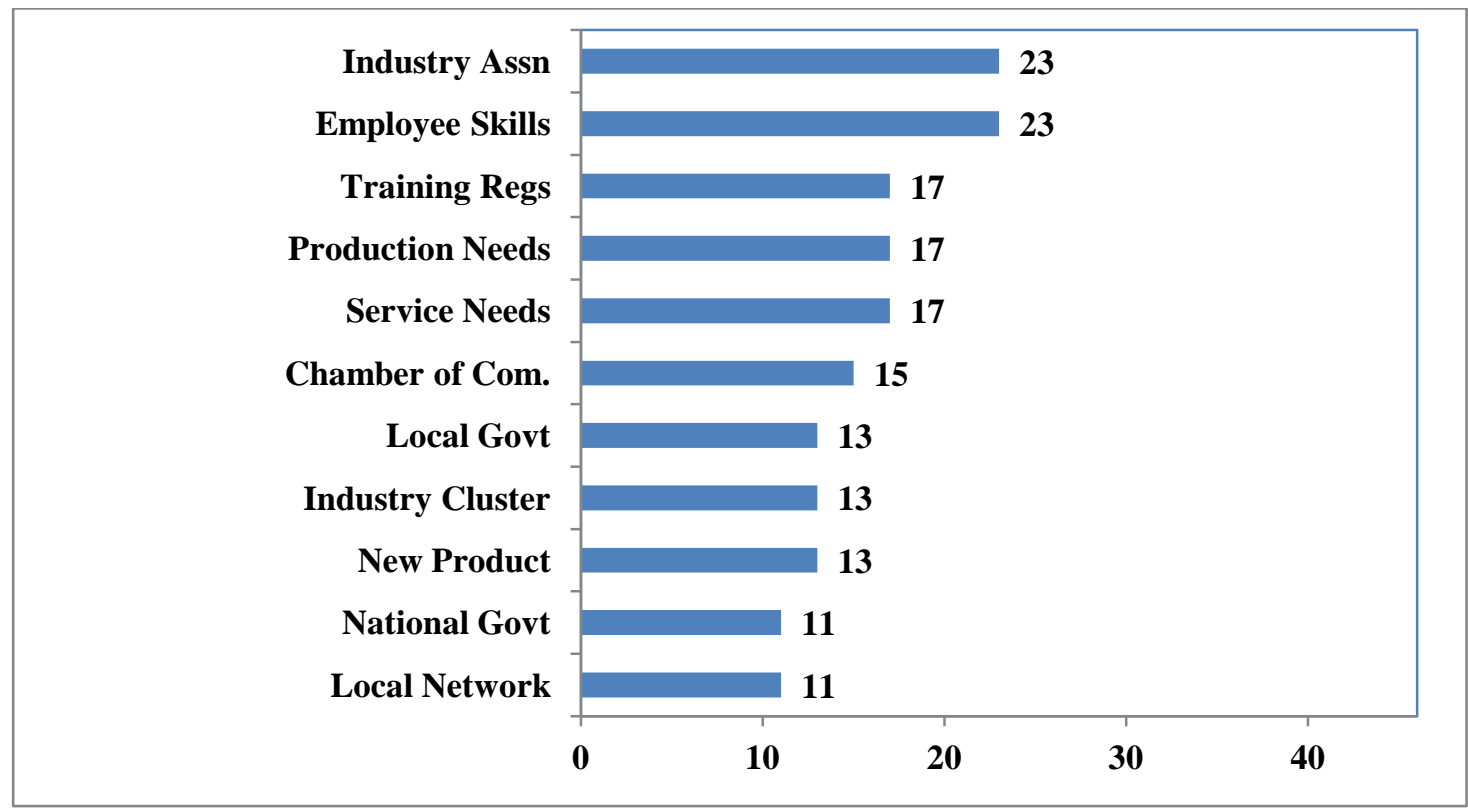

Figure 31. Motivations for participation in informal training

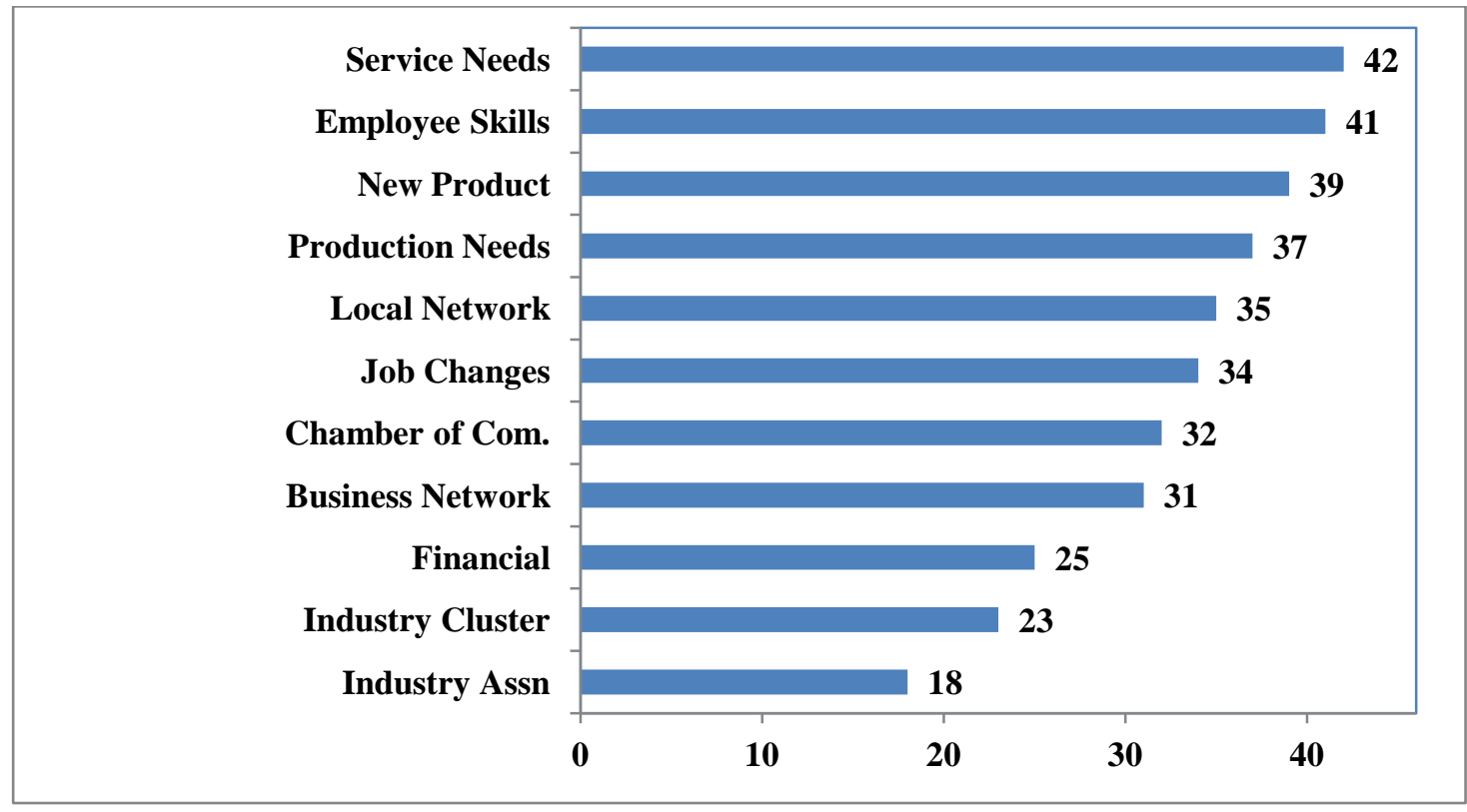

The second point to note from Figures 30 and 31 is that industry sector association services and activities is item eleven in the informal training list, but is first equal in the formal training list. This is likely to reflect the crucial role that Industry Training Organisations play in organising formal training and assessment for employees in the New Zealand system of vocational education and training. Further, the list for formal training includes country regulations (e.g. training levies, training requirements), local government programmes and country specific government programmes in its top ten items, whereas none of these three items appear in Figure 31.

The final question asked the respondent to cite the organisations with whom the business associates for training and skills development activities from a predetermined list of options. The list 
and the number of positive responses, analysed by formal and informal training, are presented in Table 3. The Industry Training Organisations (ITOs), the Institutes of Technology and Polytechnics (ITPs) and Universities tended to be associates in formal training activities, while business organisations, Chambers of Commerce and private consultants tended to be associates in informal activities. Note that the high response for Chambers of Commerce needs to be interpreted with some care, since most of the respondents to the survey were drawn from Chamber of Commerce databases.

Table 3. Number of reported types of training collaboration

Type of Organisation
Industry Training Organisations (ITOs)
Institutes of Technology / Polytechnics (ITPs)
Universities / Wānanga
Trade Unions
Business Organisations
Chambers of Commerce
Firms from Value-Chain (suppliers, clients)
Government Departments
Private Consultants and Paid Advisors
Private Training Providers
Local Councils / Municipalities
Local Community Organisation
Other Parts of the Same Enterprise Group
Other Education Providers

$\begin{array}{cc}\begin{array}{c}\text { Formal: } \\ \text { Industry Training and VET Activities }\end{array} & \begin{array}{c}\text { Informal: } \\ \text { Other Interactive Activities }\end{array} \\ 28 & 10 \\ 18 & 10 \\ 15 & 8 \\ 2 & 1 \\ 12 & 18 \\ 21 & 30 \\ 5 & 7 \\ 14 & 10 \\ 11 & 21 \\ 14 & 14 \\ 3 & 5 \\ 6 & 3 \\ 6 & 8 \\ 2 & 2\end{array}$

\subsection{Skills training and "green skills"}

There is considerable interest among policy advisors to understand the impacts that climate changes, and especially subsequent mitigation and adaptation policies, are having on labour market developments. As noted, for example, in a recent working paper prepared as part of a project on Climate Change, Employment and Local Development undertaken under the auspices of the OECD LEED Directing Committee, within the framework of the OECD's Green Growth Strategy "adapting labour markets to achieve more jobs and better quality jobs to move towards a low-carbon economy requires strengthening education and training systems as well as supporting skills development activities both at the industry and public sector levels for which we have little knowledge and understanding of the dominant dynamics" (OECD, 2010, p. 5).

Consequently, the OECD added a number of questions relevant to the issue of skills training and "green employment" to the survey reported in this chapter. These additional questions were answered by the second wave of 16 respondents. This low number means that the results cannot stand on their own as reliable evidence, but they do support similar results that have been obtained from the surveys carried out in the other countries participating in this research programme. They are also consistent with feedback in the five case studies reported in Chapter 3 and are suggestive of the need for further research in this area. A summary of the core results are presented in Table 4.

Four of the sixteen firms (25\%) reported that they had made changes in the previous twelve months in terms of introducing a new product or service or operation due to climate change adaptation or regulation. This percentage was low compared to other forms of innovation: $62 \%$ reported a product innovation; $56 \%$ an operation innovation; $44 \%$ a management innovation; and $31 \%$ a technology innovation.

The awareness of firms regarding green skills and training needs for the future appears to be limited. The in-depth interviews confirmed that although some need of skills upgrading is foreseen there is relatively little knowledge of the areas or the way the training should be implemented. Indeed, the preliminary results in Table 4 suggest that existing "green" vocational education and training 
participation may be very limited (12\% of firms). Knowledge intensive green activities appear to be more frequent (50\% of firms in Table 4), highlighting the role of informal learning for SMEs to green their activities and skills. In both learning and training approaches, green skills acquisition is higher for high-medium skilled employees than for low-skilled employees.

\section{Table 4. Responses from 16 firms about "green skills"}

Has your business made changes in the past 12 months in terms of introducing a new product/service/operation due to climate change adaptation/regulation?

$\begin{array}{ccc}\text { Yes } & \text { No } & \text { Not Answered } \\ 4 & 11 & 1\end{array}$

Do you think additional training is needed in your business (ongoing need or newly needed) over the next 12 months in the following area: Green - specific skills required to adjust your products, services or operations due to climate change adjustments, requirements or regulations?
High Need
Some Need
No Need
5
Not Answered

Did any of your employees participate in industry training or vocational education and training (VET) activities in any of the following areas during the past 12 months: Green skills development?
Regularly
One-Off
1
Did Not Do
13
Not Answered
1

In your opinion, did your employees get any of the following outcomes from the above training: improved green skills (e.g. adjusting to climate change)?

For High-Medium Skilled Staff

4

For Low Skilled Staft

1

Neither Group

12

Not Answered

0

In addition to any training activities that were mentioned previously, did your business carry out, in the past 12 months, any of the following activities which significantly increased the skills, competencies or knowledge of your employees: Green skills development (e.g. co-operation with other organisations to find ways to adjust production to minimise climate change)?
Regularly
One-Off
5
Did Not Do
7
Not Answered
1

In your opinion, did your employees get any of the following outcomes from participating in these activities (in the short or long term): improved green skills (e.g. adjusting to climate change)?

For High-Medium Skilled Staff 3
For Low Skilled Staff 2
Neither Group 9
Not Answered 3 


\section{Part II}

The Regional Skills and Training Ecosystem in Canterbury 



\section{Chapter 2 - The OECD Workshop in Christchurch}

The OECD survey presented in Part I of this report provides new data on how firms manage formal and informal alternative learning to improve relevant skills of their staff. A second aim of the OECD research project was to explore features of the regional training ecosystem supporting these individual firms. The concept of "regional training ecosystems" originated in David Finegold's (1999) case study of high tech firms clustered in Northern and Southern California. Finegold's study focused on "high skills ecosystems" but other authors have since argued it can be extended to other sectors of the economy; see especially Buchanan et al, (2001) and Windsor and Alcorso (2008). In this approach a skill ecosystem is defined as "a self-sustaining network of workforce skills and knowledge in an industry or region" (Windsor and Alcorso, 2008, p. 5). The network is comprised of a range of actors, as shown in Figure 32. This figure is for a high skill ecosystem, but the authors also note that a low skill ecosystem characterised by "low productivity, low wages and a low value-add business strategy" can also discourage individuals from pursuing work-related learning (idem).

\section{Figure 32. A high skill ecosystem}

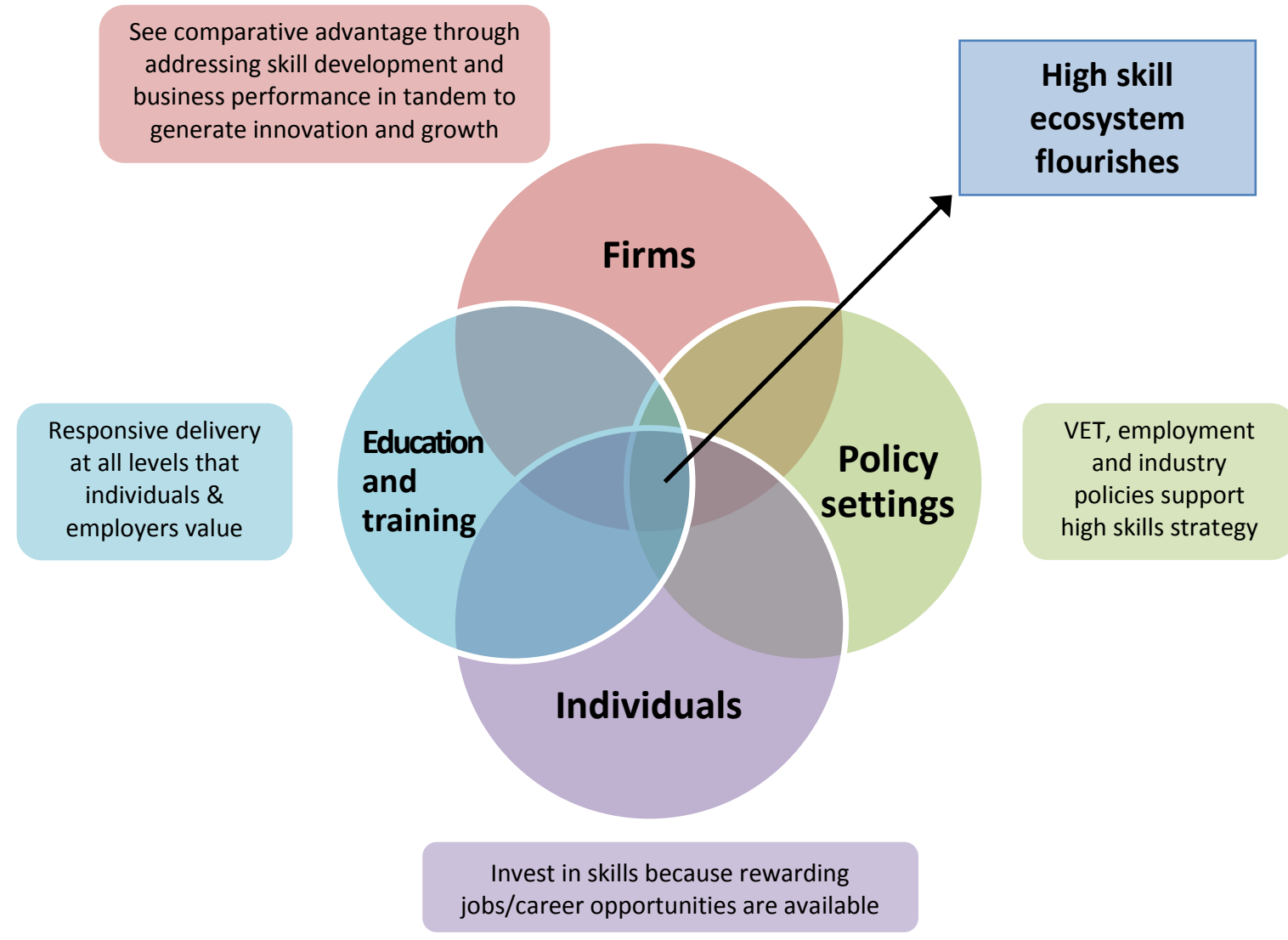

Source: Windsor and Alcorso (2008, p. 5) 
To explore this concept in a New Zealand setting, the OECD arranged for a Skills and Training Ecosystem Workshop to be held in Christchurch (the largest city in the Canterbury region) on 1 July 2009. The workshop was hosted by the Canterbury Employers' Chamber of Commerce, the AERU Research Unit at Lincoln University, the Christchurch Polytechnic Institute of Technology and the Canterbury Development Corporation, in conjunction with the New Zealand Department of Labour. ${ }^{5}$

The workshop focused on four themes. Each theme began with a presentation based on early results from the first wave of the survey analysed in Part I of this report, followed by small discussion groups focusing on questions provided by the research team. Each group reported back to a plenary session of the workshop and there was time for further discussion in the full group. The workshop ended with a roundtable of summaries and key messages.

\subsection{Skill needs}

The first thematic discussion focused on the survey finding that additional skills training was needed over the next twelve months, especially in the areas of management skills, social skills, generic skills and technical skills (see Figure 12 earlier in this report). Participants in the workshops were asked to discuss: whether employees in SMEs and local talent are able to provide these skills; how could these skills be developed and be ready for local firms to utilize them; what could be done by public agencies intermediaries and by business organisations and training organisations so that the level of skills needs is reached; and whether there were any clear skills shortages being experienced by firms in the region.

The discussion analysed these questions at two levels: the level of the individual enterprise and the level of regional or national institutions (including the educators).

At the individual firm level, there was a view that it is a specific skill to be able to determine the in-house needs for skill capabilities, to identify skills gaps in the current employees, to be knowledgeable about training opportunities (including public subsidies), and to design an skills development plan that fits within the firm's budget and time constraints. It was suggested that this may not be appreciated by SME managers who may have little time for training themselves. Some SMEs adopt a strategy based on a low cost workforce, and are not interested in raising the skills of their staff. In other cases, training resources may be entirely absorbed by compliance to meet health and safety regulations. Employees can have mixed attitudes towards ongoing training, especially if there is no clear financial reward for learning achievements. It was also suggested that some employees have unrealistic expectations about rapid advancement while they are still inexperienced. In contrast, some SMEs deliberately maintain a strong culture of embedded learning, with an emphasis on using local internal resources for raising skill levels (through mentoring schemes, for example).

At the regional level, there was considerable discussion about low literacy, numeracy and basic computing skills in some segments of the labour force. This was being addressed through the New Zealand Skills Strategy (see New Zealand Government, 2008), and this focus was strongly supported. The recession had reduced skills shortages in the region, which had been more pronounced one to two years earlier. Nevertheless participants reported that there were still skill shortages in areas such as the construction sector, health professionals, pre-school education and aged care, and also suggested that the recession provided an opportunity to invest in skills development (for example through greater government support for apprenticeships). There were also suggestions that there is a need for more

5 The research team is grateful to Peter Townsend (CECC), Gay Sharlotte (CPIT), Simon Worthington (CDC) and Paul Barker (Department of Labour). We are also grateful to Dr Teresa Cunningham and Meike Guenther (AERU) for helping to organise the workshop, and to Tamara Weyman (University of Western Sydney) who took extensive notes at the workshop which she made available for the writing of this report. 
training aimed at middle managers and that not-for-profit organisations need to have good training programmes for their volunteer members.

It was considered that there is good mix of public and private providers of training in Canterbury, sufficient to meet local demand. The Industry Training Organisations (ITOs), for example, are well placed to arrange for relevant training for employees. Nevertheless, the wide range of providers can make it difficult for a small business to find the right organisation for its training needs. In many cases, training programmes by the larger organisations are not appropriate, or are pitched at the wrong level (too low or too high), or are not suited for workers who learn best through practical application rather than reading or writing. There may be a promotional role for government agencies or employer groups or the ITOs to communicate about what training options are available, especially from private training enterprises (PTEs). Smaller firms might want to form a long-term training partnership with a PTE as a way to maximise the value of their training dollar.

Some sectors have achieved a better level of interaction between educators and business than others. It was reported that engineering faculties, for example, are more connected with local business than commerce faculties. It was also reported that careers in the trades are not well promoted in secondary schools, especially compared to academic pathways. It was suggested that there is potential for greater involvement of industry with career education in schools.

There was a lot of discussion about the tension between generic trainer-determined programmes and flexible business-determined programmes supplied by private training enterprises (PTEs). This discussion suggested that funding tends to favour the former (perhaps because generic courses are cheaper to operate) rather than the latter. Consequently, ITOs and polytechnics may not be well geared up to meet training that will address the specific needs of an individual SME. While generic funding policies are not aimed to meet the firm-specific needs of firms, they do provide for some SMEs, along with other stakeholders, to have a strong role in influencing the nature of training provision in their region. This suggests an important role for the Tertiary Education Commission (TEC) in providing information to SMEs about how best they can liaise with tertiary providers to encourage supply of education that does meet their demands.

\subsection{Training and competence building in SMEs}

The second thematic discussion focused on the survey finding that half of the respondents in the Canterbury survey reported that the level of training and competence building activities in their firm was less than they would have liked to have carried out in the previous twelve months (see Figure 16 earlier in this report). The survey also revealed that cost and time are major barriers (Figure 17). Participants in the workshops were asked to discuss: whether those results were under or over estimated; is training reaching the low skilled, younger or older workers, and disadvantaged groups; and are there specific issues for SMEs that larger firms don't have to face.

The general consensus among the workshop participants was that the reported result of $50 \%$ of firms do not do all they training they would like is reasonable, although it was noted that this may affected by "non-response bias" because managers with a greater interest in training are more likely to respond to a survey of this type.

There was also a general consensus that training is universally available in New Zealand, and some training is succeeding in reaching certain target groups. This includes literacy and numeracy modules embedded in ITO programmes, although penetration rates are less than desirable in some areas. Formal training tends to be dominated by people under 25; older men without qualifications may find it harder to access training. There is a concern that informal training may be facing some gaps as the older generation of trades people retire without people of similar experience behind them to take their place (because of the lost cohort of training during and immediately after New Zealand's economic reforms of 1984 to 1994). 
Three issues were identified for young people. First, concern was expressed that young people are not getting the full picture about trades training paths from careers guidance at school; indeed it was suggested that schools have tended to undervalue trade vocations and training in favour of a focus on university education. Second, policy needs to cater for young people who dropped out of learning at school but are looking to reengage with training options. The spike in youth unemployment during the current recession makes this particularly important. Third, within a firm a young person may benefit greatly from training but not be in a position where they can push themselves forward to be considered for training. A lot may depend on the employers' expectations.

A number of issues were identified for SMEs, both positive and negative. Larger firms have the resources to employ a dedicated human resource manager who can oversee a formal training plan and link it to business needs. Without this specialist expertise, it may be difficult for an SME manager to evaluate the benefits of training for the firm or to foresee how new skills developed through training could be used to raise labour productivity. Costs and time away from productive work are often seen as large barriers in an SME. It is not really economic to arrange for one-on-one training, but how can an SME arrange for six of its staff to participate together in a training session? The disruption to the shop floor may be unmanageable. It may be harder for an SME to have a workplace training assessor to obtain formal qualifications for staff learning skills in-house.

On the positive side, small firms with a positive training culture can build up strong employee loyalty with lower turnover costs. A positive training culture may include deliberately maintained mentoring relationships, perhaps involving the founder-manager in a small firm. The reputation effect of being a good employer can attract better quality staff, especially in small communities. A small business may have periods of less intensive work, including during the current recession, when training may be easier to arrange, although this may not be possible if the quiet times are associated with cash flow difficulties.

It was suggested that size need not be decisive in skills development within an enterprise. Some business founders have a strongly positive attitude towards workplace learning while others are equally strongly negative. The industry environment can play a role: in some cases health and safety regulations demand ongoing training, perhaps with formal certification. SMEs may have a business plan based on increasing labour productivity through skilled staff while others may base their competitiveness on maintaining a low-paid workforce. A firm's commitment to training is likely to change as it grows and develops. A particular issue is whether the manager of an SME is able to find time for his or her own skills development.

\subsection{Role of training networks}

The third thematic discussion began with an overview by Gay Sharlotte (CPIT) on how the New Zealand government's regional facilitation programme had operated in Christchurch over the previous three years. This was a programme implemented by the Tertiary Education Commission to encourage regional training networks facilitated by the local institute of technology or polytechnic (ITP). The Christchurch Polytechnic Institute of Technology (CPIT) had convened a steering group that had organised education and training provider forums to identify regional training needs, gaps and priorities. This had produced, among other things, the Regional Statement of Tertiary Education Needs, Gaps and Priorities in Canterbury, 2008-2010 (CPIT, 2008) and had fed into the development of a Canterbury regional labour market strategy (CLMS Governance Group, 2008). The regional facilitation programme was being phased out after a change in government policy, but it had shown that a "network of networks" could produce positive outcomes for learners, trainers and employers.

The OECD survey found that regional training networks were generally well known to the responding firms (see Section 1.4). Participants in the workshops were asked to discuss the role of public agencies, business organisations, trade unions, and tertiary education organisations on the 
functioning of the skills and training system in Canterbury. They were also asked to suggest strategies for increasing linkages between firms and training organisations in Canterbury, and for improving the region's training levels.

There are formal training networks among educators in Canterbury, including the Canterbury Tertiary Alliance and the Canterbury Training Providers Association. These tend to be student focused rather than addressing the needs of industry. There are also some informal networks as a result of previous programmes such as Regional Facilitation, which was designed to focus on the relevance of provision of training to industry. At a national level, Industry Training Organisations have a legal responsibility to work with their industries to create strategic plans that then inform provision of training.

There are examples of good industry level partnerships between businesses and trainers. The Trades Innovation Institute at the CPIT is an outstanding example of collaboration. This has taken time to build up cohesion, but is now bearing fruit. The health sector is another area where collaboration between employers and trainers is good. A further example is the SiteSafe programme, initiated by four large companies to set up a non-for-profit organisation to address a serious common goal (supported by the Department of Labour and the Accident Compensation Corporation).

Nevertheless, there was a general view that the partnerships are fragmented, with the networks being independent of each other and largely dictated by funding sources. It was also noted that the information and communications technology sector does not have an ITO, although there have been partnerships created between large employers and tertiary educators (the universities and the polytechnics). The workshop participants thought it would be very difficult to answer these questions in the context of informal training activities.

The workshop found it difficult to suggest concrete strategies for increasing linkages between firms and training organisations. There was a strong consensus about the need for greater coordination and communication along the lines proposed in the regional facilitation programme, but it was not easy to determine how this could be achieved. The CPIT, for example, had recognised there were missing voices in the regional facilitation forums (for example; small businesses, recent migrants, unemployed workers, Asian communities and youth) and had not succeeded in finding ways to involve representatives. More generally, it was thought difficult for business owners to have opportunities for input into government agencies to keep training up-to-date. Four suggestions were made:

- Better advice and training pathways for international students

- Greater co-ordination between the ITOs at a regional level

- Secondment projects between firms and academics

- Better alignment of funding streams

There was a strong debate in the workshop about what was perceived as a very large number of qualifications (nearly 6000 , including 3455 certificates and 1059 diplomas) on New Zealand's Register of Quality Assured Qualifications. Some considered that the large number reduces their relevance to employers, who in some cases may turn to other mechanisms for making judgements about a potential employee's skills (for example, testimonials or retesting themselves). This side of the discussion called for an overhaul that would produce greater alignment and simplification. Another point of view argued that the large number is the result of the way in which the system is administered (recording everything) and that there is no evidence that the large number of qualifications per se is causing any serious problems. This view argued that regional qualifications that meet national standards (one of the causes of the number of qualifications) provide valuable flexibility. This issue was reviewed by the New Zealand Qualifications Authority and the Ministry of 
Education (see, for example, Vermillion-Peirce and Grice, 2009, and Vermillion-Peirce and Parker, 2009), which has led to seven recommendations (NZQA, 2009, p. 3):

1. Develop a unified New Zealand qualifications framework.

2. Require the use of existing quality assured qualifications and change the design rules for National (standards-based) and New Zealand (course-based) qualifications to allow for more inclusion of local components.

3. Require mandatory periodic reviews of qualifications to determine whether they are still fitfor-purpose.

4. Strengthen and standardise qualification outcome statement requirements.

5. Introduce a mandatory pre-development assessment stage for qualification developers.

6. Strengthen recognised industry involvement in qualification development.

7. Provide the public with clear information about whether a qualification is active, inactive or closed.

\subsection{Outcomes of training and competence building activities}

The final thematic discussion began with the survey result that most participants recognised beneficial outcomes of training or/and competence building activities for their firm, but fewer reported benefits for their industry or the local region (see Figures 14 and 15 for formal training and Figures 25 and 26 for informal training). Nevertheless there was some recognition that industry and regional innovation and competitiveness are enhanced by formal and informal training. Workshop participants were asked to consider: whether local firms are visibly influencing skills levels in the local workforce, and whether this is having any regional impact; whether the region is "specialising" in certain skills; and whether the region is missing out if firms are only able to invest in training that produces immediate benefits to their business.

Participants were able to suggest specific examples where the region has clusters of specialist skills being actively developed in Canterbury, including electronics and software (the high tech cluster), performing arts, biotech and medical instrumentation, manufacturing and innovative foods. Reference was made to a recent Department of Labour report on knowledge intensive sectors that had Canterbury well behind Auckland and Wellington, but which drew the following conclusions about Christchurch City (Department of Labour, 2009, p. 29):

The Canterbury region is, unsurprisingly, dominated by Christchurch City in terms of its knowledge economy (chart 3.16). Christchurch City has both the highest number of KI [knowledge intensive] sector workers, and the highest proportion of its workforce in these sectors (30\%).

Christchurch City has seen strong employment growth of 50\% in its private KI sectors over the period 2000-08. This is considerably faster growth than the growth in either Auckland City or Wellington City, and is well ahead of the overall national figure of $35 \%$ growth....

Christchurch is in a promising position for further development with an international airport, two universities and two polytechnics. If a higher proportion of South Island graduates can be attracted to develop their careers 
and business ideas in Christchurch then there will be a steady flow of high calibre workers available to local businesses.

There were Canterbury examples from the primary sector. Dairy farmers in North Canterbury had been experiencing difficulties in attracting staff, and so developed a collective code of practice for employers that including training for management as well as staff). Fonterra (a very large firm responsible for more than a third of international dairy trade and co-operatively owned by about $96 \%$ of all New Zealand dairy farmers) has a skills training package that has had an impact in small towns with a Fonterra factory. Wine growers in North Canterbury have collaborated to include a strong sustainability focus in their production and marketing.

Attention turned to informal competence building activities. It was suggested that these tend to be firm based as part of an enterprise's strategy for building and maintaining competitive advantage, and for retained valued staff. A common activity involves drawing on in-house skills to raise the capabilities of other members of the staff, or to capture potential productivity improvements recognised by employees. Consequently, it can be difficult to measure the benefits from informal training activities, especially since firms do not want to share their innovative practices with competitors.

Nevertheless, the workshop did consider that there are advantages in thinking further about how to assist SMEs with informal competence building activities. A firm relying exclusively on in-house skills may simply reinforce the internal status quo and not adopt cutting-edge technologies. Networking, finding areas of common need where collaboration would be cost-effective, using external facilitation by a credible facilitator, and involving tertiary education organisations (private and public) may all have roles to play. This raises questions of who pays, and how the balance should be struck among the contributions of employers, employees and the government.

\subsection{Summary}

Reflecting on the material produced in the OECD workshop, it would appear to be premature to speak of a single skills and training ecosystem in Christchurch city or the wider Canterbury region. Some sectors have developed good connections between tertiary educators and employers, particularly in formal training for people in occupations connected to health and the skilled trades. There are also examples of collaboration among training providers such as the Canterbury Tertiary Alliance and the Canterbury Training Providers Association. Nevertheless, there was a general view that in many cases partnerships are fragmented, with networks being independent of each other and largely dictated by funding sources.

The OECD workshop took place in Christchurch shortly after the New Zealand government's three-year "regional facilitation" programme had concluded. This programme had sought to foster connections between tertiary educators and other stakeholders in the local labour market. This initiative had met with mixed success. A better understanding of local skill needs had been produced, but the global recession meant this was no longer directly relevant in the immediate short-term. It had been particularly difficult to achieve involvement from SMEs in the process, for all the well-known reasons that have motivated this report.

A potentially fruitful point of tension in the local skills and training environment in New Zealand lies at the interface between industry training organisations (ITOs) and institutes of technology or polytechnics (ITPs). The ITOs have a statutory responsibility to provide training leadership in their industry, while ITPs have a mandate to provide training that is relevant for their region. In the OECD workshop, it was noted that not all ITOs are represented in the Canterbury region (and that there is no ITO for the information and communications technology sector). There was also some controversy about the extent of regional qualifications registered on New Zealand's national Register of Quality 
Assured Qualifications, with some participants arguing that there are too many, reducing their relevance to employers.

Within this institutional framework, it was recognised that private training enterprises (PTEs) could sometimes be more flexible in providing business-determined programmes.

The workshop identified three particular issues for young people. First, young people may not be getting the full picture about trades training paths from careers guidance at school. Second, there is a group of vulnerable young people who have dropped out of learning at school and need to be reengaged with training options. Third, within a firm a young person may benefit greatly from training but not be in a position where they can push themselves forward to be considered for training.

The workshop struggled to identify the extent of knowledge intensive service activities being used by SMEs in the Canterbury region. Participants did consider that there are advantages in thinking further about how to assist SMEs with informal competence building activities since firms relying exclusively on in-house skills may simply reinforce the internal status quo. But it was difficult to suggest positive ways in which this might be achieved, or how its success might be measured. 


\section{Chapter 3 - The Canterbury SME Case Studies}

In order to gain further insights into the Canterbury regional skills ecosystem, the author interviewed managers of five small to medium sized enterprises. The interviews focused on how the SME approached formal training and informal competence building for its staff. The SMEs were chosen to give a range of sectors and enterprise size, but they also displayed significant differences in their approaches to training and competence building that add some considerable richness to the new data collected in the Canterbury survey and the discussion in the Christchurch workshop. Table 5 lists the names of the firms, their sectors and their number of employees.

Table 5. The SMEs interviewed as case studies

$\begin{array}{llc}\text { Enterprise } & \text { Sector } & \text { Number of Employees } \\ \text { EFI Engineering Ltd } & \text { Custom Engineering } & 12 \\ \text { Independent Line Services Ltd } & \text { Electricity Network Services } & 41 \\ \text { Windflow Technology Ltd } & \text { Wind Turbine Design and Manufacture } & 60 \\ \text { Alchemy Group Ltd } & \text { Purpose Built Software Systems } & 12 \\ \text { Lakewood Court Rest Home and Straven House } & \text { Aged Care Accommodation } & 51\end{array}$

\subsection{EFI Engineering Ltd}

EFI Engineering was set up in 1995 by Grahame and Helen Wright as a result of the major restructuring in the New Zealand engineering industry that followed the 1987 share market crash. The firm specialises in custom design and manufacture of quality plant and machinery, and is also committed to general engineering and maintenance work both in house and on site. It has been involved in development work for automated mooring systems of ships at ports, repair work and maintenance of large machinery, and design and manufacture of bakery equipment. The versatility required to do this type of custom work requires its twelve staff to be practical and skilled trades people, able find effective solutions to unusual problems.

The manager, Grahame Wright, had considerable experience in training apprentices when he was at Savage Engineering - a much larger engineering firm that had closed down after the 1987 crash. They used to get 40 applicants a year, the two most academically gifted of whom they would select as apprentices. The firm came to realise, however, that it was effectively training people to become managers in other enterprises since these apprentices did not want to be trades people for any longer than they needed. So they changed their selection criteria to aim for people who were less academically inclined but who showed abilities with their hands and a real enthusiasm for working with machinery. This still represents the type of person who suits his current business, which has some important implications for his approach to training.

First, Wright is passionate about staff training, and estimates that he has spent between NZD 20000 and NZD 25000 in direct training costs, not including the opportunity costs of time 
away from the factory floor. Nevertheless, he no longer finds value in formal apprenticeships. He cites the following problems:

- It is impossible for him to release staff for a six week block course.

- If a staff member is released to get a qualification, he could resign to go to another firm next week.

- Most of the staff do not require the whole programme; just the introductory material (at least initially).

- The apprenticeship curriculum is designed for the needs of big firms, and covers too much too quickly.

- Read-write learning at a fast pace are not useful for staff who are practical, who think in pictures (not maths), or who need time to absorb new material.

Instead, the firm uses a private training firm, VJ Henderson Associates, which Wright describes as a very high quality educator, teaching small classes. This firm is based in Dunedin (outside the Canterbury region), but was chosen by Wright because he finds that this provider understands his need to develop skills in his staff that will be directly beneficial to his business. VJ Henderson Associates offers a range of one-day courses in Christchurch that suitable staff can be selected to attend. They also come on-site and offer training on specific issues important for the firm. Anyone on the staff who wants to participate is eligible.

Wright reported some clear benefits from his partnership with VJ Henderson Associates:

- Perhaps the most important benefit is that this form of training "develops the right skills for the right staff". This means his employees are developing firm-specific skills, so that the firm grows and does not have to be concerned about workers being poached by competitors.

- It teaches people to think not just like engineers, but develops wider communication skills and teamwork among his employees.

- It encourages and rewards "independent" workers, although Wright has been careful to address "tall poppy syndrome" reactions when one worker advances quickly.

- It is highly motivating to the staff, and turnover is very low. As a result, Wright comments that "my staff are the best team I have ever worked with".

There are benefits to the staff. Wright gives as an example one of his employees who came into the firm with no qualifications at all. He started with night courses in mathematics at his local high school, and then enrolled in a computer assisted design module at the Christchurch Polytechnic Institute of Technology. At first the firm paid half his enrolment fee, and then reimbursed him for the remaining half on completion. The firm then began paying all his fees as he continued his studies. This employee has now been with the firm for six or seven years, and has been promoted to a very senior position.

One of the issues raised in the OECD survey concerns whether firms are making changes in response to new laws about environmental issues. Wright's answer to this line of question was an interesting one:

This doesn't have anything to do with us. Mind you I am introducing a new machine that will filter all the water we put down our drains. But this isn't in response to any law change; I have wanted to do this for a long time. I couldn't fit the machine in before, but we have just redesigned the factory floor and now it will work. 
In the author's experience, this attitude would be common among SMEs in Canterbury. Business people have an appreciation of the importance of avoiding damage to the natural environment, and will take steps to do so if it is practical and affordable.

\subsection{Independent Line Services Ltd}

- Independent Line Services was established in 1995 as an electricity network contracting company with an initial staff of four, including a trainee. It has grown to a staff of 41, including three trainees, and has become one of New Zealand's largest independent line contractors. A large part of its work is contract work for Orion New Zealand Limited, which owns and operates the electricity distribution network in central Canterbury. Training is an essential part of the firm's business plan, and is considered by its managing director, Matt Southern, as an investment in the firm's future for three reasons.

- The company constructs, repairs and maintains high voltage lines where a mistake can be fatal. Health and safety is a daily consideration, reinforced by the industry's regulatory framework.

- Staff retention is greatly improved if the company offers a learning environment and career paths that supports staff in their personal development and recognises their learning attainments.

- The age structure of the company's staff means that it needs to train young people now in order to maintain the capability to deliver its skilled services in the future.

Training in the industry is organised by the Electricity Supply Industry Training Organisation (ESITO), an organisation set up under the Industry Training Act 1992 to: set standards and register qualifications on the National Qualifications Framework that meet the needs of the electricity supply industry; manage training arrangements that enable employees in the industry to achieve these standards and qualifications; and provide leadership to the industry on skill and training matters.

All of the company's staff do the relevant training determined by ESITO in full. A large part of the training takes place within the company, but it also includes participation in 6 week courses at the Trades Innovation Institute of the Christchurch Polytechnic Institute of Technology (CPIT). The latter is a significant cost to the firm in terms of time away from work, but Southern reports that the cost is outweighed by improvements in labour productivity. The employees are offered one-on-one mentoring within the firm to get them through the more academic parts of the coursework.

There are clear career paths within the firm that are opened up to workers as they gain their qualifications. They become a "qualified man", and then leader of a two-person truck, and then leader of a three-person truck. Attaining qualifications is celebrated within the firm, and leads to pay increases.

Southern strongly supports the role of ESITO and CPIT. The strengths of the ITO system is that everyone can access the ITO standards and qualifications regardless of size, its training programmes are standardised, and it is industry focused rather than firm focused. There are, however, some weaknesses: the curriculum can be hijacked by the larger firms and subsidies provided by the ITO for credits achieved means training can be an income-earner for the employer, regardless of the outcomes for staff. Southern has been an industry participant in some of the working groups that established the ESITO programmes, and someone from ESITO consults with him at least once a year.

Phil Agnew, the Head of the Trades Innovation Institute at CPIT, had fostered a very strong partnership between the Institute and local electricity supply companies. This has resulted in relevant and practical training for the industry, aided by substantial investment in a purpose built facility at the Institute that replicates a real work environment. 
There is a statutory requirement for refresher training on health and safety in the electricity supply industry. The firm meets this requirement with regular in-house training provided by an independent educator. To keep these sessions interesting they normally include some other relevant material. This does not include "soft skills" training in areas such as communication or customer service. These elements are regarded as part of the culture of the company, emphasised in everything it does, reinforced at every opportunity by Southern and the other managers. The firm aims to recruit for these capabilities, focusing on appointing applicants who have the right personalities and people skills for the company.

Southern explicitly links the strong training culture in his enterprise with innovation. The industry has fixed standards for the quality of the work, so that competitive advantage is built on finding ways to meet those standards more efficiently. Workers at any level of the firm who have innovative ideas know that they will be listened to and rewarded by management. This is further encouraged by monthly meetings of the whole company, and an open door policy operated by managers. It is all part of the team culture that is an essential element of work in the sector.

When asked if the firm has made any changes in response to new laws about environmental issues, Southern replied, "We are required to use "sustainable practices", but this isn't having a strong effect at present. There is a push to put lines underground, and we are preparing for that to continue. Otherwise there is not much for the green revolution affecting us."

\subsection{Windflow Technology Ltd}

Windflow Technology was floated as a shareholder company in 2001. It was founded by its Chief Executive Officer, Geoff Henderson, on the propositions that demand for renewable energy sources represented a new economy and sustainable future and that engineering innovation was needed to develop a more cost-effective and reliable wind turbine capable of harnessing strong and turbulent winds such as those experienced in New Zealand. The firm is primarily a wind turbine design and assembly company. Its main capabilities are in: engineering design, research and development; production engineering; and wind farm development, operations and maintenance. Its primary technology is the Windflow 500 wind turbine that has been designed to include several technological, economic and environmental advantages, particularly for small to medium sized wind farms.

The firm had 15 staff in April 2007, which had increased to 50 in April 2008 and to 60 people by the middle of 2009. This period of fast growth has meant significant changes to the way in which the enterprise approaches skills training within the business, which is under the direction of its quality and training manager, Tim Armitage. Armitage is a Chartered Professional Engineer and an accredited assessor for the Institute of Professional Engineers of New Zealand (IPENZ). He has 30 years of experience in training staff in New Zealand and overseas.

It was relatively easy to manage the training when there were only a dozen or so employees in 2006, since he was able to know them personally and identify where training of a staff member could fill a capability gap in the firm. The increase to 60 employees has required a shift to a more formal system which he was beginning to implement in 2009. The new system requires each position in the enterprise to be evaluated for the competencies required of the employee holding that position. People appointed to a position must either have those competencies, or have the capacity to gain them within twelve months. Each employee discusses their training needs with their line manager to draft an individual training plan each year, which goes to the quality and training manager for oversight. Training options include:

- $\quad$ pairing up with a mentor in the enterprise;

- enrolment in a block course at the Christchurch Polytechnic Institute of Technology;

- $\quad$ enrolment in a graduate course at the University of Canterbury; 
- $\quad$ participation in an external training day at an industry event;

- $\quad$ provision of in-house training by an expert on the capability; and

- $\quad$ attendance at a relevant seminar or conference in the staff member's field.

Armitage gave specific examples of training that had been arranged under these headings. A staff member had been mentored by himself to study for a qualification in professional management. There is usually at least one person on staff enrolled in studies towards a trade certificate in order to become a registered electrician. This training is organised through the Electrotechnology Industry Training Organisation (ETITO). Two staff members are enrolled in a graduate management diploma programme at the University of Canterbury. There are advantages in having staff members networking with other industry participants at external training days or seminars (such as breakfasts with a guest speaker organised by the Canterbury Employers' Chamber of Commerce or the New Zealand Institute of Management), but when the training plans reveals similar needs among several staff it is more efficient to search for a suitable expert to provide the training in-house. An example of the latter is the health and safety training on working safely at height. In all of these cases, it is company policy to pay for any training that is recognised as relevant for the current or future needs of the business.

A feature of these formal training events is that they are typically directed towards increasing skills to meet urgent production or business issues faced by the company. A specific example is that senior management recognised a need to prepare an integrated strategic plan and budget. The company engaged experts from the University of Canterbury to provide structured in-house training for the management team so that they were able to learn the necessary skills as they developed the integrated document. The company also recognises it needs more project management skills, and is paying the training costs of people to develop these capabilities.

Informal learning is a vital part of the enterprise's innovation culture. Indeed, one of the features of that attracts people to join the company is the opportunity to work closely with the founder, Geoff Henderson, who is recognised for expertise and leadership in wind power engineering. The engineering staff work in teams to solve problems, which encourages cross fertilisation of ideas among colleagues. Suppliers of materials to the enterprise often offer training in the use of their materials. The company's quality assurance processes include peer review by a world expert to achieve product certification from the International Electrotechnical Commission. The company is moving towards adopting LEAN manufacturing principals so that workers on the factory floor are involved in identifying ways to eliminate waste and to organise their workstations more efficiently.

\subsection{Alchemy Group Ltd}

Alchemy Group Ltd was founded in 1996 by Steve Smith (who is the Managing Director) and Dean Ashby. They were joined by David Eaves in 1998 and Howard Nicholls in 2000. The company specialises in providing purpose built software systems for clients, with capabilities to tackle a wide range of applications. It employs 12 staff on an ongoing basis, and also employs contractors to work on specific projects. A system jointly built by Airways New Zealand and Alchemy won two categories in the Computerworld Excellence Awards 2008. The Collaborative Arrivals Manager, a web application that interacts with the air traffic management system to improve the management of aircraft flight arrival times and so reduce delays for passengers, won awards for "Excellence in the Use of ICT in Customer Service" and "Best Sustainable ICT Project".

From its earliest days, Alchemy has held a strong ethos of supporting the software industry in Canterbury. Steve Smith was the founding chairperson of Canterbury Software Incorporated (CSI), succeeded on the committee by Howard Nicholls. CSI is a voluntary association of software producers and support agencies working together to help innovative software companies in 
Canterbury commercialise their products and improve service relationships. Nicholls has been involved in helping one of the local universities design its computer science curriculum, serving for several years on the industry liaison committee of Lincoln University's applied computing group. He was a member of a major review of its computing programme in 2005, which led to a new Bachelor of Software and Information Technology degree in 2007.

These past involvements represented a substantial commitment of resources from a small firm, which has not been possible to sustain as sales have grown. Nevertheless, the firm still believes these are good things to do. It is important for the industry and for firms like Alchemy that the region builds world-class capability for innovative software design, and exercising leadership in the sector is very good exposure for the firm and its principles. Potential customers and potential employees come to hear of the firm and its directors, either directly or through recommendations from people who know about their contributions.

The firm is still at a size where it does not yet have a formal or comprehensive system of staff appraisal or training plans. This is recognised as an area for development of the firm's systems. Required skills depend on what projects the company is undertaking, and there are three options if a skills gap is identified: (1) train a current staff member to develop the required skill; (2) seek to recruit a new staff member who already has the required skill; or (3) employ a contractor on a short-term basis to do the work requiring the missing skill. The firm has used all three options in recent years.

It is not easy to recruit people locally. The company is often seeking specialist skills, and they also require a successful applicant to have some work experience since graduation. Because the firm is small, its employees need to be productive as soon as they are appointed. The firm has employed graduates from the three local public tertiary institutions, which provide a satisfactory range of graduates covering a wide cross-section of knowledge and skill-sets in software development. It has also had several students on internships to work on very specific mini-projects. The firm is very open to recruitment from overseas, although it requires candidates to have already applied to immigrate to New Zealand before they are considered.

If a skills gap is identified in the current staff, the first thought is to see if one of the tertiary institutions offers a short course on the topic. Some time ago, for example, one of the firm's employees was sponsored to enrol in a Masters degree at the University of Canterbury to deepen their knowledge in a particular area.

Generally speaking, however, the firm finds that the universities and CPIT do not offer short courses that would meet its specialist needs. The firm then looks at courses offered by private trainers such as Software Education, an Australasian firm with offices in Brisbane, Sydney and Wellington. Staff have participated in these courses, which has provided new skills, but the firms finds it an expensive option, especially if it is wanting a team of staff members to develop the skills or if the course involves travel to Wellington or Sydney. A three day course would cost about NZD 2500 (including travel) plus the opportunity cost of releasing the staff members from work when the business has lots of work to do and deadlines to meet. It is harder for a smaller enterprise to take "time out" even if it would be worth it in the long-run.

A more effective option can be to recruit a new staff member who already has the required skills (backed up with work experience) who can participate in a team project that will allow other staff members to learn from their new colleague. This involves staff in self-study based on recommended reading of texts or visits to relevant websites, supported by a mentor with the specialist knowledge. This need not be linked to a specific project. Any new staff member will have a range of skills that might allow the firm to expand into new areas if other staff members build capabilities in the same area through self-study.

Staff participate in local industry events, including conferences, seminars and talks. Important examples include the Test Professionals Network of the New Zealand Computer Society and the 
Canterbury Java Users Group. These events focus on technical training to keep people up-to-date with the latest developments in relevant technologies. The firm does not involve its staff in training on items such as customer relations, but it does involve people in weekly reviews of the latest projects' outputs. These reviews seek to identify what has gone well and what has not, so that the firm is continuously learning how to improve its processes and performance.

\subsection{Lakewood Court Rest Home and Straven House}

David O’Neill and Mary Anne Beckingsale are the owners and managers of two facilities providing accommodation and care for elderly patients. Lakewood Court Rest Home offers dementia care for up to 36 residents, while Straven House offers rest home care for up to 24 residents. The two facilities employ 51 staff in total. Most of the employees are part-time so that these staff represent about 18 full-time equivalent employees.

The businesses provide services that are subsidised by the New Zealand Government through the Canterbury District Health Board (Canterbury DHB). There are 21 DHBs in New Zealand, with each one for providing or purchasing Government funded health care services for the population of a specific geographical area. The Canterbury DHB enters into purchase contracts with facilities such as the Lakewood Court Rest Home and Straven House, and these contracts set out standards that much be met by the supplier. These standards include requirements for trained staff, plus training updates that must be regularly undertaken by the staff (especially refresher training to maintain First Aid Certificates). Suppliers must report on their standards, and are subject to audit by the DHB.

These arrangements are reflected in the employment contracts signed by employees in Lakewood Court Rest Home and Straven House. Staff are required to participate in in-house training to meet the standards set out in the DHB contract. This includes 12 scheduled training sessions during the year, plus any other in-house training sessions that may be arranged. Staff can also be directed to take part in a training event or course if a gap in their capabilities is identified during an annual performance review or as a consequence of a workplace incident requiring attention.

The in-house training is provided by people with expertise from a wide range of sources, such as Alzheimers New Zealand or the New Zealand Continence Association. Particularly important, because it is recognised by the Canterbury DHB, is the Aged Care Education programme (ACE) designed by the Health Ed Trust. This programme is approved by the New Zealand Qualifications Authority and carries unit standards. The employer pays once for the relevant resources - manuals, workbooks, DVDs (or videos), assessments and answers - and then there is a small processing fee for each student in each programme. The supplied material is backed up by telephone support during office hours. When ACE programmes are completed, the employee qualifies for a National Certificate in Support of the Older Person or a National Certificate in Community Support Services.

There is some resistance from staff to participating in the regular in-house training, although this is a requirement in their employment contracts. The employers have introduced a "mystery prize draw" at each training event to offset the reluctance of some to participate.

Managers and senior staff in both institutions are expected to provide on-the-job training to their colleagues. This is provided in work situations to ensure that policies and procedures are being properly carried out, with particular attention to resident safety and well-being.

There are some limited opportunities for staff training at an external institution. On one occasion the employers paid for a staff member to attend a course in another city, and it is possible to enrol in a relevant course at the Christchurch Polytechnic Institute of Technology. The main issue is getting coverage to release the staff member for the time away.

The owners participate in their own training and professional development, particularly by attending the annual conference of the New Zealand Aged Care Association. The Association also 
offers occasional training and professional development days for caregivers, enrolled or registered nurses, and managers.

There are some indirect benefits from the training to the Lakewood Court Rest Home and Straven House. Poorly trained staff would provide poor care, which would be reflected in lower occupancy rates. There are also costs, particularly financial costs in arranging for trainers, paying for training materials and arranging for staff cover for people involved in training. Given these considerations, the standards set out in the contract with the Canterbury DHB are decisive. The training programmes are managed to ensure that these standards are continuously met. 


\section{Part III}

\section{Analysis of Major Themes and Conclusions}





\section{Chapter 4 - Major Themes}

The purpose of this project has been to gather and analyse New Zealand data on SMEs labour force participation in formal and informal alternative ways training, analyse the impact of training and skills development activities in firms, and examine local approaches to learn how incentives can be provided to employers and employees for training activities that generate results for all employees. The research involved a web-based survey of SMEs in Canterbury, a workshop on the regional skills and training ecosystem in Canterbury, and five case studies of SMEs to give greater depth to the other gathered data. This chapter presents the major themes to emerge from this research. It begins with further analysis of the difference between the highly innovative firms and the other firms in the webbased survey. The chapter then discusses issues around training in SMEs, focusing in particular on the differences between formal and informal training and on the differences between the training of medium to high skilled workers and the training of low skilled workers. This is followed by a section on informal training, and some important differences compared to formal education. The chapter finishes with a discussion of other issues revealed in the research. Chapter 5 then presents conclusions for future research and policy development on leveraging training and skills development in SMEs.

\subsection{Innovation and training}

The discussion of Figure 6 in Chapter 1 explained that the more highly innovative firms in the survey sample were defined as those that reported they had made at least one radical innovation or had made serial innovations in three or four of the four dimensions (product, process, management or technology) in the previous twelve months. This resulted in just over half of the sample, 37 out of 72 firms, being defined as highly innovative enterprises. That discussion also reported that these 37 highly innovative enterprises in the sample tended to be older and in a mid-range size band:

- $76 \%$ of the innovative firms were 10 years or older, compared to $57 \%$ of the less innovative firms.

- $35 \%$ of the innovative firms had $10-19$ employees, compared to $20 \%$ of the less innovative firms.

Further analysis of the data reveals other important differences in the approach to training adopted by the highly innovative firms compared to the other firms in the sample. First, there was a small difference in the likelihood of having a training budget, but the highly innovative firms were much more likely to have a formal training and career development plan. This is shown in Figure 33, which records that $54.1 \%$ of the highly innovative firms reported they had a formal plan, while only $40.0 \%$ of the remaining firms reported a formal training and career development plan.

The highly innovative firms were more likely to employ older staff (50 years of age or older). The comparison is shown in Figure 34. The percentage of the workforces aged between 24 and 49 years is similar in the two subsamples, but the high innovation firms reported only $9.0 \%$ of their workforce aged below 24 (excluding the "not known" responses), compared to $17.0 \%$ for the low innovation firms. 
Figure 33. Training arrangements for high and low innovation firms

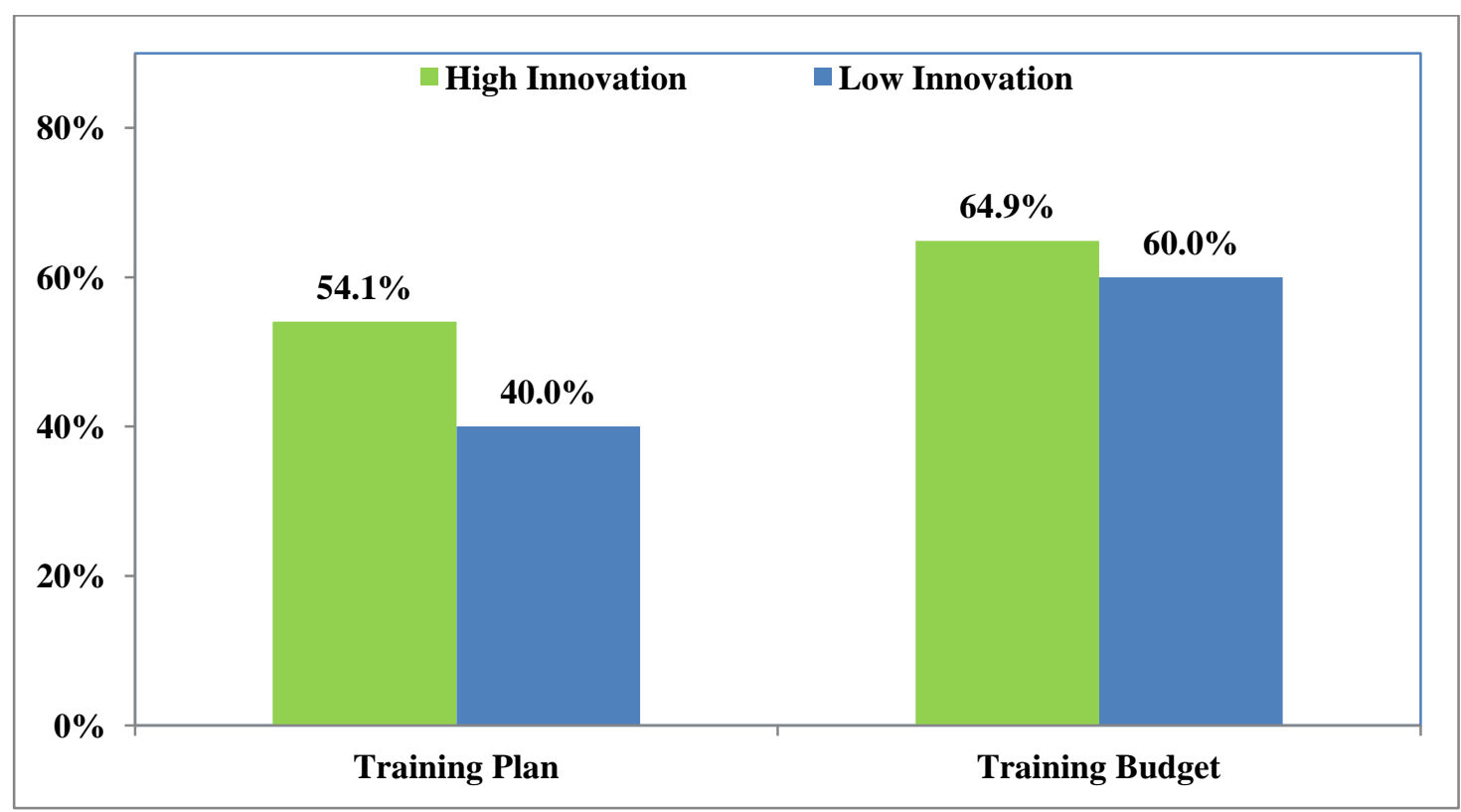

Figure 34. Age structure of high and low innovation firms

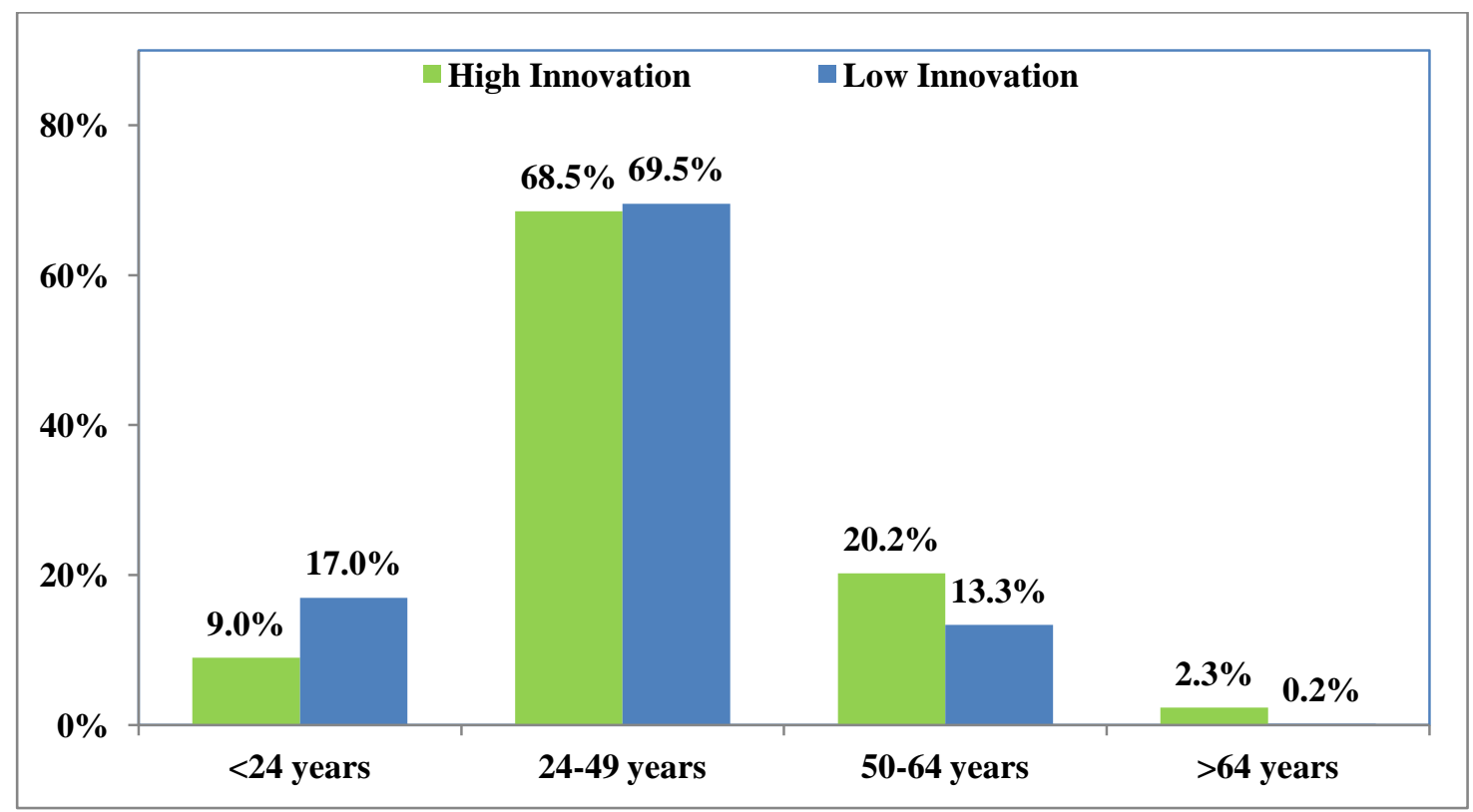

Note: These data exclude employees whose age was reported as not known 
Figure 35. Types of formal training in high and low innovation firms (\%)

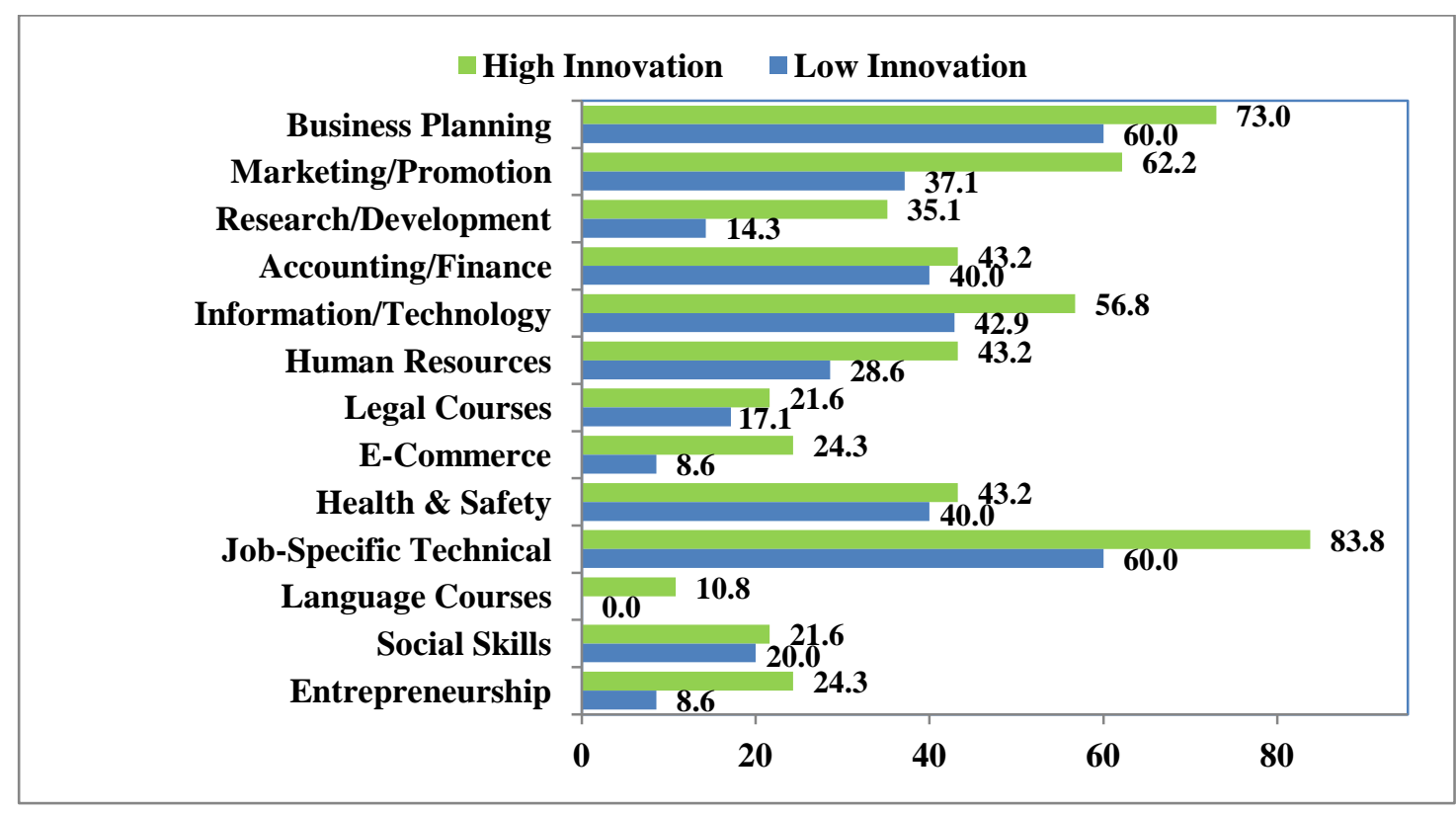

Figure 36. Types of informal training in high and low innovation firms (\%)

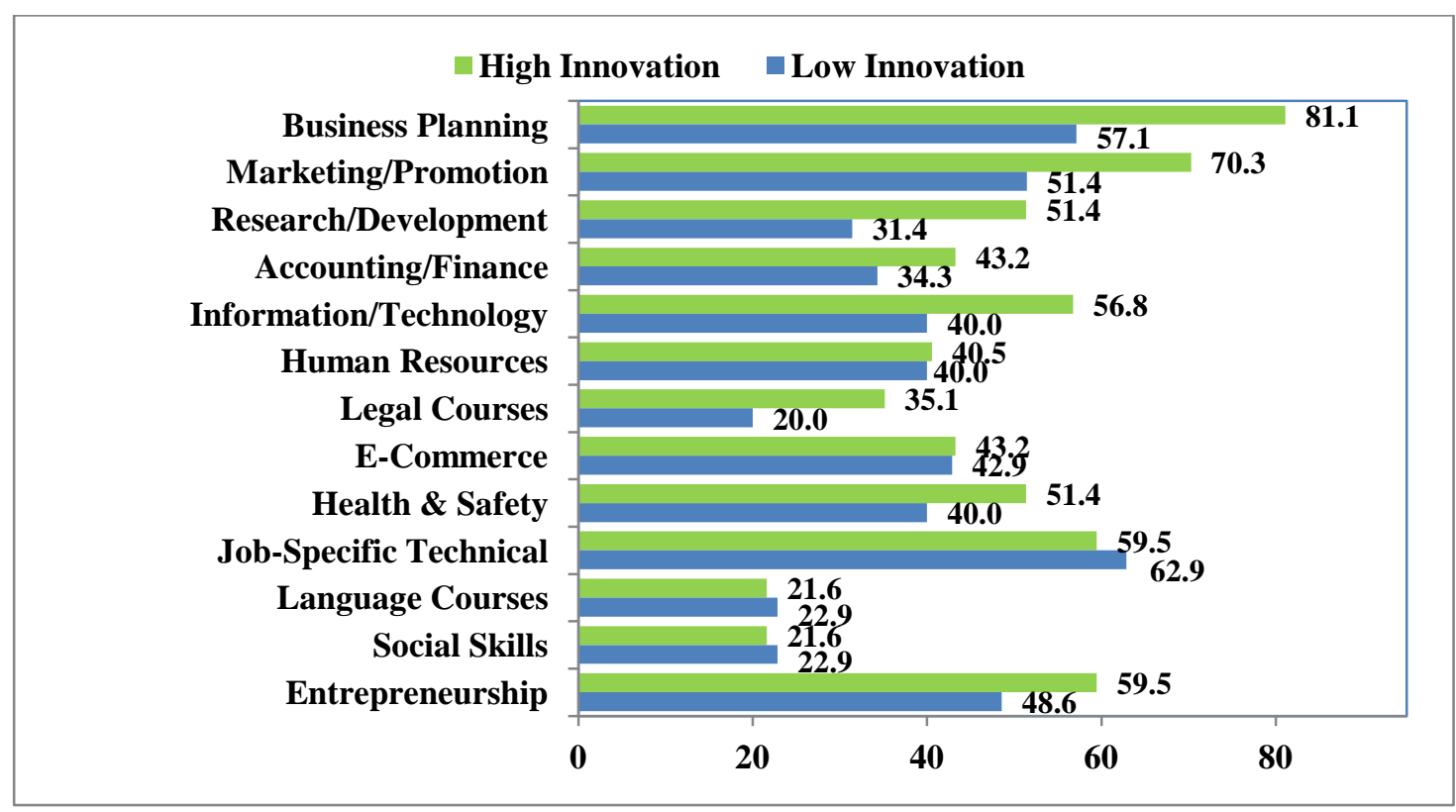

Figures 35 and 36 show the percentage of firms who report that their staff are involved in the different categories of capability building, analysed by formal training and by other informal training activities. No distinction is made in these figures between one-off training and regular training. The highly innovative firms were more likely than the low innovation firms to report in the survey that their staff are involved in training under almost every heading. There were three exceptions in informal capability building: a slightly greater percentage of the low innovation firms reported informal capability building in language courses and in social skills, and a greater difference in jobspecific technical skills (62.9\%, compared to $59.5 \%$ of the high innovation firms). 
The last observation may be a reflection that in the area of job-specific technical skills the more innovative firms tend to put more weight on formal training than on informal capability building activities. 83.8\% of the highly innovative firms indicated that their staff are involved in formal training in job-specific technical skills, which is the highest value in the two figures. This was more than 20 percentage points higher than for the low innovation firms (60.0\%) and also more than 20 percentage points higher than the proportion of highly innovative firms reporting informal training in these skills (59.5\%).

As might be expected, the highly innovative firms were much more likely than the others to report formal and informal training related to research and development. There is a very interesting comparison in the differences reported in training for marketing and promotion. Among the highly innovative firms, $62.2 \%$ reported staff involvement in formal marketing and promotion training, compared to only $37.1 \%$ among the low innovation firms. This was the biggest gap between the two groups of firms in the two figures. The gap was smaller for informal capability building activities associated with marketing and promotion, but still large (70.3\% of the high innovation firms and $51.4 \%$ of the low innovation firms).

This comparison suggests that a feature of the highly innovative firms may be that they are more driven by the search for new market opportunities (hence a greater need for staff training in marketing and promotion) than the low innovation firms. This might also explain why the highly innovative firms are more likely to be involved in formal or informal training for business planning. Further evidence is offered in Figure 37, which compares the sources of informal training in the two groups of firms. Both groups indicated that clients were the most important sources, but the proportion of highly innovative firms giving this indication was $86.5 \%$, compared to $74.3 \%$ of the low innovation firms.

Figure 37. Sources of informal training in high and low innovation firms (\%)

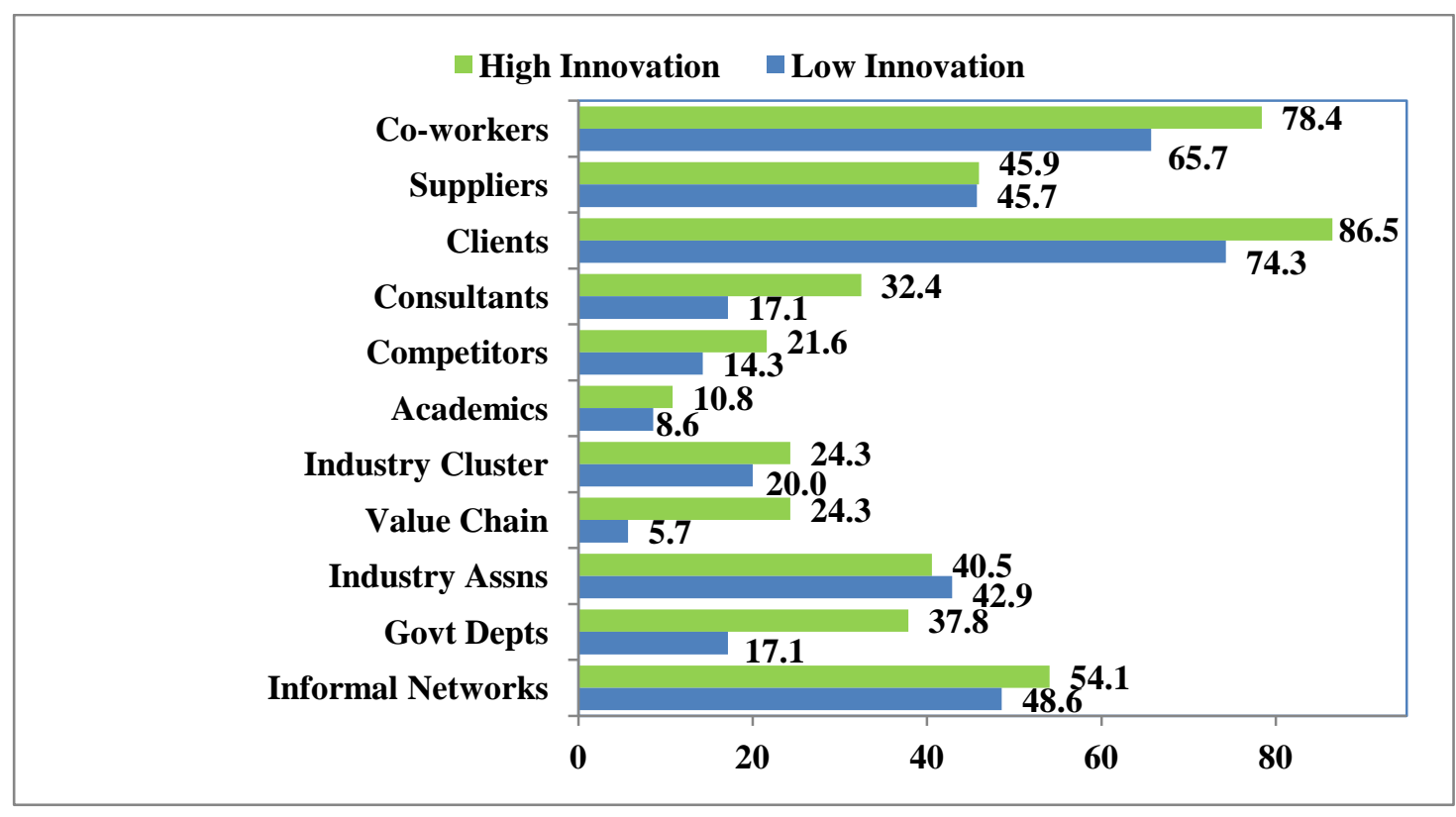

These insights are also suggested by the five case studies in Chapter 3. EFI Engineering Ltd and Alchemy Group Ltd are in the size range identified in the survey as more likely to be highly innovative, while Windflow Technology Ltd was in that range in mid 2007 before expanding considerably over the next two years. In all three cases, training was considered essential for the enterprise's business and was directed to developing capabilities that would meet immediate business issues or market expectations. The other two businesses in the case studies were providing services to a dominant purchaser (Orion New Zealand Limited and the Canterbury District Health Board 
respectively). In both cases the training framework was set by the firm's statutory or contract obligations to maintain health and safety standards. Innovation might be a consequence of this framework (and in the case of Independent Line Services, actively encouraged), but was more likely to be incremental innovation in processes rather than radical innovation as reported in the project's other three case studies.

\subsection{Training issues in SMEs}

The results from the web-based survey reveal that the level of staff training is an issue for Canterbury SMEs. Evidence for this observation includes:

- $50 \%$ of the respondents reported they had "desired training not carried out" in the previous twelve months.

- $50 \%$ of the respondents identified that their business needed training in at least five different areas (out of seven).

- $53 \%$ of the respondents reported that they have no formal training plan.

- $63 \%$ of the respondents reported an annual training budget, but only $24 \%$ said this was greater than NZD 5000.

- $68 \%$ of the respondents reported that their firm has no apprentices or trainees.

- $\quad 69 \%$ of the respondents reported "some need" for management training, and 19\% reported "high need” for entrepreneurial training.

These results were generally supported by the participants in the Canterbury training ecosystem workshop held in Christchurch on 1 July 2009. Indeed, the suggestion was that these results may underestimate the training issues since managers with a greater interest in training are more likely to have responded to a survey of this type.

The survey suggested that formal training and informal capability building are dominated by two or three areas, as listed in Table 6. With respect to formal training, $72.2 \%$ of the respondents reported their staff were involved in job-specific technical training, and $66.7 \%$ reported involvement in business planning. These two areas were also among the top three for informal capability building activities (61.1\% and $69.4 \%$ respectively), joined by informal training in marketing/promotion activities (also 61.1\%). Business planning, marketing and promotion are knowledge intensive service activities (KISA; defined in the introduction of this report); their appearance at the top of the list for informal training highlights the importance of this new concept for SME analysis.

The evidence from the survey, the workshop and the case studies is that there is a good range of education and training providers in the Canterbury region. This includes two universities and two polytechnics, industry training organisations (many with a local office) and a large number of private training establishments. Firms welcome the flexibility provided by this choice, which allows firms in different sectors and at different stages of their growth to find training that suits their needs.

For smaller firms, this tends to be driven by immediate business needs, with an emphasis on firmspecific skills. This provides benefits to compensate for the direct costs and lost work-time from worker participation in training, and also reduces the risk of losing a newly trained employee to another firm in the industry. For medium-sized firms, it becomes more feasible to move to a capability-based approach, in which employees are encouraged to increase their skills as part of the enterprise's drive to greater productivity. 
Table 6. Dominant areas of training in the survey

\begin{tabular}{llll}
\hline Area of Training & Regular & One-Off & Total \\
\hline Formal Training & & & $72.2 \%$ \\
$\quad$ Job-specific technical training & $30.6 \%$ & $41.7 \%$ & $66.7 \%$ \\
Business Planning & $11.1 \%$ & $55.6 \%$ & $69.4 \%$ \\
Informal Capability Building Activities (KISA) & & & $61.1 \%$ \\
Business Planning & $31.9 \%$ & $37.5 \%$ & $61.1 \%$ \\
Marketing/Promotion & $31.9 \%$ & $29.2 \%$ & $37.5 \%$ \\
$\quad$ Job-specific technical training & $23.6 \%$ & & \\
\hline
\end{tabular}

Firms were asked about barriers to formal training. The largest response for medium to high skilled employees was high costs (25 firms, or $34.7 \%$ ). This was followed by responses indicating the difficulty of interrupting production (that is, "no time", reported by 18 firms) and of accessing training at a suitable time or location (15 firms). A smaller number of responses were made for low skilled employee training, although recall that only $25 \%$ of the sample reported that they employ workers in the occupation categories identified as low skilled. The same three issues were mentioned for these workers among the top four, but the top category was that the skills could be recruited (indicated by 9 firms).

The survey included a focus on informal training opportunities for youth. 54\% of the firms reported they did not have youth employees (that is, employees aged under 24), and a further $4 \%$ did not know either their employees' ages or their involvement in training. A further $20 \%$ reported they had youth employees, but that these employees were not involved in informal training, so that only $22 \%$ of the firms in the sample reported they offer informal training to youth (see Figure 23).

\subsection{The importance of informal alternative ways of training}

A major motivation of the research presented in this report has been to better understand informal training issues faced by SMEs. Recall from Section 1.1 that the OECD definition of informal training "refers to learning resulting from daily activities related to work, family or leisure. It is not organised or structured in terms of objectives, time or learning support. Informal learning is in most cases unintentional from the learner's perspective." This informal learning is carried out through Knowledge Intensive Service Activities (KISA).

Respondents to the survey reported that informal training is important for their businesses. In Figure 22, 39\% stated that all of their staff are involved in informal training, and just over one-half stated that $80 \%$ or more of staff were involved. Only $7 \%$ reported that less than one-fifth of their workforce participated in informal training. Further, there was some evidence that firms had put more emphasis on informal training as a response to the recession that had emerged in the previous twelve months. This was presented in Figure 11. Generally this reported an increase in training over that period, but also reported that 22 firms had increased their emphasis on informal learning instead of formal learning (compared to one firm that had reduced this emphasis).

The most important sources of informal training were clients and co-workers, followed by informal networks, suppliers and industry associations (see Figure 21). The informal training was reported as leading to improved skills and other employee benefits (see Figures 24 and 25). The firms emphasised improved management and technical skills for medium to high skilled staff, and improved routine skills for low skilled staff. Both groups of staff benefited with improved social skills from 
informal training. Other employee benefits were reported as being largely captured by the medium to high skilled staff, with half the firms saying that this group advanced their career through informal training.

There are some interesting differences in the motivations for participation in informal training compared to formal training (see Figures 30 and 31). In both cases, raising employee skills was cited as one of the top two reasons, but Industry Association was offered as the first motivating factor for formal training in contrast to its thirteenth position on the list for informal training. This is likely to reflect the key and appreciated role of Industry Training Organisations (ITOs) in managing formal training. Similarly, training regulations featured prominently among the motivations for formal training, but not at all in informal training. Again this is likely to reflect the role of ITOs, but is also likely to reflect the role of formal health and safety regulations in some industries or occupations.

There were considerably more responses explaining motivations for participation in informal training than for formal training, and the top four categories were all business related: service needs; employee skills; new product; and production needs. Each of these categories was indicated by more than half of the survey's respondents. This suggests that informal training is more directed towards the firm's business needs, rather than being framed by industry or regulatory requirements.

Figure 38 brings together data from Figures 14 and 20 to compare the firms' reports of staff participation in formal and informal training in the previous twelve months. The figure does not repeat the distinctions between one-off and regular training, but generally speaking a greater proportion of the training tended to be one-off in the formal training activities than in the informal training activities.

In most categories, the number of positive responses is similar, but there are also some obvious differences. More firms reported participation in formal training for job-specific technical skills (52 firms), for example, than in informal training (44 firms). There were six categories where a noticeably larger number of firms reported participation in informal training than participation in formal training: marketing and promotion; research and development, legal advice; e-commerce; language coaching; and entrepreneurship. The gap for the last category was particularly large. Only 12 firms reported that their staff had engaged in formal training activities for entrepreneurship, but 39 firms reported engagement in informal training activities. 
Figure 38. Participation in formal and informal training in the last twelve months

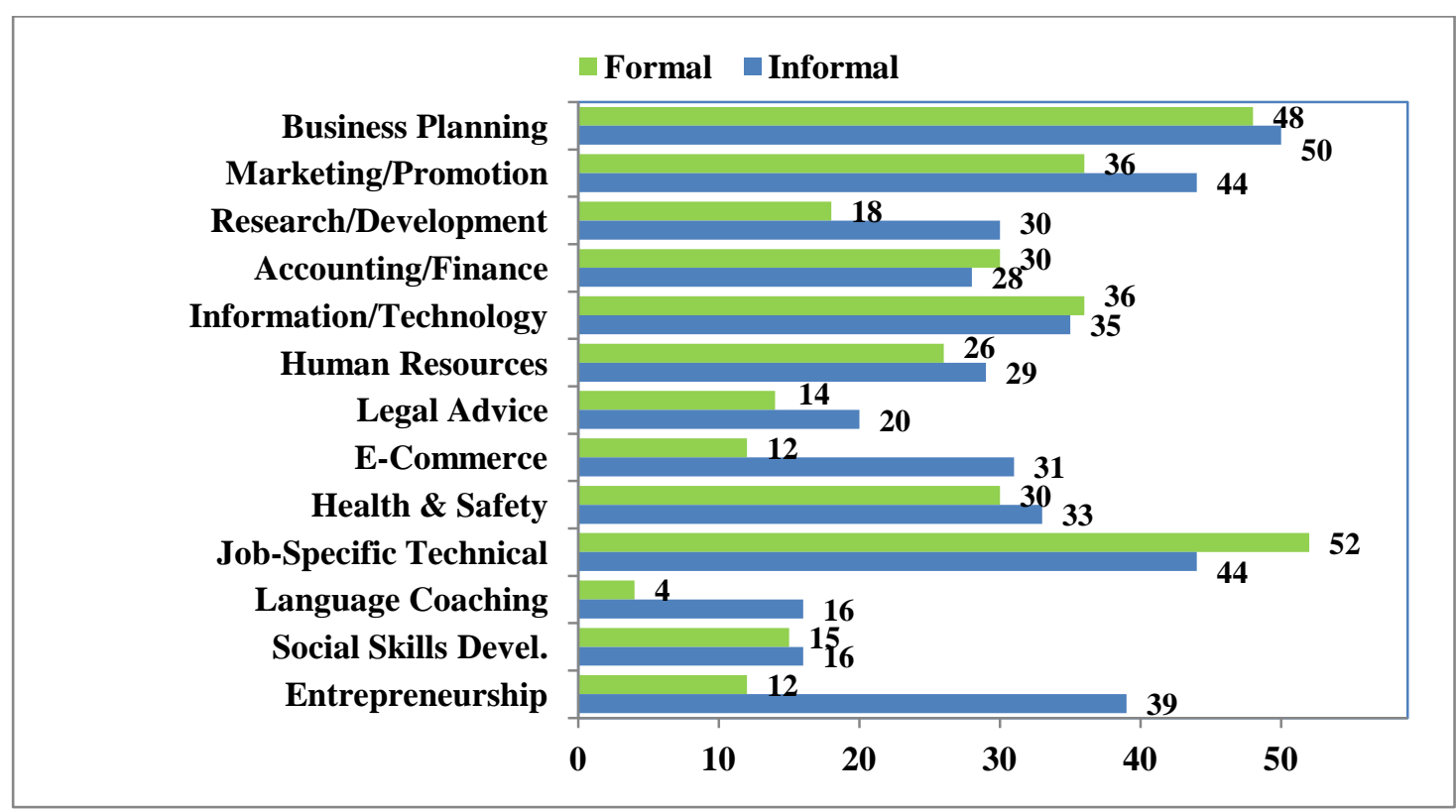

Despite these observations, there did not appear to be a strong view among the majority of the respondents that informal training is better than formal education in any of the above categories (see Figures 28 and 29). The highest level of support was for business planning by medium to high skilled employees. 33 out of the 72 respondents indicated that informal training activities are better sources of learning than formal courses, but even in this case the level of support was less than half (45.8\%).

An interesting point in Figures 28 and 29 is the different emphasis given to informal training for low skilled staff compared to medium to high skilled staff. For the low skilled employees, the top four categories were social skills, health and safety, job-specific technical skills and language coaching. For the medium to high skilled employees, the top four categories were business planning, marketing and promotion, information and technology, and entrepreneurial skills. Thus the sample appeared to support that firms value knowledge-intensive service activities for its more skilled staff, and that a solid minority of managers think that informal training is a better source of learning than formal courses in these areas.

Taken together, these elements of the survey suggest that entrepreneurial training for SME staff could be an important subject for further research. The number of firms reporting that their staff are engaged in informal training in entrepreneurship was three times the number reporting formal training. It would be valuable to understand the reasons for this large gap (does it, for example, reflect an inadequate supply of suitable formal courses), given that the majority of respondents did not report a view that informal training is better than formal courses for learning these skills.

Figure 39 brings together data from Figures 15 and 26 to compare the reported benefits to the firm from formal and informal training. The two sets of figures are very similar. In both cases, the two top benefits were enhanced skills levels and productivity, followed by improved market position and competitiveness. Improved innovation ranked fifth in both sets of data. 
Figure 39. Benefits to the firm of formal and informal training

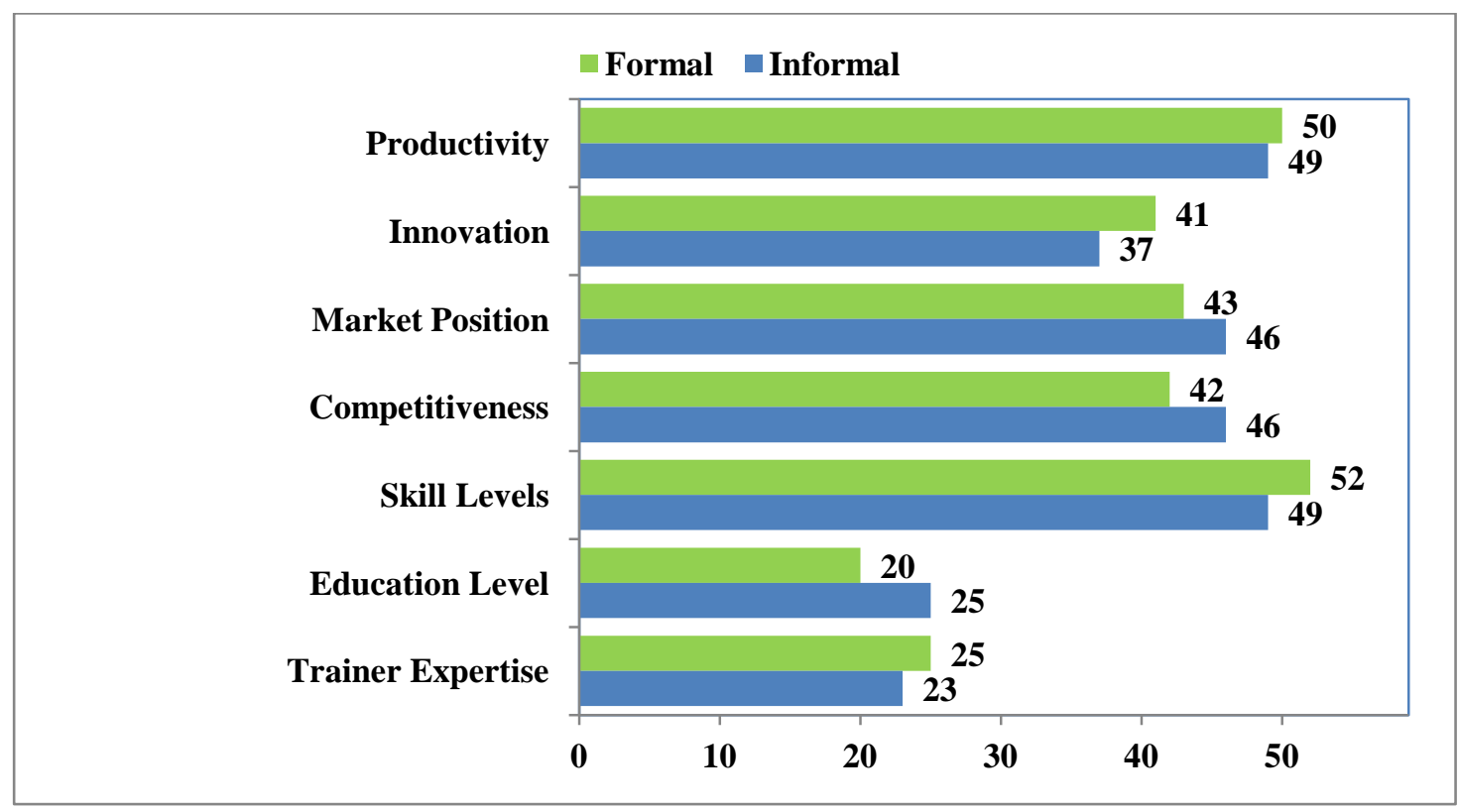

\subsection{Other issues from this research}

The research identified some other issues related to the main themes discussed in the three sections above. These are recorded in this final section for further consideration.

Participants in the survey were much clearer about firm benefits than industry or regional benefits for both formal and informal training. It is not possible without further research to determine whether this indicates that skills development genuinely has little benefit at an industry or regional level, or whether this indicates that firms focus their attention only on the benefits to their own business (and so they are unable to comment on any wider benefits). The feedback from the case studies is that the five firms were willing to invest in skills training (formally or informally learned) that directly benefited their business. Thus the manager of EFI Engineering, for example, reported using a private trainer because it "develops the right skills for the right staff". This did not exclude the possibility of releasing staff for general qualifications, but only if the qualification was directly relevant to the business's capabilities or regulatory framework.

There appears to be a particular issue for small firms as they grow beyond ten to twenty staff. The case studies included small firms describing how they needed to move towards more formal training systems within the enterprise as they expanded. These studies, as well as participants in the training ecosystem workshop, suggested that the art of identifying skill needs, constructing training plans, and linking learning achievements to remuneration is itself a skill.

Related to this question is the observation that in the survey sample, the highly innovative firms were more likely to be 10 years or older, and to have 10-19 employees. It must be emphasised that this was a small sample in a single region of New Zealand; nevertheless, these data suggest a hypothesis that in order to grow successfully through this range, small firms have to introduce at least one radical innovation or a range of incremental innovations across a number of their business and production systems. There was evidence in support of this hypothesis in the case studies.

If this hypothesis is indeed valid, then the growing small firm may find it has some important skill gaps that need to be filled urgently. This might be done by recruitment, by releasing a staff member for formal education, or by engaging in informal training in-house or externally. In all cases, the motivation is provided by the pressing business need, and it is not difficult to imagine that training in 
creating or using knowledge-intensive service activities could be a priority for such a growing enterprise. It would be valuable for more New Zealand research on this issue.

More generally, the research suggests that firms can adopt distinct strategies for expanding and maintaining their skill capabilities. Some firms appear to focus on recruiting the right skills (including - and perhaps especially - the "soft skills" such as ability to work in teams), while others appear to focus on training for them. For some firms, the fostering of a learning culture within the workplace, supported by strategic opportunities for formal education or informal training, is regarded as an explicit source of competitive advantage. It can be a way of reducing staff turnover and of building a team of employees who are capable of exercising initiative and solve business-related problems. For a small firm, close contact with the firm's skilled and experienced founder can be an important attraction for employees wanting to develop their own skills and experience.

The training ecosystem workshop included a debate about the number of qualifications on New Zealand's Register of Quality Assured Qualifications. Different points of view were expressed about the balance between "diverse provision" and "fragmented policies". This issue is the subject of current policy review in New Zealand, and so has not been considered further in this report.

Finally, a research issue being explored in the wider OECD research programme concerns the impact of environmental issues on the business practice of SMEs. Questions related to this issue were added to the survey after the first wave of invitations was sent to New Zealand firms to participate. This means there is no large quantitative data on this issue, but the five case studies suggested that environmental concerns are recognised by firms as part of acknowledged good practice, but without any sense that environment-based regulations are having a major impact on their operations. It is, however, not possible to put too much weight on this result, given the very small number of firms interviewed. 


\section{Chapter 5 - Conclusions}

This chapter summarises the research findings presented this report and offers conclusions as the basis for further research and policy development aimed at better leveraging training and skills development in small to medium-sized enterprises in New Zealand. Before doing so, it is important to reiterate the point made in the introductory chapter that the research in this report has included new areas of enquiry in New Zealand, particularly in those parts of the research that sought to better understand informal training issues faced by SMEs. Further, the study involved a relatively small number of participants (both in the survey and in the case studies) drawn from just one region in the country. Both points suggest the need for caution in drawing policy-related inferences from the research findings.

It should also be noted, however, that this country report has been prepared as part of a wider research programme on training and skills development in SMEs overseen by the Local Economic and Employment Development (LEED) programme of the OECD. The survey was designed in consultation with all the participant countries, drawing on best practice in the international literature and other research programmes within the OECD. This feature of the study provides more confidence in the research findings, especially when they are consistent with findings from other countries and in other studies.

To recap, the study set out to identify ways of overcoming barriers to workforce development in SMEs, acknowledging the important roles of both formal and informal learning process. This included investigation of the following specific factors:

- The nature and impact of training and skills development in firms, particularly focused on skills development that naturally occurs during the process of engaging in knowledgeintensive or productivity enhancing service activities (termed KISA by the OECD);

- The extent to which there are differences in the extent to which low qualified and older workers have access to such opportunities and are considered to benefit from them, relative to younger and higher-skilled workers;

- The incentives on firms and employees to participate in both formal and informal training as well as barriers to participation; and

- How SMEs' networks contribute to their participation in training and skills development activities, using a "skills ecosystem" frame for analysis.

The research aimed to provide evidence that could be used to address some specific policy questions:

- How can SMEs be encouraged to increase participation of low skills and low-qualified older workers in KISA? What incentives would work?

- How might skills developed through informal learning be recognised in formal qualifications?

- How might SMES' supply chains, and "skill ecosystems" contribute to achieving greater participation in training and skill development activities in firms? 


\subsection{General conclusions}

At the most general level, the research presented in this report supports the hypothesis that small and medium-sized enterprises undertake skills development using a variety of formal and informal training sources. It records that skills developed through these diverse sources is viewed by firm managers as being an important contributor to productivity and competitiveness, at least for individual enterprises (there was less support for contributions at the industry or regional levels). More specifically, the research has confirmed some findings from previous research in New Zealand, including the following observations:

- Raising skills in the labour force is viewed as strategically important as an significant driver of productivity growth.

- $\quad$ SMEs continue to face distinctive challenges in accessing training for employees, and many see formal training as being primarily designed for larger firms.

- Many firms have positive views of the role of Industry Training Organisations in facilitating formal vocational education and training (VET) activities, while other, even quite small firms continue to have a preference for arranging their own training in line with their particular business needs. There is scope for Industry Training Organisations to further expand their industry "reach" to include SMEs, and help SMEs to connect with both formal and informal modes of skill development.

- Private training establishments have an important role in providing training that is accessible to small and medium-sized enterprises.

- The large number of qualifications recognised in New Zealand presents difficulties to firms navigating their way through the system to determine training opportunities.

- A significant proportion of SMEs with training plans report that they have continued to invest at planned levels of formal and informal training despite the recession.

In addition, the study affirms the value of Institutes of Technology and Polytechnics continuing to engage regionally to facilitate the effective operation of regional "skill ecosystems"; that is, strengthening connections between businesses and education providers aimed at ensuring skill supply matches the nature and level of demand. This suggests that further work could systematically review regional practice, the incentives operating and examples of success in the engagement between education providers, their customers, business and the wider community.

The research provided some new data illuminating ways in which firms draw together opportunities for skill development to build a more diverse set of learning opportunities than that which formal training for qualifications can provide. For some this is more of a conscious choice than for others, but for all there are transaction costs. These findings point to the potential benefit for firms from greater facilitation in accessing these learning opportunities.

The New Zealand data has not been able to shed light on all of the project's avenues of inquiry. The very small sample size of firms employing young people, for example, meant it has not been possible to draw robust conclusions on the issue of young people's access to training. Furthermore, significant numbers of middle-aged or older workers in the sample were relatively highly skilled, and therefore, the research has not provided a strong basis for conclusions about the particular circumstances of older, low skilled workers in SMEs.

\subsection{Possible implications for policy development and further research}

The findings in this report suggest some possible implications for further policy development in New Zealand. 
- Entrepreneurial skills: The Tertiary Education Commission could be encouraged to support work on entrepreneurial skills that examines international practice in tertiary education policies relating to the demand for, and supply of, formal entrepreneurship skills training, which has a positive and high rate of return.

- Knowledge-intensive service activities: The Government could continue to refine and better link training assistance to SMEs, with the following objectives:

- Encouraging firms to understand the value of "learning while doing" for both employees and firm capability, and to build it more deliberately into their business plans and into their purchasing and training decisions for employees at all levels of skill, in the interests of boosting firms' capability and productivity levels;

- Facilitating a more closely connected suite of assistance aimed at reducing firms' search and decision costs on meeting needs for staff training and development;

- Facilitating access to a flexible suite of training alternatives that meet firms' needs - not limited to full qualification-bearing courses. There appears to be a particular need for this among higher skilled and managerial staff.

- Barriers and incentives to train: The Ministry of Education and the Tertiary Education Commission could be encouraged to investigate the extent to which costs of formal training (including fees, transport and opportunity costs) and time constraints are barriers to SMEs investing in formal training of medium to high-skilled and managerial staff in SMEs, and identify options for encouraging appropriate levels of training in these areas. In addition, the Tertiary Education Commission could refine publicly available data about provider and programme performance to better assist SMEs to match their training needs to the most relevant providers and programmes.

- There is also an important role for private sector business organisations to raise awareness, champion and help better connect SMEs to skill development. All New Zealand businesses must be able to engage in effective skills development - both formal and informal - and have ready access to such opportunities. This applies to all levels of skills, including management and innovation-related skills through technical and specialist skills to basic social and language skills.

In addition, the findings have raised questions for further research, including:

- Young people and informal training: More research could explore the extent to which young people in the workplace participate in informal training activities; whether there are any patterns relating to levels of pre-existing skills or qualifications; and the nature of enterprise-level factors influencing any differences between their levels of participation and those in other age cohorts.

- Innovation and training: More research could explore the nature of the relationship between pre-existing levels of innovation in a firm, and levels of investment in both formal and informal training. A particular focus of this research might address the links between innovation and training for small firms in New Zealand that are growing through the range from 10 to 20 employees.

- The national skills and training ecosystem: An important part of this project was the workshop on the regional skills and training ecosystem in Canterbury (see Chapter 2). More research could explore the nature of New Zealand's national skills and training ecosystem and whether there are opportunities for policy frameworks in secondary education, tertiary education, industry training and life-long learning to be better integrated to strengthen interaction between employers, employees, students and education or training providers. 



\section{References}

Barker, P. (2007), "Skills Strategies for Competitiveness: The New Zealand Experience", paper presented to the conference on Designing Effective Employment Strategies through Local Economic Development in China: Policy and Governance Issues, Beijing, 26 April.

Buchanan, J., K. Schofield, C. Briggs, G. Considine, P. Hager, G. Hawke, J. Kitay, G. Meagher, J. Macintyre, A. Mounier and S. Ryan (2001), Beyond Flexibility: Skills and Work in the Future, NSW Board of Vocational Education and Training, Sydney.

Business New Zealand (2009), Setting New Zealand Apart - Getting More Productive and Competitive - A Plan for Action, Business New Zealand, Wellington.

Cameron, A. and C. Massey (1999), Small and Medium Sized Enterprises: A New Zealand Perspective, Addison Wesley Longman, Auckland.

CLMS Governance Group (2008), Globally Competitive Canterbury: Smart People In Smart Workplaces, Department of Labour, Christchurch.

Coetzer, A. (2002), "Employee Learning and Development in the Small Business", New Zealand Journal of Applied Business Research, Volume 1(1), pp. 1-11.

Coetzer, A. (2007), "Employee Perceptions of their Workplaces as Learning Environments", Journal of Workplace Learning, Volume 19(7), pp. 417-434.

Coetzer, A., L. Lee, K. Lewis, C. Massey and M. Perry (2007), "Learning to Thrive or Learning to Survive? A Report on NZ SMEs and Workplace Learning”, New Zealand Centre for Small and Medium Enterprise Research, Massey University, Palmerston North.

CPIT (2008), Regional Statement of Tertiary Education Needs, Gaps and Priorities in Canterbury, 2008-2010, Christchurch Polytechnic and Institute of Technology, Christchurch.

Department of Labour (2009), The New Zealand Knowledge Economy: A Refined Methodology and Further Findings on the Structure and Growth of the Knowledge Economy, Department of Labour, Wellington.

Field, L. (1998), “Shifting the Focus from 'Training' to 'Learning': The Case of Australian Small Business", Australian and New Zealand Journal of Vocational Education Research, Volume 6(1), pp. 49-68.

Finegold, D. (1999), “Creating Self-Sustaining, High-Skill Ecosystems”, Oxford Review of Economic Policy, Volume 15(1), pp. 60-81.

Fraser, T. (2005), Small Businesses and Industry Training: Individualised Approaches that Work, Industry Training Federation, Wellington.

Long, M., R. Ryan, G. Burke and S. Hopkins (2000), "Enterprise-based Education and Training: A Literature Review”, Ministry of Education, Wellington.

Martinez-Fernandez, M. C. (2006), "Introduction”, in Martinez-Fernandez and MartinezSolano (eds.) Knowledge Intensive Service Activities (KISA) in Software Innovation, International Journal of Services Technology and Management, Volume 7(2), pp. 109-114. 
Massey, C. and C. Ingley (2007), "The New Zealand Policy Environment for the Development of SMEs”, New Zealand Centre for Small and Medium Enterprise Research, Massey University, Palmerston North.

MED (2009), SMEs in New Zealand: Structure and Dynamics 2009, Ministry of Economic Development, Wellington.

New Zealand Government (2008), New Zealand Skills Strategy 2008, discussion paper published by a tripartite committee serviced by the Department of Labour, Wellington.

New Zealand Treasury (2008), Putting Productivity First, New Zealand Treasury Productivity Paper 08/01, New Zealand Treasury, Wellington.

NZQA (2009), Targeted Review of the Qualifications System: Focussing on Certificate and Diploma Levels, New Zealand Qualifications Authority, Wellington.

OECD (2003), "Knowledge Intensive Service Activities in the Software Industry", draft synthesis report of TIP Innovation Case Studies on KISA: Software Module, Directorate for Science, Technology and Industry/Science and Technology Policy/ Innovation and Technology Policy, Volume 11, OECD, Paris.

OECD (2006), Innovation and Knowledge-Intensive Service Activities, OECD, Paris.

OECD (2008a), "Leveraging Training and Skills Development in SMEs: Exploratory Analysis", internal document produced by the OECD LEED Programme, OECD, Paris.

OECD (2008b), "Leveraging Training and Skills Development in SMEs: Proposal and Methods”, internal document produced by the OECD LEED Programme, OECD, Paris.

OECD (2010), "Greening Jobs and Skills: The Local Labour Market Implications of Addressing Climate Change", internal document produced by the OECD LEED Programme, OECD, Paris.

Saunders, C. and P. Dalziel (2006), "Identifying the Way Forward for High Growth Firms in the ICT Sector”, report prepared for the HiGrowth Project Trust, Auckland.

TEC (2005), The Challenge of Engagement: Involving Small and Medium Sized Enterprises in Industry Training, Tertiary Education Commission, Wellington.

Vaughan, K. (2002), Turning Barriers into Opportunities: A Literature Review on Small to Medium-Sized Enterprise (SME) Engagement with Formal Training, New Zealand Council for Educational Research, Wellington.

Vermillion-Peirce, P. and J. Grice (2009), "The Clarity of Certificates and Diplomas on the New Zealand Register of Quality Assured Qualifications”, New Zealand Qualifications Authority, Wellington.

Vermillion-Peirce, P. and S. Parker (2009), "The Currency of Certificates and Diplomas on the New Zealand Register of Quality Assured Qualifications”, New Zealand Qualifications Authority, Wellington.

Williams, J. (2006), "KISA in Innovation of New Zealand Software Firms", International Journal of Services Technology and Management, Volume 7(2), pp. 154-162.

Windsor, K. and C. Alcorso (2008), Skills in Context: A Guide to the Skill Ecosystem Approach to Workforce Development, NSW Department of Education and Training, Sydney. Downloaded 5 November 2009 from www.skillecosystem.net.au. 


\section{Appendix: National Data on Enterprise Training}

This report has provided new research on training in SMEs located in the Canterbury region of New Zealand. To provide some context, this appendix offers some national data related to training in firms. The first data source is the annual Business Operations Survey undertaken by Statistics New Zealand, of which the latest published version was completed in 2008 (BOS 2008; see www.stats.govt.nz/methods_and_services/information-releases/business-operations-survey.aspx). The target population for BOS 2008 was live enterprise units on Statistics New Zealand's Business Frame that at the population selection date satisfied five criteria including that they:

- Were economically significant enterprises (those that have an annual GST turnover figure of greater than NZD 30 000);

- Had six or more employees; and

- Had been operating for one year or more.

Note that these criteria exclude businesses with five or fewer employees, which would have excluded 17 of the firms from the Canterbury survey in Chapter 1 of this report (23.6\%). Note also that the survey has no upper bound on firm size, although some results are reported in band of firm size, with the highest band being 100 employees or more. An enterprise is defined for the survey as a business or service entity operating in New Zealand, such as a company, partnership, trust, government department or agency, state-owned enterprise, university or self-employed individual. The estimated population size was 36075 enterprises. The sample design was a two-level stratification according to ANZSIC industry and employment size groups. The response rate was 81.1 percent, which represented 5543 businesses.

Section C of the survey is headed Business Strategy and Skills. Figure A1 shows the factors in firms with 6 to 99 employees resulting in staff not having all the skills to do their job. Just over onehalf of the sample reported that all of their staff were fully skilled. The most common problem was lack of experience in the staff, reported by 34\%. Only 8\% reported "lack of internal training and development of staff" and only 5\% reported "inability of workforce to keep up with change".

Figure A2 shows the skills that firms reported were most in need of improvement among their staff. Customer service and sales was the most common skill reported under this heading (26\%) followed by team working and oral communication (both 21\%). All of the predetermined categories appear to be an issue, however, with even the lowest of the categories (marketing) being indicated by $11 \%$ of the sample.

Table A1 reports the involvement of firms in training their staff in the previous financial year. As a general trend, firms were likely to training new staff members. A smaller percentage reported training staff for new roles, while the percentage training all existing staff for existing roles was lower again. 
Figure A1. Factors resulting in staff not having all the skills to do their job, firms with 6-99 employees (\%)

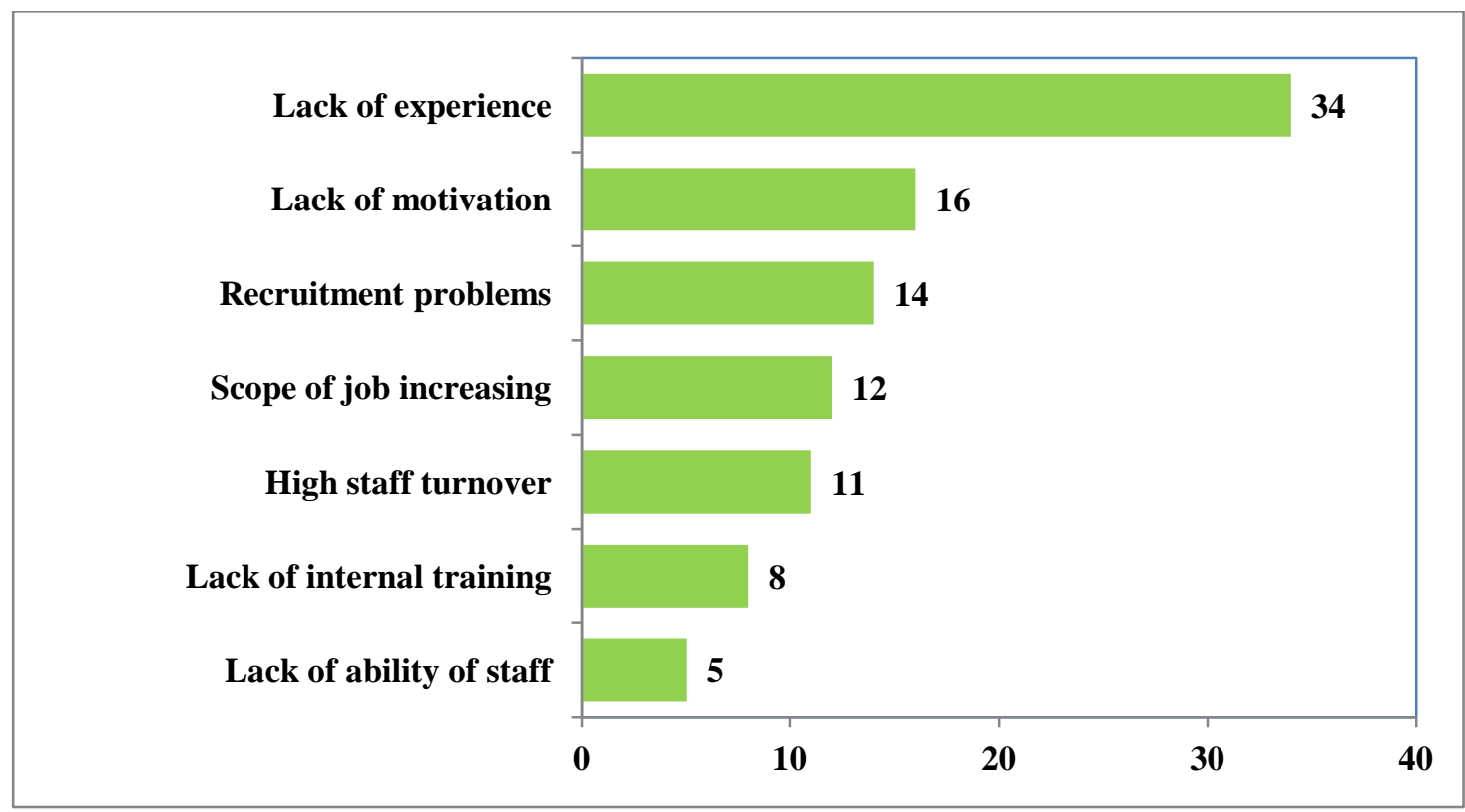

Source: BOS 2008, Table 45.

Figure A2. Skills that existing staff most need to improve firms with 6-99 employees (\%)

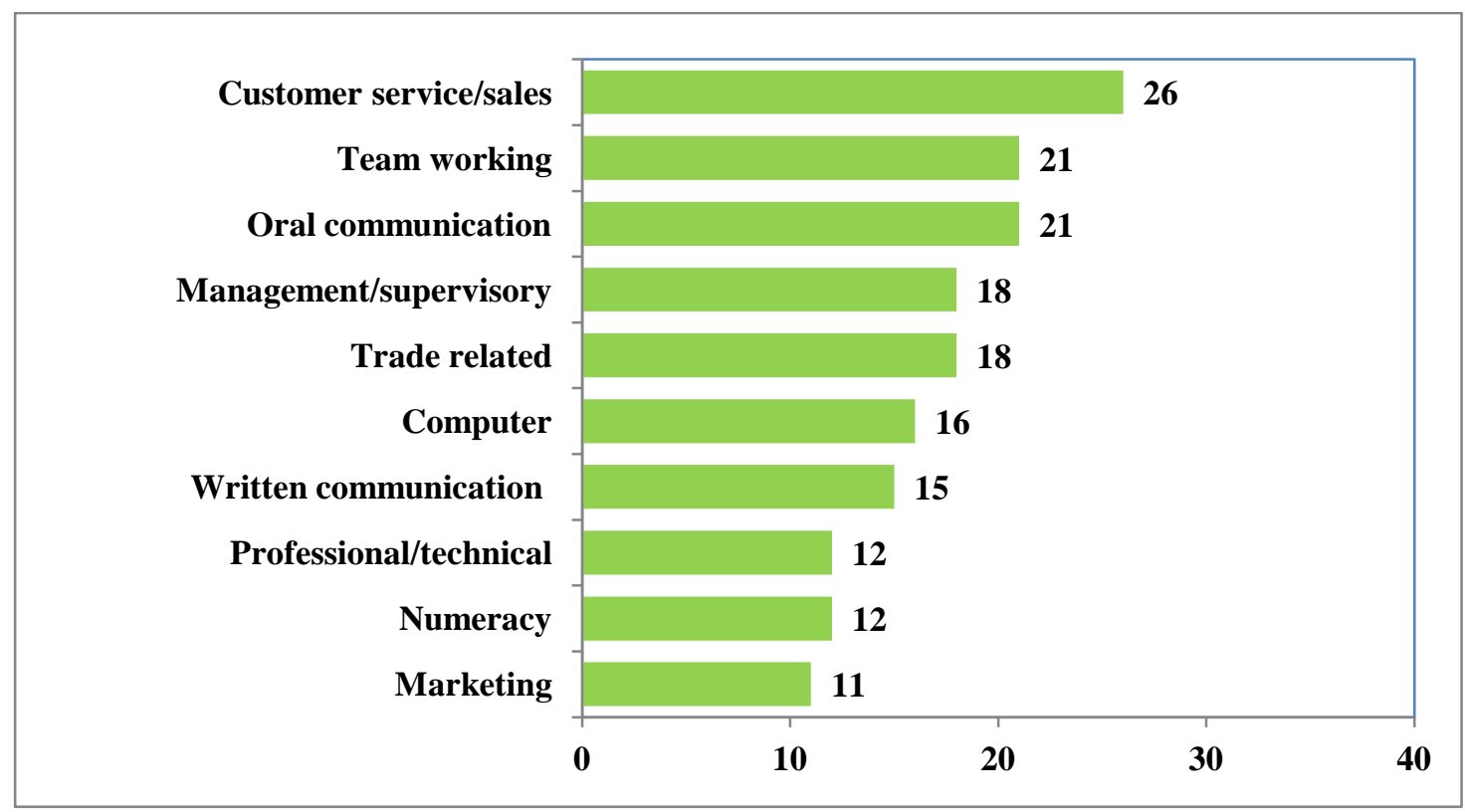

Source: BOS 2008, Table 46. 
Table A1.Involvement of firms in training staff in the previous financial year

\begin{tabular}{lccc}
\hline Area of Training & Less than Half & Half or More & All Staff \\
\hline New Staff & & & $48 \%$ \\
6-19 employees & $8 \%$ & $11 \%$ & $61 \%$ \\
$20-49$ employees & $10 \%$ & $11 \%$ & $65 \%$ \\
$50-99$ employees & $11 \%$ & $17 \%$ & $21 \%$ \\
Existing Staff Changing Roles & & & $30 \%$ \\
6-19 employees & $12 \%$ & $10 \%$ & $37 \%$ \\
$20-49$ employees & $18 \%$ & $16 \%$ & $24 \%$ \\
$50-99$ employees & $21 \%$ & & $28 \%$ \\
Existing Staff for Existing Roles & & $22 \%$ & $26 \%$ \\
$6-19$ employees & $23 \%$ & $25 \%$ & $19 \%$ \\
$20-49$ employees & $33 \%$ & $32 \%$ & \\
$50-99$ employees & $41 \%$ & & \\
\hline
\end{tabular}

Source: BOS 2008, Table 47.

Figure A3. Staff training for skills in the previous financial year, firms with 6-99 employees (\%)

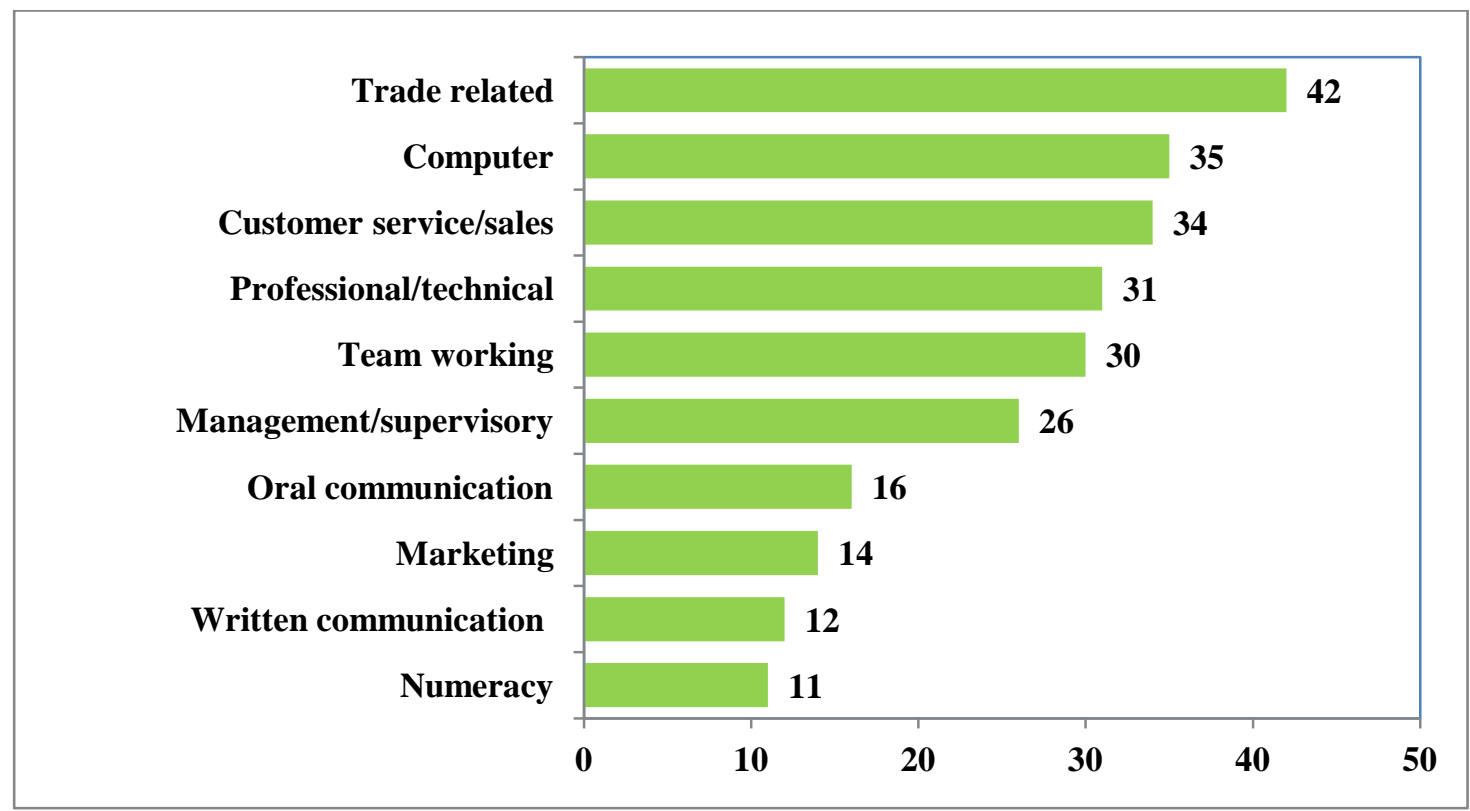

Source: BOS 2008, Table 48.

Figure A3 reports the results of a question: During the last financial year, did this business's staff participate in the following types of training provided or funded by this business? Trade related skills were the most common type of training reported (42\%). The least common types of training reported by business were numeracy (11\%) and written communication (12\%). 
The second source of national data is the semi-regular Skills and Training Survey operated by Business NZ, recently in conjunction with the Industry Training Federation (ITF). The 2007 version of the Survey was website-based and distributed through the four regional business organisations of Business NZ (EMA Northern, EMA Central, the Canterbury Employers' Chamber of Commerce and the Otago Southland Employers' Association) and through affiliated industry associations. The results of the survey are reported in a publication by Nicholas Green, Nicholas Huntington and Stephen Summers, Skills and Training Survey 2007: Full Report, published in July 2008 by Business NZ and ITF.

The 2007 survey drew responses from 536 enterprises. Note that these were not limited to SMEs, and $15 \%$ employed more than 100 staff. Just less than two-thirds (65\%) of respondents were private limited liability companies. A further $8.6 \%$ were self-employed or sole proprietors and $68 \%$ of respondents had been in operation for longer than 10 years. $90 \%$ of firms that responded to the survey had provided some form of training to their staff in the previous two years. $44 \%$ of firms had increased the numbers of employees receiving training over that period and only 5\% had reduced training numbers.

Smaller firms were less likely to provide training to their staff $-72 \%$ of firms with $0-5$ employees reported providing training, compared to $100 \%$ of firms with 100 or more staff. The median amount of training provided per employee was two days, which was lower than in the previous survey (in 2003, which reported a median of three days). However, the median amount of payroll costs spent by firms on training increased from $2.0 \%$ in 2003 to $2.5 \%$ in 2007.

Table A2 reports the skills identified as most important in the respondent's enterprise. Specific technical and trade skills stands out in this list: $43.9 \%$ of respondents identified it as the most important skill required, and $70.8 \%$ listed in among their top three. Communication skills, and literacy and numeracy skills, were the next two most cited skill sets, with a reasonable gap to the rest of the list.

Table A3 compares the forms of training offered in 2007 compared to the 2003 survey. There is a noticeable decline in the numbers reporting training in the more recent year. This decline is also reflected in Table A4, which compares the numbers reporting training in different skill types, with the most notable decline being in supervisory training.

Comparing Tables A2 and A4, there were some interesting differences in the 2007 responses between the types of training respondents reported providing and the skills identified as important to their enterprise. While almost 50\% of respondents identified literacy and numeracy as important, for example, only $9 \%$ offered or supported training in this area. Conversely, $43 \%$ offered or supported training in computing/ICT, although only $22 \%$ identified it as one of the three most important skills for their enterprise. 
Table A2.Three most important skills for respondent's enterprise (\% of respondents)

\begin{tabular}{|c|c|c|c|c|}
\hline \multirow{2}{*}{ Skills } & \multicolumn{3}{|c|}{ Ranking of Importance } & \multirow{2}{*}{$\begin{array}{c}\text { Overall } \\
\text { Frequency }\end{array}$} \\
\hline & 1 & 2 & 3 & \\
\hline Specific Technical and Trade Skills & $43.9 \%$ & $15.0 \%$ & $12.3 \%$ & $70.8 \%$ \\
\hline Literacy and Numeracy Skills & $19.0 \%$ & $16.7 \%$ & $14.1 \%$ & $49.3 \%$ \\
\hline Communication Skills & $18.9 \%$ & $28.0 \%$ & $20.4 \%$ & $66.7 \%$ \\
\hline Management Skills & $6.4 \%$ & $8.1 \%$ & $10.6 \%$ & $24.9 \%$ \\
\hline Health and Safety Skills & $4.0 \%$ & $6.3 \%$ & $7.1 \%$ & $17.1 \%$ \\
\hline Team and Negotiation Skills & $3.0 \%$ & $11.2 \%$ & $14.5 \%$ & $28.3 \%$ \\
\hline Other Skills & $2.8 \%$ & $3.0 \%$ & $2.5 \%$ & $8.3 \%$ \\
\hline Computing/ICT Skills & $1.3 \%$ & $8.5 \%$ & $12.7 \%$ & $22.2 \%$ \\
\hline Supervisory Skills & $0.8 \%$ & $3.2 \%$ & $5.8 \%$ & $9.6 \%$ \\
\hline
\end{tabular}

Source: Skills and Training Survey, 2007, Table 1.

Table A3.Forms of training offered or supported, 2003 and 2007

(\% of respondents)

\begin{tabular}{lll}
\hline Forms of Training & $\mathbf{2 0 0 3}$ & $\mathbf{2 0 0 7}$ \\
\hline External courses and programmes & $85.8 \%$ & $73.1 \%$ \\
In-house training programmes & $79.4 \%$ & $60.6 \%$ \\
Conferences & $47.6 \%$ & $51.7 \%$ \\
One-off seminars & $67.1 \%$ & \\
Induction & $72.5 \%$ & $50.4 \%$ \\
Other & $3.8 \%$ & $7.3 \%$ \\
\hline
\end{tabular}

Source: Skills and Training Survey, 2007, Table 13. 
Table A4. Types of skills training offered or supported, 2003 and 2007

(\% of respondents)

\begin{tabular}{lll}
\hline Forms of Training & $\mathbf{2 0 0 3}$ & $\mathbf{2 0 0 7}$ \\
\hline Specific Technical and Trade Skills & $83.5 \%$ & $72.8 \%$ \\
Health and Safety Skills & $77.6 \%$ & $54.1 \%$ \\
Computing/ICT Skills & $61.6 \%$ & $42.9 \%$ \\
Management Skills & $53.6 \%$ & $40.1 \%$ \\
Communication Skills & $44.2 \%$ & $38.8 \%$ \\
Team and Negotiation Skills & $40.0 \%$ & $32.1 \%$ \\
Supervisory Skills & $50.4 \%$ & $31.7 \%$ \\
Literacy and Numeracy Skills & $10.8 \%$ & $8.8 \%$ \\
Other Skills & $9.6 \%$ & $8.2 \%$ \\
\hline
\end{tabular}

Source: Skills and Training Survey, 2007, Table 14.

Figure A4. Providers of training used by respondents

(\% of respondents)

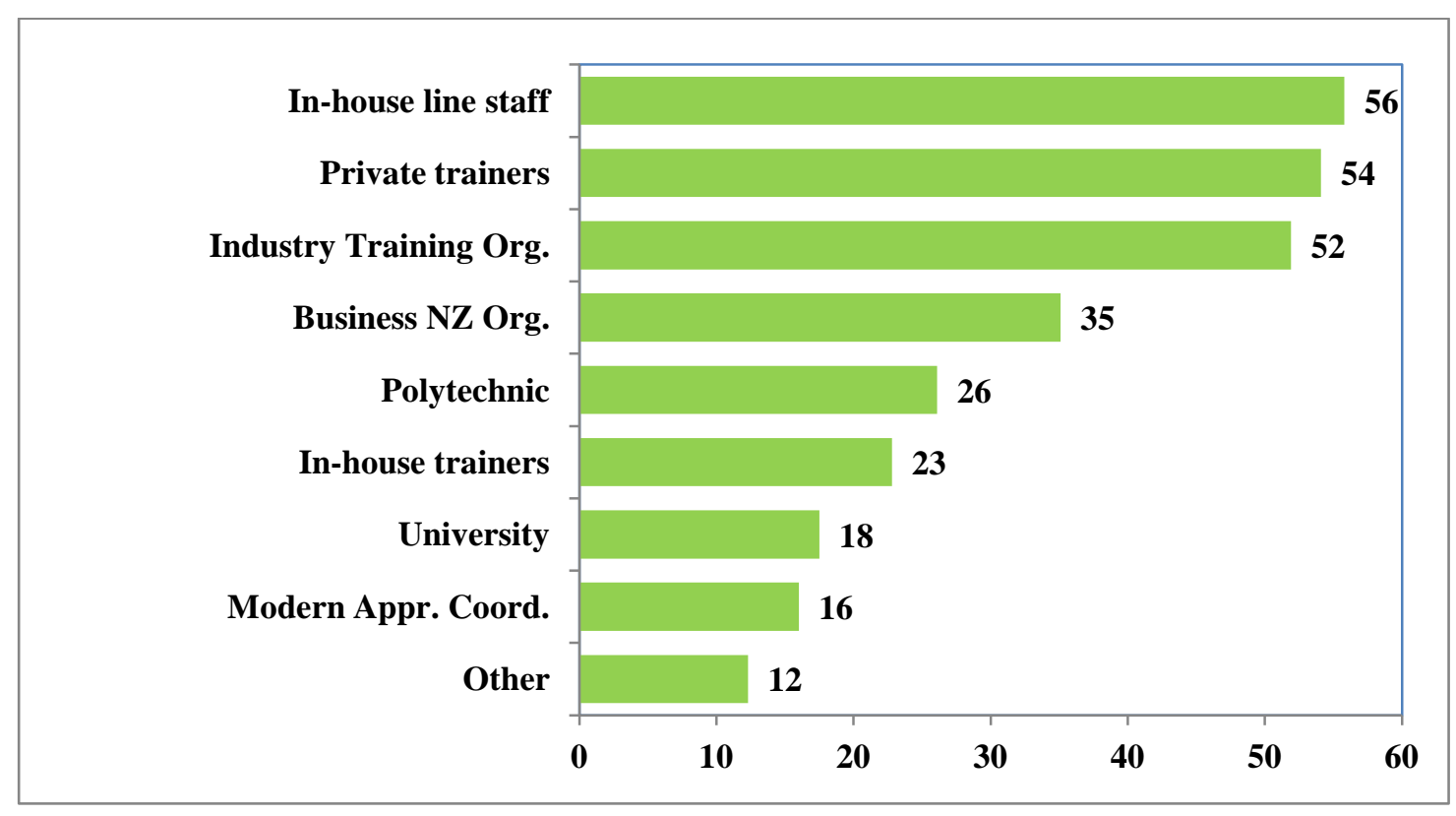

Source: Skills and Training Survey, 2007, Table 16. 
Figure A4 shows the sources of training. The top three sources were in-house line staff (e.g. supervisors), private training consultants or providers, or through Industry Training Organisations.

The survey defined formal training as training that is assessed in some way. Table A5 presents the percentage of respondents who indicated their proportion of formal training analysed in ten percentage point bands. The largest group of respondents (17.0\%) used formal training for half of all their training efforts. Nevertheless, the responses were weighted towards informal training, with just under half reporting that they used formal training for only $0-30 \%$ of their total training.

Table A5.Proportion of training that is formal (i.e. assessed), 2007

\begin{tabular}{lcc}
\hline Percentage Band & Number of Respondents & Percentage of Respondents \\
\hline $0 \%$ & 63 & $14.3 \%$ \\
$1-10 \%$ & 60 & $13.6 \%$ \\
$11-20 \%$ & 49 & $11.1 \%$ \\
$21-30 \%$ & 43 & $9.7 \%$ \\
$31-40 \%$ & 29 & $6.6 \%$ \\
$41-50 \%$ & 75 & $17.0 \%$ \\
$51-60 \%$ & 25 & $5.7 \%$ \\
$61-70 \%$ & 22 & $5.0 \%$ \\
$71-80 \%$ & 38 & $8.6 \%$ \\
$81-90 \%$ & 19 & $4.3 \%$ \\
$91-100 \%$ & 19 & $4.3 \%$ \\
Total & 442 & $100 \%$ \\
\hline
\end{tabular}

Source: Skills and Training Survey, 2007, Table 19.

Finally, Table A6 gives an indication of barriers to training by showing the responses to a questions asking for the three most important reasons for supporting less or no training. Affordability of training was the most cited first reason, by a factor greater than two compared to the next most cited first reason (not enough relevant training). There was little support for the view that training is an employee's responsibility ( $2.1 \%$ overall), although $28.9 \%$ cited lack of employee interest as one of their top three reasons. High staff turnover or a fear that a trained employee might be poached by a competitor were also well done the list (both $11.7 \%$ overall). 
Table A6. Three most important reasons for supporting less or no training

\begin{tabular}{|c|c|c|c|c|}
\hline \multirow{2}{*}{ Reason } & \multicolumn{3}{|c|}{ Ranking of Importance } & \multirow{2}{*}{$\begin{array}{l}\text { Overall } \\
\text { Frequency }\end{array}$} \\
\hline & 1 & 2 & 3 & \\
\hline Affordability of training & $28.9 \%$ & - & $13.6 \%$ & $39.7 \%$ \\
\hline Not enough relevant training & $13.0 \%$ & $9.3 \%$ & $14.1 \%$ & $32.6 \%$ \\
\hline Lack of information about training & $5.4 \%$ & $23.8 \%$ & $6.3 \%$ & $31.8 \%$ \\
\hline Requires too much staff time off work & $7.9 \%$ & $11.7 \%$ & $16.2 \%$ & $31.4 \%$ \\
\hline Lack of interest from employees & $11.7 \%$ & $12.6 \%$ & $7.3 \%$ & $28.9 \%$ \\
\hline $\begin{array}{l}\text { Decline or uncertainty in business } \\
\text { environment }\end{array}$ & $5.9 \%$ & $7.5 \%$ & $11.0 \%$ & $21.3 \%$ \\
\hline Can't assess the likely benefit & $3.8 \%$ & $6.5 \%$ & $9.4 \%$ & $17.2 \%$ \\
\hline "Red tape" involved in arranging training & $5.4 \%$ & $6.5 \%$ & $5.2 \%$ & $15.5 \%$ \\
\hline High staff turnover in the enterprise & $4.6 \%$ & $4.7 \%$ & $3.7 \%$ & $11.7 \%$ \\
\hline Trained employees will be "poached" & $2.9 \%$ & $5.1 \%$ & $5.2 \%$ & $11.7 \%$ \\
\hline $\begin{array}{l}\text { High availability of suitably skilled labour in } \\
\text { the industry }\end{array}$ & $5.0 \%$ & $4.2 \%$ & $1.6 \%$ & $10.0 \%$ \\
\hline Other reason & $4.6 \%$ & $2.8 \%$ & $3.7 \%$ & $10.0 \%$ \\
\hline Too difficult to train employees & $0.8 \%$ & $3.3 \%$ & $2.1 \%$ & $5.4 \%$ \\
\hline Training is an employee's responsibility & - & $1.9 \%$ & $0.5 \%$ & $2.1 \%$ \\
\hline
\end{tabular}

Source: Skills and Training Survey, 2007, Table 25.

Table A7 lists the participants in the workshop, and also indicates what part of the regional training ecosystem they represented. 
Table A7.Participants in the skills and training ecosystem workshop

\begin{tabular}{|c|c|}
\hline Participants & Organisation \\
\hline \multicolumn{2}{|l|}{ International } \\
\hline $\begin{array}{l}\text { Sylvain Giguère } \\
\text { Cristina Martinez-Fernandez } \\
\text { Tamara Weyman }\end{array}$ & $\begin{array}{l}\text { CFE/LEED, OECD } \\
\text { CFE/LEED, OECD } \\
\text { University of Western Sydney }\end{array}$ \\
\hline \multicolumn{2}{|l|}{ National Policy } \\
\hline $\begin{array}{l}\text { Paul Barker } \\
\text { Liz Cowley } \\
\text { Olga Gladkikh } \\
\text { Daniel Haines }\end{array}$ & $\begin{array}{l}\text { Department of Labour } \\
\text { Department of Labour } \\
\text { Tertiary Education Commission } \\
\text { Tertiary Education Commission }\end{array}$ \\
\hline \multicolumn{2}{|l|}{ Regional Policy } \\
\hline $\begin{array}{l}\text { Jo Aldridge } \\
\text { Claire Bryant } \\
\text { Darel Hall } \\
\text { Paul Isherwood } \\
\text { Irvine Paulin }\end{array}$ & $\begin{array}{l}\text { Ministry of Social Development } \\
\text { Department of Labour } \\
\text { Policy Consultant } \\
\text { Workbridge } \\
\text { New Zealand Trade and Enterprise }\end{array}$ \\
\hline \multicolumn{2}{|l|}{ Employers } \\
\hline $\begin{array}{l}\text { Paul Blackler } \\
\text { Heather McDonald } \\
\text { Carrie Murdoch } \\
\text { Peter Townsend } \\
\text { John Tyler }\end{array}$ & $\begin{array}{l}\text { Mainzeal Property and Construction } \\
\text { Athena Research Ltd } \\
\text { Business New Zealand } \\
\text { Canterbury Employers Chamber of Commerce } \\
\text { Bowls Canterbury Inc }\end{array}$ \\
\hline \multicolumn{2}{|l|}{ Trade Unions } \\
\hline Murray Kerse & New Zealand Dairy Workers Union \\
\hline \multicolumn{2}{|l|}{ Industry Training Organisations } \\
\hline $\begin{array}{l}\text { Andrea Frost } \\
\text { Mike Gorinski } \\
\text { Liz Stephenson } \\
\text { Mike Webster }\end{array}$ & $\begin{array}{l}\text { Industry Training Federation } \\
\text { Apparel and Textiles Industry Training Organisation } \\
\text { Careerforce } \\
\text { Electricity Supply Industry Training Organisation }\end{array}$ \\
\hline \multicolumn{2}{|l|}{ Private Training Enterprises } \\
\hline $\begin{array}{l}\text { Tony Atkin } \\
\text { lan Douthwaite } \\
\text { Christina Fawcett } \\
\text { Andrew Murray }\end{array}$ & $\begin{array}{l}\text { Alliance Learning } \\
\text { going places } \\
\text { National Trade Academy } \\
\text { Academy New Zealand }\end{array}$ \\
\hline \multicolumn{2}{|l|}{ Public Education } \\
\hline $\begin{array}{l}\text { Gay Sharlotte } \\
\text { Claire Taylor } \\
\text { Russel Wordsworth }\end{array}$ & $\begin{array}{l}\text { Christchurch Polytechnic Institute of Technology } \\
\text { Hagley Community College } \\
\text { University of Canterbury }\end{array}$ \\
\hline \multicolumn{2}{|l|}{ Local Government } \\
\hline $\begin{array}{l}\text { Cat Hannah } \\
\text { Lesley Symington } \\
\text { Heather Warwick } \\
\text { Simon Worthington }\end{array}$ & $\begin{array}{l}\text { Enterprise North Canterbury } \\
\text { Selwyn District Council } \\
\text { Enterprise North Canterbury } \\
\text { Canterbury Development Corporation }\end{array}$ \\
\hline \multicolumn{2}{|l|}{ Project Research Team } \\
\hline $\begin{array}{l}\text { Paul Dalziel } \\
\text { Meike Guenther }\end{array}$ & $\begin{array}{l}A E R U, \text { Lincoln University } \\
A E R U, \text { Lincoln University }\end{array}$ \\
\hline
\end{tabular}




\section{Leveraging Training}

\section{Skills Development in SMEs}

The leveraging training and skills development in SMEs project is an international effort to look at policy issues related to the:

- Low access to training in SMEs

- Barriers encountered by SMEs to training

- Formal and informal ways SMEs access knowledge that is relevant for their business operations.

The project examines how formal and alternative ways of training and skills development relate to specific outputs for the firm and employees, for the industry and for the local area where they are located. In particular the role of skills and training ecosystems at the local level is analysed.

Participant countries: New Zealand, United Kingdom, Poland, Belgium (Flanders) \& Turkey. The project is supported by: the European Commission, DG Employment, Social Affairs and Equal Opportunities.

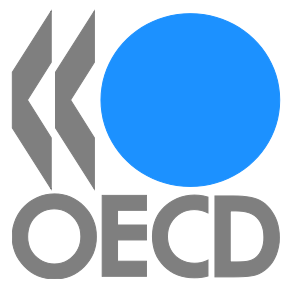

